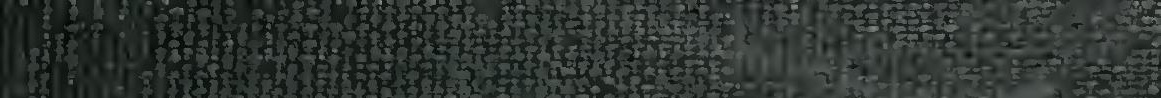





\begin{tabular}{lll}
\hline Vol. III & 1946 & No. I \\
\hline \hline
\end{tabular}

\section{MEMOIRS \\ of the}

\section{Southern California Academy of Sciences}

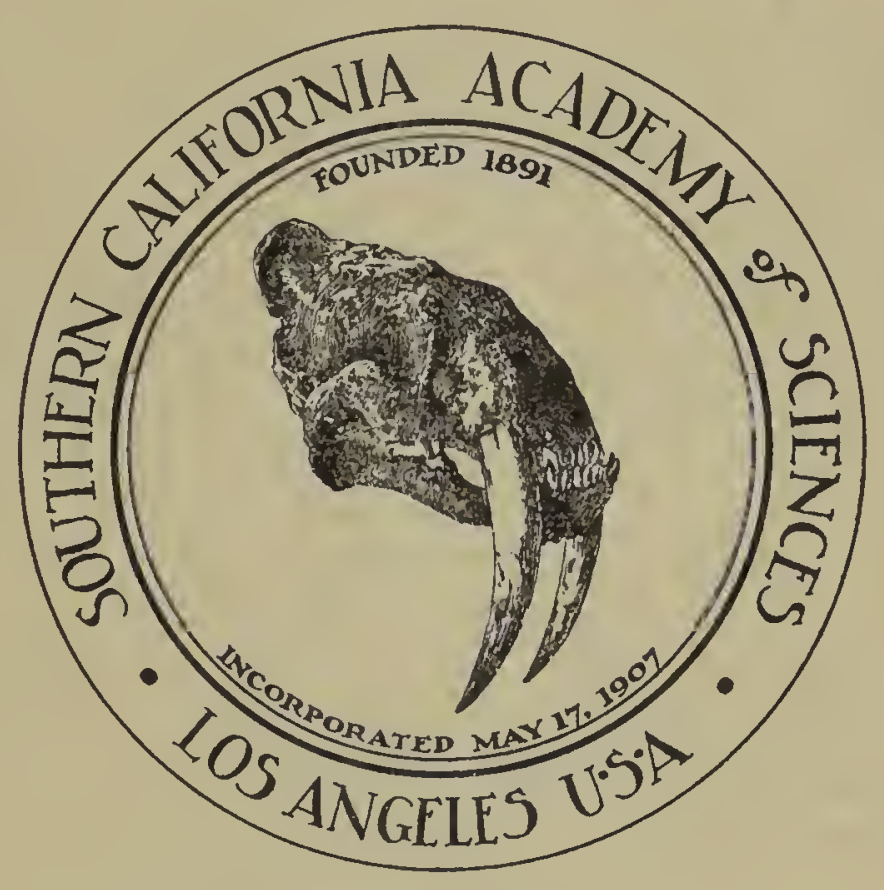

A Guide to the Literature and Distributions of the Marine Algae of the Pacific Coast of North America

by E. YALE DAWSON 


\section{Southern California Academy of Sciences}

OFFICERS and DIRECTORS

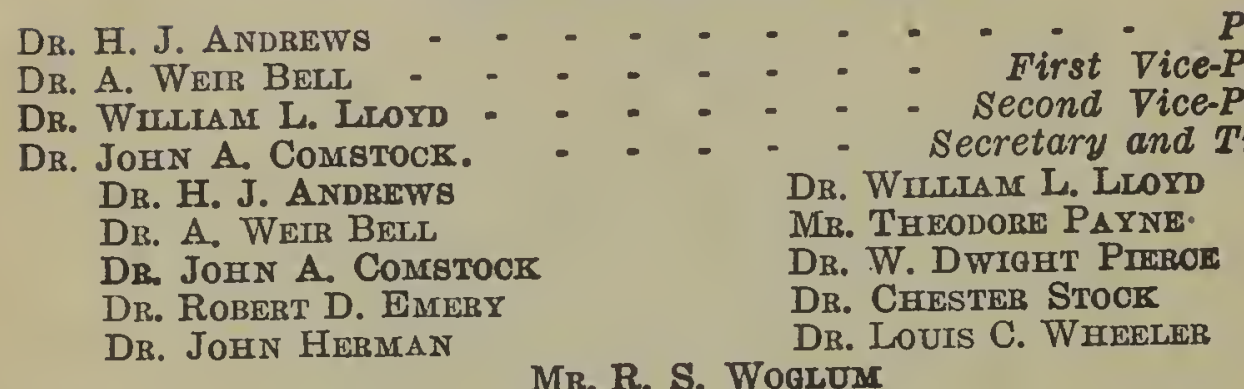

President

ADVISORY BOARD

Mr. FrEL E. BURLEW

Mr. A. YoRK EsoatarTi.

Mr. Samuel Moody Haskins
Dr. HowARD R. HUL

DR. R. H. SWIFT

DB. ShebwiN F. WoOd

BOTANICAL SECTION

Dr. George R. JoHnstone, Chairman

SECTION OF HEALTH AND SANITATION

DR. ROBERT D. EMERY, Chairman

SECTION OF ZOOLOGICAL SCIENCES

Dr. A. WeIR BELL, Chairman

SECTION OF CHEMICAL SCIENCES

MAJOR Jos. B. FICKLEN III, Chairman

SECTION OF EARTH SCIENCES

Dr. Chester Stook, chairman

SECTION OF PHYSICAL SCIENCES

Dr. LEE DEFOREST, Chairman

SECTION OF AGRICULTURAL SCIENCES

Mr. RUSSELL S. WOGLUM, Chairman

SECTION OF JUNIOR SCIENCE

MR. A. YoRK, ESCALANTE, Chairman

ARCHEOLOGICAL SECTION

Mr. ARTHUR WOODWARD, Chairman

FINANCE COMMITTEE

Mr. FRED E. BURLEW, Chairman

Mr. Samuer Moody Haskins DR. JoHn A. Comstock

PROGRAM COMMITTEE

Dr. ROBERT L. RUTHERFORD, Chairman

DR. HOWABD R. HIII

HOSPITALITY COMMITTEE

DR. W. DWIGHT PIERCE, Chairman

Mrs. Eunice IKING Mr. Hugh D. AUstin

COMMITTEE ON PUBLICATION

DR. JoHN A. CoMstock, Chairman

Dr. Ciester Stock Dr. Howard R. Hill Dr. William L. Lloyd

COMMITTEE ON CONSERVATION

Dr. JoHn A. Comstock, Chairman

Mr. Theodore PaYNe

Prof. J. Stanley Brode

OFFICE OF THE ACADEMY

Los Angeles County Museum, Exposition Park, Los Angeles 7, Calie. 




\section{A GUIDE TO THE}

Literature and Distributions

OF THE

Marine Algae of the

Pacific Coast of

North America

Q

By

E. YALE DAWSON

Memoirs of the Southern California Academy of Sciences Vol. 3, No. 1, 1946 
79544

tou a d ing

Fonet.

$$
x+A=2=y
$$




\title{
A GUIDE TO THE LITERATURE AND DISTRI- BUTIONS OF THE MARINE ALGAE OF THE PACIFIC COAST OF NORTH AMERICA
}

\author{
By
}

\author{
E. YALE DAWSON
}

\section{INTRODUCTION}

More than two decades have elapsed since the monographs by Setchell and Gardner of the Chlorophyceae and Phaeophyceae brought our knowledge of these groups of marine algae on the Pacific Coast of North America up to date for 1920 and 1925, respectively. Although these works are still highly authoritative and moderately complete, a considerable number of papers dealing with the green and brown algae of our coasts have subsequently appeared, creating changes and additions in these classes. The status of the Rhodophyceae, moreover, has long been unsatisfactory, for no assembly of the literature dealing with Pacific Coast species, nor complete survey of the species, has ever been accomplished. The existing information is badly scattered and largely inaccessible except to those few who have access to a large library and to collections such as those of the University of California. Aiming toward alleviating this situation, an attempt has been made to assemble here the published records of determinations and distributions of all the marine algae of the Pacific Coast of North America, with the exception of the Myxophyceae.

The appearance of three important works within the past year, each dealing with the algal flora of a different part of the Pacific Coast, has made this task immeasurably easier and more practicable. Smith's Marine Algae of the Monterey Peninsula, California, in treating of a large proportion of the species occurring on the Pacific Coast of the United States, has been of signal value in bringing together a great amount of information on these northern plants. The author's monograph of the Marine Algae of 
the Gulf of California has brought that region up to date such that no further assembly nor review of its literature was necessary. The valuable work of Taylor: Pacific Marine Algae of the Allan Hancock Expeditions to the Galapagos Islands has provided abundant information on the algal floras of the Mexican and Central American coasts of which almost nothing was previously known.

Citation of all the references to any given species has not been possible, but the references cited include the most recent ones and will serve in each case as a key to the previous literature.

The limits of the "Pacific Coast of North America" are taken as the Aleutian Islands on the north and the Gulf of Panamá on the south. The coastwise distance between Attu Island and Panamá is nearly 6500 miles. For the sake of consistency, distribution records are cited from north to south.

La Jolla, California, June 30, 1945. 


\section{LIST OF SPECIES \\ C H LOROPH Y C E A E}

(GREEN ALGAE)

\section{Order VOLVOCALES}

\section{Fam. Polyblepharidaceae}

Stephanoptera gracilis (Artari) G. M. Smith Smith, 1944

San Francisco Bay; Monterey, Calif.

Dunaliella salina (Dunal) Teodoresco

Smith, 1944

San Francisco; Monterey, Calif.

\section{Fam. Chlamydomonadaceae}

Platymonas subcordiformis (Wille) Hazen

Smith, 1944

Monterey, Calif.

\section{Order TETRASPORALES}

\section{Fam. Chlorangiaceae}

Collinsiella tuberculata Setchell \& Gardner Smith, 1944

Vancouver Is., B. C. to Pacific Grove, Calif.

Prasinocladus lubricus Kuckuck

Smith, 1944

Monterey, Calif.

\section{Order ULOTRICHALES}

\section{Fam. Ulotrichaceae}

Ulothrix FLACCA (Dillwyn) Thuret

Setchell \& Gardner, 1920

Alaska to California

ULOTHRIX IMPLEXA Kützing

Smith, 1944

Bering Sea to Monterey, Calif. 
Ulothrix laetevirens (Kützing) Collins

Setchell \& Gardner, 1920

Unalaska, Alaska to California

Ulothrix PSEUdoflacCA f. MiNor Wille

Setchell \& Gardner, 1920

Sitka, Alaska

ULOTHRIX PSEUdOFLACCA $f$. MAJOR Wille

Setchell \& Gardner, 1920

San Francisco, Calif.

Ulothrix pseudoflacca f. Maxima Setchell \& Gardner

Setchell \& Gardner, 1920

San Francisco, Calif.

\section{Fam. Chaetophoraceae}

Bulbocoleon piliferem Pringsheim

Setchell \& Gardner, 1920; Dawson, 1945B

Southern Calif.

Pilinia Lunatiae f. simplex Thivy

Taylor, 1945

Panama City, Panamá

Pilinia maritima f. pacifica Thivy

Taylor, 1945

Is. Clarion, Revilla Gigedo Arch.

Phaeophilia dendroides (Cronan) Batters

Taylor, 1945

Is. María Magdalena, Nayarit

Phaeophilin Engleri Reinke

Taylor, 1945

Is. Clarion, Revilla Gigedo Arch.; Tangola-Tangola, Oaxaca to Is. Taboga, Panamá

PhaEophilia Polymorpha Jao

Jao, 1937

San Juan Is., Wash.

Entocladia cingens Setchell \& Gardner

Setchell \& Gardner, 1920

San Diego, Calif.

Entocladia codicola Setchell \& Gardner

Smith, 1944; Dawson, 1945B

Monterey Peninsula to La Jolla, Calif.

Entocladia condensata Setchell \& Gardner

Dawson, 1944

Puerto Libertad, Sonora; Is. San Esteban, Gulf of Calif. 
Entocladia mexicana Setchell \& Gardner

Dawson, 1944

Is. Angel de la Guarda, Gulf of Calif.; La Paz, Baja Calif.

Entocladia Polysiphoniae Setchell \& Gardner

Dawson, 1944

Guaymas, Sonora; La Paz, Baja Calif.

Entocladia viridis Reinke

Smith, 1944

Moss Beach, San Mateo Co.; Monterey, Calif.

Endophyton RAmosum Gardner

Smith, 1944

San Francisco; Monterey Peninsula, Calif.

Pseudodictyon geniculatum Gardner

Smith, 1944

San Francisco; Pacific Grove, Calif.

Internoretia Freyeana Setchell \& Gardner

Setchell \& Gardner, 1920

Friday Harbor, Wash.

Ulvella Setchellir Dangeard

Smith, 1944; Ulvella Lens in Setchell \& Gardner, 1930

Pacific Grove, Calif.; Is. Guadalupe, Baja Calif.

Pseudoulvella applanata Setchell \& Gardner

Smith, 1944

Carmel, Calif.

Pseudoulvella consociata Setchell \& Gardner

Setchell \& Gardner, 1920

San Francisco Bay at Alameda, Calif.

Pseudoulvella prostrata (Gardner) Setchell \& Gardner

Setchell \& Gardner, 1920

San Francisco, Calif.

Pseudopringsheimia apiculata Setchell \& Gardner

Smith, 1944

San Francisco; Monterey, Calif.

Pringsheimjella Marchantae (Setchell \& Gardner) Schmidt

Schmidt, 1935; Pringsheimia Marchantae in Dawson, 1944

La Paz, Baja Calif. 


\section{Fam. Trentepohliaceae}

Gomontia polyrhiza (Lagerheim) Bornet \& Flahault Smith, 1944

Neah Bay, Wash.; Monterey, Calif.

Trentepohlia odorata (Wiggers) Wittrock

Sanborn \& Doty, 1946

Coos Bay, Oregon

Trentepohlia odorata var. umbrina (Kützing) Hariot Setchell \& Gardner, 1920

San Pedro, Calif.

\section{Order ULVALES}

\section{Fam. Ulvaceae}

Monostroma areolatum Setchell \& Gardner

Setchell \& Gardner, 1920

Sitka, Alaska

Monostroma fractum Jao

Jao, 1937

Turn Is., Wash.

Monostroma fuscum (Postels \& Ruprecht) Wittrock

Setchell \& Gardner, 1920

Alaska to Puget Sound, Wash.

Monostroma fuscum var. SPLEndens (Ruprecht) Rosenvinge

Setchell \& Gardner, 1920

Alaska to Vancouver Is., B. C.

Monostroma fuscum var. Blyttir (Areschoug) Collins

Setchell \& Gardner, 1920

Vancouver Is., B. C. ; Washington

Monostroma Grevillei (Thuret) Wittrock

Setchell \& Gardner, 1920

Unalaska, Alaska

Monostroma Grevillei var. Lubricum (Kjellman) Collins

Setchell \& Gardner, 1920

Sitka, Alaska

Monostroma Grevillei var. Vahli (J. Agardh) Rosenvinge

Setchell \& Gardner, 1920

Kukak Bay; Sitka, Alaska

Monostroma latissimum (Kützing) Wittrock

Setchell \& Gardner, 1920

Vancouver, B. C. to central California 
Monostroma orbiculatum Thuret

Setchell \& Gardner, 1920

Central California

Monostroma QUATERnARIUM (Kützing) Desmazières

Setchell \& Gardner, 1920

Washington to southern California

Monostroma zostericola Tilden

Smith, 1944

Vancouver Is., B. C. ; Puget Sound, Wash.; Monterey Peninsula, Calif.

ENTEROMORPHA ACANTHOPHORA Kützing

Dawson, 1944

Gulf of Calif.

Enteromorpha clathrata (Roth) Greville

Smith, 1944

Sitka, Alaska to Carmel, Calif.

Enteromorpha crinita (Roth) J. Agardh

Setchell \& Gardner, 1920

Valdes, Alaska to San Diego, Calif.

ENTERomorpha COMPRESSA (Linnaeus) Greville

Smith, 1944 ; Dawson, 1944

Bering Sea to central México; Gulf of Calit.

ENTEROMORPHA ERECTA J. Agardh

Setchell \& Gardner, 1920

Comox, Vancouver Is., B. C. to Santa Rosa Is., Calif.

Enteromorpha rlexuosa (Wulfen) J. Agardh

Setchell \& Gardner, 1920; Taylor, 1945

Santa Barbara, Calif. to Port Parker, Costa Rica

Entromompha groenlandica (J. Agardh) Setchell \& Gardner

Setchell \& Gardner, 1920

Bering Sea to Unalaska, Alaska

Enteromorpha intestinalis (Linnacus) Link

Smith, 1944; Dawson, 1944

Kukak Bay, Alaska to La Paz, Baja Calif.; Gulf of Calif.

Enteromorpha intestinalis f. cylindracea I. Agardh

Setchell \& Gardner, 1920

Alaska to México

Enteromorpha intestinalis f. maxina J. Agardh

Setchell \& Gardner, 1920

Alaska to México 
Enteromorpha intestinalis f. clavata J. Agardh Setchell \& Gardner, 1920

Alaska to México

Enteromorpha lingulata J. Agardh

Setchell \& Gardner, 1920; Taylor, 1945

Is. Guadalupe, Baja Calif. to Balboa, Canal Zone

Enteromorpha marginata J. Agardh

Setchell \& Gardner, 1920

Vancouver Is., B. C. to Calif.

ENTEROMORPHA MICROCOCCA Kützing

Smith, 1944

Dutch Harbor, Alaska to México

ENTEROMORPHA MicrocCA f. SUbSALSA Kjellman

Setchell \& Gardner, 1920

Skagway, Alaska to Puget Sound, Wash.

Enteromorpha minima Nägeli

Smith, 1944

Dutch Harbor, Alaska to México

ENTEROMORPHA PLUMOSA Kützing

Setchell \& Gardner, 1920; 1930

Puget Sound, Wash.; San Francisco, Calif.; Is. Clarion, Revilla Gigedo Arch.

Enteromorpha proltfera (Müller) I. Agardh

Setchell \& Gardner, 1920; Dawson, 1944

Alaska to Central America

Enteromorpha salina var. polyclados Kützing

Setchell \& Gardner, 1920

San Francisco Bay, Calif.

Enteromorpha torta (Mertens) Reinbold

Setchell \& Gardner, 1920; Jao, 1937

Friday Harbor, Wash.; San Diego, Calif.

Enteromorpha tubulosa Kützing

Smith, 1944; Dawson, 1945E

Sausalito, Calif. to Cabo Colnett, Baja Calif.

Ulva Angusta Setchell \& Gardner

Smith, 1944; Dawson, 1944; Setchell \& Gardner, 1930

Humboldt Co. to Carmel, Calif.; Is. Griadalupe, Baja Calif. ?; Guaymas, Sonora

Ulva CALIFornica Wille

Setchell \& Gardner, 1920

San Diego Co., Calif́. 
Ulva Dactylifera Setchell \& Gardner

Setchell \& Gardner, 1920; Dawson, 1944

Southern Calif. to San Roque, Baja Calif.; southern Gulf of Calif.

Ulva EXPansa (Setchell) Setchell \& Gardner

Smith, 1944

Puget Sound, Wash. to La Paz, Baja Calif.?

Ulva fenestrata Postels \& Ruprecht

Setchell \& Gardner, 1920

Sitka, Alaska to Puget Sound, Wash.

Urva Lactuca Linnaeus

Smith, 1944; Dawson, 1944; Taylor, 1945

Bering Sea to Panamá

Urva Latissima Linnaeus

Setchell \& Gardner, 1920

Juneau, Alaska

Ulva Linza Linnaeus

Smith, 1944

Orca, Alaska to La Paz, Baja Calif.

Ulva lobata (Kützing) Setchell \& Gardner

Smith, 1944; Taylor, 1945

San Francisco to San Diego, Calif.; Bahía Petatlán, Guerrero

Ulva Rigida C. Agardh

Smith, 1944; Dawson, 1944; Taylor, 1945

Uyak Bay, Alaska to La Paz, Baja Calif.; Gulf of Calif.; Is. María Madre, Nayarit

Ulva stenophylla Setchell \& Gardner

Smith, 1944

Bolinas to Monterey, Calif.

Ulva TaEniata (Setchell) Sctchell \& Gardner

Smith, 1944 ; Dawson, 1945E

Coos Bay, Oregon to Carmel, Calif.; Punta Descanso;

Cabo Colnett, Baja Calif.

Ulva vexata Setchell \& Gardner

Setchell \& Gardner, 1920

San Francisco, Calif.

Percursaria percursa (C. Agardh) Rosenvinge

Setchell \& Gardner, 1920

Unalaska, Alaska to San Francisco Bay, Calif. 


\section{Order SCHIZOGONIALES}

\section{Fam. Schizogoniaceae}

Prasiola borealis Reed

Setchell \& Gardner, 1920

Unalaska, Kodiak and Baranof Is., Alaska

Prasiola calophylla (Carmichael) Meneghini

Setchell \& Gardner, 1920

Whidbey Is., Wash.

Prasiola delicatula Setchell \& Gardner

Setchell \& Gardner, 1920

Sitka, Alaska

Prastola meridionalis Setchell \& Gardner

Smith, 1944

Friday Harbor, Wash. to Carmel, Calif.

Gayella constricta Setchell \& Gardner

Smith, 1944

Friday Harbor, Wash.; Tomales Point; Monterey, Calif.

Gayella polyrhiza Rosenvinge

Setchell \& Gardner, 1920

Amaknak Is., Alaska

\section{Order CLADOPHORALES}

\section{Fam. Cladophoraceae}

Rhizoclonium implexum (Dillwyn) Kützing

Smith, 1944

Unalaska, Alaska to Carmel, Calif.

Rhizoclonium Kerneri Stockmayer

Setchell \& Gardner, 1920; Taylor, 1945

Victoria, B. C. ; Is. Clarion, Revilla Gigedo Arch.

Rhizoclonium Riparium (Roth) Harvey

Smith, 1944

Unalaska, Alaska to Carmel, Calif.

Rhizoclonium tortuosum (Dillwyn) Kützing

Smith, 1944

Alaska to Carmel, Calif.

Lola lubrica (Setchell \& Gardner) A. et G. Hamel

Dawson, 1944; Rhizoclonium lubricum in Setchell \&

Gardner, 1920; Taylor, 1945

Rocke Harbor, Wash. to Puerto Culebra, Costa Rica 
Hormiscia dolitiera Setchell \& Gardner Setchell \& Gardner, 1920

San Francisco, Calif.

Hormiscia Grandis (Kylin) Setchell \& Gardner

Setchell \& Gardner, 1920

Unalaska, Alaska to Puget Sound, Wash.

HoriIsCIA PENICILLIFORMis (Roth) Fries

Setchell \& Gardner, 1920; Urospora peniciliformis in Smith, 1944

Bering Sea to Carmel, Calif.

Hormiscia sphaerulifera Setchell \& Gardner

Setchell \& Gardner, 1920

Whidbey Is., Wash.

Hormiscia tetraciliata Frye \& Zeller

Setchell \& Gardner, 1920

San Juan County, Wash.

Hormiscia vancouveriana (Tilden) Setchell \& Gardner

Setchell \& Gardner, 1920

Oak Bay. Vancouver Is., B. C.

Hormiscia Wormskioldi (Mertens) Fries

Setchell \& Gardner, 1920

Friday Harbor, Wash. to Gualala, Calif.

Chaetomorpha aerea (Diliwyn) Kützing

Smith, 1944; Dawson, 1944

Santa Cruz to San Diego, Calif.; northern Gulf of Calif.

Chamtomorpha antennina (Bory) Kützing

Setchell \& Gardner, 1920; Dawson, 1945B, 1945E; Taylor, 1945

La Jolla, Calif. to Panamá

Chaetomorpha californica Collins

Setchell \& Gardner, 1920

Laguna Beach to La Jolla, Calif.

Chaetomorpha cannabina (Areschoug) Kjellman

Setchell \& Gardner, 1920

Alaska to Puget Sound, Wash.

Chaetomorpha clavata (C. Agardh) Kützing

Dawson, 1945E

Punta Descanso; Cabo Colnett, Baja Calif.

Chantomorpha crassa (C. Agardh) Kützing

Taylor, 1939

Bahia Magdalena, Baja Calif. 
Chaetomorpha melangonium (Weber \& Mohr) Kützing

Setchell \& Gardner, 1920

Unalaska; Kodiak Is., Alaska

Chaetomorpha tenuissima Jao

Jao, 1937

Friday Harbor, Wash.

Chaetomorpha torta (Farlow) McClatchie

Setchell \& Gardner, 1920; Dawson, 1945B

Southern Calif.

Cladophora albida (Hudson) Kützing

Setchell \& Gardner, 1920; Dawson, 1944

East Sound, Wash.; San Pedro, Calif.; Kino, Sonora

Cladophora amphibia Collins

Setchell \& Gardner, 1920

San Francisco Bay, Calif.

Cladophora Bertolonit var. hamosa (Kützing) Ardissone

Smith, 1944

Pacific Grove, Calif.

Cladophora delicatula Montagne

Smith, 1944; Dawson, 1944

Monterey Peninsula; San Diego, Calif.; Rio Mayo, Sonora

Cladophora flexuosa (Griffiths) Harvey

Smith, 1944

Annettee Is., Alaska to San Diego, Calif.

Cladophora glaucescens (Griffiths) Harvey

Setchell \& Gardner, 1920

Nanaimo, B. C. to Oakland, Calif.

CLADOPHORA GRACILIS (Griffiths) Kützing

Setchell \& Gardner, 1920

Sitka, Alaska; Neah Bay, Wash.

Cladophora gracilis f. expansa Farlow

Taylor, 1945

Is. Clarion, Revilla Gigedo Arch.

Cladophora graminea Collins

Smith, 1944; Dawson, 1944 ; 1945E

Santa Cruz, Calif. to Guaymas, Sonora

Cladophora hemisphaerica Gardner

Smith, 1944

Monterey Peninsula, Calif. 
Cladophora hesperia Setchell \& Gardner

Dawson, 1944

Kino, Sonora to cape district, Baja Calif.

Cladophora Hutchinsiae (Dillwyn) Kützing

Setchell \& Gardner, 1920

Vancouver Is., B. C.

Cladophora Hutchinsiae var. distans (C. Agardh)

Kützing

Setchell \& Gardner, 1920

West coast of Vancouver Is., B. C.

Cladophora laetevirens (Dillwyn) Kützing

Setchell \& Gardner, 1920

Vancouver, B. C. and Straits of Juan de Fuca

Cladophora MacDougalit Howe

Dawson, 1944

Bahía San Felipe, Baja Calif.

Cladophora microcladioides Collins

Smith, 1944; Dawson, 1944; 1945E

Vancouver, B. C. to Gulf of Calif.

Cladophora microcladioides f. stricta Collins

Setchell \& Gardner, 1920

San Diego, Calif.

Cladophora ovoidea Kützing

Smith, 1944

Santa Cruz to Monterey, Calif.

Cladophora panamensis Taylor

Taylor, 1945

Bahía Honda, Panamá

Cladophora prolifera (Roth) Kützing

Taylor, 1945

Golfo Dulce, Costa Rica

Cladophora Rudolphiana (C. Agardh) Kützing

Dawson, 1944

Guaymas, Sonora

Cladophora Rudolphiana f. eramosa Gardner

Setchell \& Gardner, 1920; Dawson, 1944

San Francisco Bay, Calif.; Guaymas, Sonora

Cladophora Strmpsonit Harvey

Setchell \& Gardner, 1920

Ucluet Inlet, B. C. to southern Calif.

Cladophora tiburonensis Dawson

Dawson, 1944

Is. Tiburón, Gulf of Calif. 
Cladophora trichotoma (C. Agardh) Kützing

Smith, 1944; Dawson, 1944; 1945E

Vancouver Is., B. C. to Punta Descanso, Baja Calif.; La Paz, Baja Calif.?

Cladophora trichotoma f. Elongata Collins

Setchell \& Gardner, 1920

Point Carmel, Calif.

SPONgomorpha ARCTA (Dillwyn) Kützing

Setchell \& Gardner, 1920

Bering Sea to Puget Sound, Wash.

Spongomorpha coalita (Ruprecht) Collins

Smith, 1944

Unalaska, Alaska to Carmel, Calif.

SPONgomorpha duriuscula (Ruprecht) Collins

Setchell \& Gardner, 1920

Unalaska ; Karluk, Alaska

Spongomorpha Hystrix Stroemfelt

Setchell \& Gardner, 1920

Agattu Is. to Sitka, Alaska

Spongomorpha Mertensi (Ruprecht) Setchell \& Cardner

Setchell \& Gardner, 1920

Unalaska, Alaska to San Francisco, Calif.

Spongomorpha saxatilis (Ruprecht) Collins

Setchell \& Gardner, 1920

Alaska to San Francisco, Calif.

Spongomorpha saxatilis var. Chamissonis (Ruprecht)

Collins

Setchell \& Gardner, 1920

Alaska to Washington

SPONGOMORPHA SPINESCENS Kützing

Setchell \& Gardner, 1920

Unalaska to Coos Bay, Oregon

Microdictyon Palmeri Setchell

Setchell \& Gardner, 1930

Is. Guadalupe, Baja Calif.

\section{Fam. Valoniaceae}

Dictyosphaeria australis Setchell

Taylor, 1945

Is. Clarion; Is. Socorro, Revilla Gigedo Arch. 
Dictyosphaeria Versluysi Webet van Bosse

Setchell \& Gardner, 1930; Dawson, 1944; Taylor, 1945

Is. Guadalupe, Baja Calif.; Is. Espiritu Santo, Gulf of Calif.; Is. Socorro, Revilla Gigedo Arch.

Cladophoropsis robusta Setchell \& Gardner

Dawson, 1944; Taylor, 1945

Is. Tortuga, Gulf of Calif.; Is. Isabel, Nayarit

Boodlea composita (Harvey \& Hooker, f.) Brand

Taylor, 1945

Is. María Magdalena, Nayarit

Valoniopsis Hancockir Dawson

Dawson, 1944

Is. Angel de la Guarda, Gulf of Calif.

Valoniopsis pachynema (Martens) Børgesen

Dawson, 1944

Is. Angel de la Guarda to Is. Espíritu Santo, Gulf of Calif.

Siphonocladus pusilloides Setchell \& Gardner

Setchell \& Gardner, 1930

Is. Guadalupe, Baja Calif.

\section{Fam. Dasycladaceae}

Acetabularia parvula Solms-Laubach

Setchell \& Gardner, 1930

Is. Guadalupe, Baja Calif.

Acetabularia parvula var. americana Taylor

Taylor, 1945

Is. Socorro, Revilla Gigedo Arch.

Neomeris Vanbosseae Howe

Taylor, 1945

Is. Socorro, Revilla Gigedo Arch.

\section{Order CHLOROCOCCALES}

\section{Fam. Endosphaeraceae}

Chlorochytrium inclusum Kjellman

Smith, 1944

Sitka, Alaska to Carmel, Calif.

Chlorochytrium Porphyrae Setchell \& Gardner

Smith, 1944

Cape Flattery, Wash.; San Francisco; Monterey Peninsula, Calif. 
Chlorochytrium Schmitzil Rosenvinge

Setchell \& Gardner, 1920

Kodiak Is., Alaska

Codiolum gregarium A. Braun

Setchell \& Gardner, 1920

Friday Harbor, Wash.

Codiolum Petrocelidis Kuckuck

Smith, 1944

Whidbey Is., Wash.; San Francisco; Monterey, Calif.

Codiolum pusillum f. subsessile Jao

Jao, 1937

Brown Is., Wash.

\section{Order SIPHONALES}

\section{Fam. Halicystidaceae}

Halicystis ovalis (Lyngbye) Areschoug

Smith, 1944

Vancouver Is., B. C. to Redondo, Calif.

\section{Fam. Bryopsidaceae}

Bryopsis CORTICUlans Setchell

Smith, 1944; Dawson, 1945B

Victoria, B. C. to La Jolla, Calif.

Bryopsis galapagensis Taylor

Taylor, 1945

Is. Socorro; Is. Clarion, Revilla Gigedo Arch.

BRyopsis hypNoIdEs Lamouroux

Smith, 1944; Taylor, 1945

Victoria, B. C. to San Pedro, Calif.; Panamá City, Panamá

Bryopsis pennatula J. Agardh

Setchell \& Garclner, 1920; Taylor, 1945

San Agustin, Oaxaca; Bahía Petatlán, Guerrero

Bryopsis plumosa (Hudson) C. Agardh

Setchell \& Gardner, 1920

Friday Harbor, Wash.

Bryopsis plumosa var. pennata (Lamouroux) Børgesen

Dawson, 1944

Is. Tiburón, Gulf of Calif. 


\section{Fam. Derbesiaceae}

Derbesia Lamourouxir (J. Agardh) Solier

Setchell \& Gardner, 1920

On the coast near Tijuana, Baja Calif.

Derbesia marina (Lyngbye) Kjellman

Smith, 1944

Sitka, Alaska to San Diego, Calif.

Derbesia pacifica Jao

Jao, 1937

Turn Is., Wash.

Derbesia Vaucheriaeformis (Harvey) J. Agardh Jao, 1937

Whidbey, Is., Wash.

Fam. Vaucheriaceae

VAuCheria litoria Bang \& C. Agardh

Jao, 1937

San Juan Is., Wash.

\section{Fam. Phyllosiphonaceae}

Ostreobium Quekettir Bornet \& Flahault

Jao, 1937; Taylor, 1945

Puget Sound, Wash.; Is. Clarion, Revilla Gigedo Arch.

Ostreobium Reineckei Bornet

Setchell \& Gardner, 1930; Taylor, 1945

Is. Guadalupe, Baja Calif.; Is. Clarion, Revilla Gigedo Arch.

\section{Fam. Caulerpaceae}

Caulerpa peltata (Turner) Lamouroux

Taylor, 1945

Tangola-Tangola, Oaxaca

Caulerpa pinnata f. pectinata (Kützing) Weber van Bosse

Dawson, 1944

Is. Angel de la Guarda, Gulf of Calif.

Caulerpa racemosa var. chemnitzia (Esper) Weber van Bosse

Dawson, 1944

Bahía Agua Verde, Baja Calif.

CAulerpa RaCEMosa var. Clavifera f. Macrophysa (Kützing) Weber van Bosse

Setchell \& Gardner, 1930

Is. Guadalupe, Baja Calif. 
Caulerpa racemosa var. laetevirens i. Cylindraceae (Sonder) Weber van Bosse

Setchell \& Gardner, 1930

Is. Guadalupe, Baja Calif.

Caulerpa racemosa var. laetevirens f. typica Webèr van Bosse

Setchell \& Gardner, 1930 ; Taylor, 1945

Is. Guadalupe, Baja Calif.; Is. Clarion, Revilla Gigedo Arch.

Caulerpa racemosa var.occidentalis (C. Agardh) Børgesen

Taylor, 1945

Is. Clarion, Revilla Gigedo Arch.

Chulerpa racemosa var. uvifera (Turner) Weber van Bosse

Dawson, 1944

Is. Espíritu Santo, Gulf of Calif.

Caulerpa sertularioides (Gmelin) Howe

Dawson, 1944; Taylor, 1945

Is. Espíritu Santo, Gulf of Calif.; Tangola-Tangola. Oaxaca

Caulerpa Vanbosseae Setchell \& Gardner

Dawson, 1944

Is. Angel de la Guarda to Is. Espíritu Santo, Gulf of Calif.

\section{Fam. Codiaceae}

Codium amplivesiculatum Setchell \& Gardner

Dawson, 1944

Pond Is., Gulf of Calif.

Codium anastomosans Setchell \& Gardner

Dawson, 1944

Is. Angel de la Guarda to Is. Tiburón, Gulf of Calif.

Codium conjunctum Setchell \& Gardner

Dawson, 1944

Is. Tortuga, Gulf of Calif.

Codium cuneatum Setchell \& Gardner

Dawson, 1944

Vicinity of Smith Is., Gulf of Calif.

Codium decorticatum (Woodward) Howe

Setchell, 1933; Taylor, 1939

Bahía Magdalena, Baja Calif. ? 
Codium fernandezianum Setchell

Taylor, 1945

Bahía Santa María, Baja Calif.

Codium fragile (Suringar) Hariot

Smith, 1944; Taylor, 1945; Dawson, 1945E

Alaska to Puerto San Bartolomé, Baja Calif.

Codium isabelae Taylor

Taylor, 1945

Is. Clarion, Revilla Gigedo Arch.

Codium longiramosum Setchell \& Gardner

Dawson, 1944 ; Taylor, 1945

Pond Is., Gulf of Calif.; Is. Clarion; Is. Socorro, Revilla Gigedo Arch.; Bahía Petatlán, Guerrero

Codium Macdougalit Dawson

Dawson, 1944

Puerto Libertad, Sonora

Codium Palmeri Dawson

Dawson, $1945 \mathrm{C}$

Is. Guadalupe, Baja Calif.

Codium Setchellit Gardner

Smith, 1944; Taylor, 1945

Sitka, Alaska to Carmel, Calif.; Is. Jacarita, Panamá ?

Codium simulans Setchell \& Gardner

Setchell \& Gardner, 1930; Dawson, 1944; 1945C

La Jolla, Calif to Is. Clarion, Revilla Gigedo Arch.; Gulf of Calif.

Codium Ritteri Setchell \& Gardner

Setchell \& Gardner, 1920

Kodiak Is., Alaska to Vancouver Is., B. C.

Halimeda discoidea Decaisne

Dawson, 1944; Taylor, 1945

Is. Angel de la Guarda, Gulf of Calif. to Golfo Dulce, Costa Rica

Halimeda Opuntia (Linnaeus) Lamouroux

Setchell \& Gardner, 1930; Taylor, 1945

Is. Guadalupe, Baja Calif.; Clarion, Revilla Gigedo Arch.

Halimeda Tuna (Ellis \& Solander) Lamouroux

Taylor, 1945

Is. Clarion, Revilla Gigedo Arch.

Chlorodesmis mexicana Taylor

Taylor, 1945; Chlorodesmis comosa in Setchell \& Gardner, 1930

Is. Guadalupe, Baja Calif. to Tangola-Tangola, Oaxaca 


\section{P H A E O P Y C E A E \\ (BROWN ALGAE)}

\section{Order ECTOCARPALES}

\section{Fam. Ectocarpaceae}

Pyiaiella Gardneri Collins

Smith, 1944

San Francisco to Carmel, Calif.

Pylaiella littoralis (Linnaeus) Kjellman

Smith, 1944

Bering Sea to San Pedro, Calif.

Pylaiella tenella Setchell \& Gardner

Smith, 1944

Neah Bay, Wash.; Monterey, Calif.

Pylaiella unilateralis Setchell \& Gardner

Setchell \& Gardner, 1925

Coos Bay, Oregon

Pylaiella washingtonensis Jao

Jao, 1937

Seattle, Wash.

Ectocarpus acuminatus Saunders

Smith, 1944

Pacific Grove to San Pedro, Calif.

Ectocarpus acutus Setchell \& Gardner

Smith, 1944

Puget Sound to Carmel, Calif.

Ectocarpus affinis Setchell \& Gardner

Setchell \& Gardner, 1925

Sitka, Alaska

Ectocarpus breviarticulatus J. Agardh

Setchell \& Gardner, 1925; 1930

Is. Guadalupe, Baja Calif.; San Agustin, Oaxaca

Ectocarpus Bryantir Setchell \& Gardner

Dawson, 1944

La Paz, Baja Calif.

Ectocarpus chantransioides Setchell \& Gardner

Setchell \& Gardner, 1925

Santa Monica, Calif. 
Ectocarpus chitonicola Saunders

Smith, 1944

Monterey Peninsula, Calif.

Ectocarpus commensalis Setchell \& Gardner

Smith, 1944

Monterey Peninsula, Calif.

ECTOCARPus CONFERVoIdes (Roth) Le Jolis

Setchell \& Gardner, 1925

Yakutat Bay, Alaska to Whidbey Is., Wash.

Ectocarpus confervoldes f. parvus (Saunders) Setchell \& Gardner

Setchell \& Gardner, 1925

San Francisco to San Diego, Calif.

Ectocarpus confervoides f. pygmaeus (Areschoug) Kjellman

Smith, 1944; Dawson, 1945E Shumagin Is., Alaska to Carmel, Calif.; Punta Descanso,
Baja Calif.

ECtocarpus Confervoides f. Typicus Kuckuck

Setchell \& Gardner, 1925

Juneau, Alaska to San Francisco, Calif.

Ectocarpus corticulatus Saunders

Smith, 1944

Popof Is., Alaska to San Pedro, Calif.

Ectocarpus Cylindricus Saunders

Smith, 1944

Monterey Peninsula, Calif.

Ectocarpus cylindricus f. Codiophilus Setchell \& Gardner

Smith, 1944; Dawson, 1945B

Monterey Peninsula; La Jolla, Calif.

Ectocarpus Duchassaingianus Grunow

Setchell \& Gardner, 1930; Taylor, 1945

Is. Guadalupe, Baja Calif.; Is. María Magdalena, Nayarit; Is. Socorro, Revilla Gigedo Arch.

Ectocarpus ellipticus Saunders

Smith, 1944

Monterey Peninsula, Calif.

Ectocarpus ensenadanus Gardner

Gardner, 1940

Ensenada, Baja Calif.

Ectocarpus eramosus Setchell \& Gardner

Setchell \& Gardner, 1925

Tomales Bay, Calif. 
Ectocarpus flagelliferus Setchell \& Gardner

Setchell \& Gardner, 1925

Sitka, Alaska

Ectocarpus FlocCUliformis Setchell \& Gardner

Setchell \& Gardner, 1925

La Jolla, Calif.

Ectocarpus fructuosus Setchell \& Gardner

Setchell \& Gardner, 1925

Moss Beach, San Mateo Co., Calif.

Ectocarpus GLobifer Kützing

Setchell \& Gardner, 1925

San Pedro to La Jolla, Calif.

Ectocarpus gonodioides Setchell \& Gardner

Smith, 1944; Dawson, 1944

Carmel, Calif.; Smith Is., Gulf of Calif.

Ectocarpus Granulosoides Setchell \& Gardner

Smith, 1944; Dawson, 1945B

Monterey to La Jolla, Calif.

Ectocarpus granulosoides vat. Pygmaeus Setchell \& Gardner

Setchell \& Gardner, 1937

Is. San Martin, Baja Calif.

Ectocarpus granulosus (J. E. Smith) C. Agardh

Smith, 1944; Dawson, 1945B; 1945E

Puget Sound, Wash. to Punta Descanso, Baja Calif.

Ectocarpus Hancockil Dawson

Dawson, 1944

Turner's Is., Gulf of Calif.

Ectocarpus hemisphericus Saunders

Setchell \& Gardner, 1925

San Pedro to San Diego, Calif.

Ectocarpus hemisphericus f. MiNOR Saunders

Setchell \& Gardner, 1925 ; Dawson, 1945B

Southern Calif.

Ectocarpus isopodicola Dawson

Dawson, 1946

Newport Bay, Calif.

Ectocarpus luteolus Sauvageau

Setchell \& Gardner, 1925

San Francisco, Calif. 
Ectocarpus Mesogloine Setchell \& Gardner

Smith, 1944

Carmel, Calif.

Ectocarpus Mitchellae Harvey

Setchell \& Gardner, 1925; Dawson, 1944

Southern Calif. to San Jose del Cabo, Baja Calif.; Punta Peñasco, Sonora

Ectocarpus mucronatus Saunders

Setchell \& Gardner, 1925; Dawson, 1944

Vancouver Is., B. C. to San Pedro, Calif.; Punta Peñasco, Sonora

Ectocarpus oviger Harvey

Smith, 1944

Puget Sound to Carmel, Calif.

Ectocarpus Parksir Setchell \& Gardner

Setchell \& Gardner, 1925

San Francisco Bay, Calif.

Ectocarpus Saundersir Setchell \& Gardner

Smith, 1944

Monterey Peninsula, Calif.

Ectocarpus siliculosus (Dillwyn) Lyngbye

Setchell \& Gardner, 1925; Sanborn \& Doty, 1946

Coos Bay, Oregon to San Francisco Bay, Calif.

Ectocarpus siliculosus f. subulatus (Kützing) Setchell \& Gardner

Setchell \& Gardner, 1925

San Francisco Bay, Calif.

Ectocarpus simulans Setchell \& Gardner

Smith, 1944

Monterey, Calif.

Ectocarpus socialis Setchell \& Gardner

Setchell \& Gardner, 1925; Dawson, 1945B

Southern Calif.

Ectocarpus sonorensis Dawson

Dawson, 1944

Guaymas, Sonora

Ectocarpus Taoniae Setchell \& Gardner

Setchell \& Gardner, 1925

San Pedro, Calif.

ECTOCARPUS TERMINALIS Kützing

Setchell \& Gardner, 1925

Unalaska, Alaska to Laguna Beach, Calif. 
Ectocarpus tomentosus (Hudson) Lyngbye

Smith, 1944

Kodiak Is., Alaska to Laguna Beach, Calif.

Ectocarpus variabilis (Saunders) G. M. Smith

Smith, 1944; Dawson, 1945E; Ectocarpus confervoides

f. variabilis in Dawson, 1944

Puget Sound, Wash. to Punta Descanso, Baja Calif.; Is. Tiburón, Gulf of Calif.

Streblonema aecidioides f. pacificum Setchell \& Gardner

Setchell \& Gardner, 1925

Neah Bay, Wash.

Streblonema anomalum Setchell \& Gardner

Smith, 1944

Monterey; San Pedro, Calif.

Streblonema codicola Setchell \& Gardner

Setchell \& Gardner, 1930

Is. Guadalupe, Baja Calif.

Streblonema corymbiferum Setchell \& Gardner

Smith, 1944

Monterey; San Pedro, Calif.

Streblonema Desmarestiae Gardner

Gardner, 1940

San Juan Is., Wash.

Streblonema evagatum Setchell \& Gardner

Smith, 1944

Monterey, Calif.

Streblonema investiens (Collins) Setchell \& Gardner Setchell \& Gardner, 1925; Dawson, 1945B

San Pedro to La Jolla, Calif.

Streblonema irregulare Saunders

Setchell \& Gardner, 1925

Sitka, Alaska

Streblonema Johnstonae Setchell \& Gardner

Setchell \& Gardner, 1925

San Pedro, Calif.

Streblonema minutissium Saunders

Setchell \& Gardner, 1925

Sitka, Alaska

Streblonema myrionematoides Setchell \& Gardner

Setchell \& Gardner, 1925

Moss Beach, San Mateo Co., Calif. 
Streblonema pacificum Saunders

Setchell \& Gardner, 1925

Yakutat Bay, Alaska to San Francisco Bay, Calif.

Streblonema penetrale Setchell \& Gardner

Smith, 1944

Pacific Grove, Calif.

Streblonema Porphyrae Setchell \& Gardner

Smith, 1944

Monterey Peninsula, Calif.

Streblonema RUgosum Setchell \& Gardner

Setchell \& Gardner, 1925

Friday Harbor, Wash.

Streblonema scabiosum Setchell \& Gardner

Setchell \& Gardner, 1925

San Francisco, Calif.

Streblonema transfixum Setchell \& Gardner

Setchell \& Gardner, 1925

San Pedro, Calif.

Streblonema vorax Setchell \& Gardner

Setchell \& Gardner, 1925

Sitka, Alaska

\section{Fam. Ralfsiaceae}

Ralfsia Californica Setchell \& Gardner

Setchell \& Gardner, 1925 ; Dawson, 1944; Taylor, 1945

Central Calif.; Is. Tiburón to Is. Espíritu Santo, Gulf of Calif.; Bahía Tenacatita, Jalisco

Ralisia clavata (Carmichael) Crouan

Setchell \& Gardner, 1925

Unalaska Bay, Alaska

Ralfsia Fungiformis (Gunnerus) Setchell \& Gardner

Setchell \& Gardner, 1925; Sanborn \& Doty, 1946

Bering Sea to Coos Bay, Oregon

Ralfsia Hancockin Dawson

Dawson, 1944

San Jose del Cabo, Baja Calif.

RAlfsia hesperia Setchell \& Gardner

Smith, 1944

Carmel; Corona del Mar, Calif.

RaLfsia occidentalis Hollenberg

Taylor, 1945

Is. Socorro, Revilla Gigedo Arch. 
Ralfsia PACIFICA Hollenberg (ms)

Smith, 1944 ; Dawson, 1944

Unalaska, Alaska to Baja Calif.; northern Gulf of Calif.

Hapterophycus canaliculatus Setchell \& Gardner

Hollenberg, 1941

Redondo, Calif. to Punta Banda, Baja Calif.

Lithoderma Fatiscens Areschoug

Setchell \& Gardner, 1925

Bering Sea; Unalaska, Alaska

Hapalospongidion gelatinosum Saunders

Hollenberg, 1942; Smith, 1944

Carmel, Calif. to Punta Banda, Baja Calif.; Bahía Petatlán, Guerrero

\section{Fam. Elachistaceae}

Halothrix lumbricalis (Kützing) Reinke

Setchell \& Gardner, 1930

Is. Guadalupe, Baja Calif.

Elachistea fucicola (Velley) Areschoug

Setchell \& Gardner, 1925

Sitka, Alaska to Coos Bay, Oregon

Elachistea lubrica Ruprecht

Setchell \& Gardner, 1925

Prince William Sound to Wrangell, Alaska

Gonodia Johnstonir Setchell \& Gardner

Dawson, 1944

Is. San Marcos, Gulf of Calif.

Gonodia Marchantae Setchell \& Gardner

Dawson, 1944

La Paz, Baja Calif.

\section{Fam. Sphacelariaceae}

Sphacelaria brevicorne Setchell \& Gardner

Dawson, 1944 ; Setchell \& Gardner, 1925

La Paz and vicinity, Baja Calif.

Sphacelaria californica Sauvageau

Setchell \& Gardner, 1925

San Pedro to San Diego, Calif.

Sphacelaria didichotoma Saunders

Smith, 1944

Monterey to southern Calif. 
Sphacelaria Furcigera Kützing

Setchell \& Gardner, 1930; Dawson, 1944

Is. Tiburón, Gulf of Calif.; Is. Guadalupe; La Paz, Baja Calif.

Sphacelaria Hancockir Dawson

Dawson. 1944 Turner's Is., Gulf of Calif.; San Jose del Cabo, Baja
Calif.

Sphacelaria Masonir Setchell \& Gardner

Setchell \& Gardner, 1930

Is. Clarion, Revilla Gigedo Arch.

Sphacelaria mexicana Taylor

Taylor, 1945

Is. Socorro, Revilla Gigedo Arch.

Sphacelaria novae-hollandiae Sonder

Setchell \& Gardner, 1930

Is. Guadalupe, Baja Calif.

Sphacelaria Racemosa Greville

Setchell \& Gardner. 1925

Bering Sea to Whidbey Is., Wash.

Sphacelaria subfusca Setchell \& Gardner

Setchell \& Gardner, 1925

Sitka, Alaska to Redondo, Calif.

\section{Order CUTLERIALES}

\section{Fam. Cutleriaceae}

Cutleria Hancockit Dawson

Dawson, 1944

Is. Tiburón, Gulf of Calif.

\section{Order TILOPTERIDALES}

\section{Fam. Tilopteridaceae}

Masonophycus paradoxa Setchell \& Gardner

Setchell \& Gardner, 1930

Is. Clarion, Revilla Gigedo Arch. 


\section{Order DICTYOTALES}

\section{Fam. Dictyotaceae}

Dictyota Binghamiae J. Agardh

Setchell \& Gardner, 1925; Taylor, 1945

Southern Calif. to Bahía San Bartolomé, Baja Calif.

Is. Secas, Panamá

Dictyota CONCRESCENS Taylor

Taylor, 1945

Cabo San Lazaro, Baja Calif.

Dictyota crenulata J. Agatdh

Dawson, 1944; Taylor, 1945

Cape district, Baja Calif. to Puerto Culebra, Costa Rica

Dictyota CRIBrosa Setchell \& Gardner

Setchell \& Gardner, 1930

Is. Guadalupe, Baja Calif.

Dictyota divaricata Lamouroux, prox.

Taylor, 1945

Is. Socorro, Revilla Gigedo Arch.; Bahía Tenacatita, Jalisco

Dictyota flabellata (Collins) Setchell \& Gardnet

Smith, 1944; Taylor, 1945

Monterey to La Jolla, Calif.; Puerto Culebra, Costa Rica; Is. Secas, Panamá

Dictyota hesperia Setchell \& Gardner

Dawson, 1944

Northern Gulf of Calif.

Dictyota Johnstonir Setchell \& Gardner

Dawson, 1944

Northern Gulf of Calif.

Dictyota Masonir Setchell \& Gardner

Setchell \& Gardner, 1930

Is. Clarion, Revilla Gigedo Arch.

Dictyota Vivesiz Howe

Dawson, 1944; Taylor, 1945

Punta Gorda; Cabo San Lazaro, Baja Calif.; Is. María Magdalena, Nayarit

Dictyopteris DELICATUlA Lamouroux

Taylor, 1939; 1945; Neurocarpus delicatula in Setchell \& Gardner, 1925

Is. Clarion; Is. Socorro, Revilla Gigedo Arch.; Clipperton Is. 
Dictyopteris Johnstonei Gardner

Gardner, 1940

Santa Catalina Is., Calif.

Dictyopteris zonarioldes Farlow

Neurocarpus zonarioides in Setchell \& Gardner, 1925; Dawson, 1944

Southern Calif. to San Jose del Cabo, Baja Calif.; northern Gulf of Calif.

Taonia Lennebackerae Farlow

Setche1l \& Gardner, 1925; Taylor, 1945

Southern Calif. to Bahía San Bartolomé, Baja Calif.

Syringoderma Abyssicola (Setchell \& Gardner) Levring

Levring, 1940; Chlanidophora abyssicola in Setchell \& Gardner, 1925

San Juan Is., Wash.

Zonaria Farlowir Setchell \& Gardner

Setchell \& Gardner, 1925; 1930; Taylor, 1945

Southern Calif. to Bahía Santa María, Baja Calif.

Pocockiella variegata (Lamouroux) Papenfuss

Taylor, 1945; Zonaria variegata in Taylor, 1939

Is. Clarion; Is. Socorro, Revilla Gigedo Arch.; Clipperton Is.

Padina Durvillaei Bory

Dawson, 1944 ; Taylor, 1945

Is. Cedros, Baja Calif. to Panamá

Padina caulescens Thivy

Taylor, 1945

Is. María Magdalena, Nayarit

Padina crispata Thivy

Taylor, 1945

Is. María Madre, Nayarit; Golfo Dulce, Costa Rica; Bahía Honda, Panamá

Padina mexicana Dawson

Dawson, 1944

Turner's Is., Gulf of Calif.

Padina tetrastromatica Hauck

Setchell \& Gardner, 1930

Is. María Madre, Nayarit ? 


\section{Order CHORDARIALES}

\section{Fam. Corynophloeaceae}

Petrospongium rugosum (Okamura) Setchell \& Gardner Smith, 1944

San Mateo Co. to San Diego, Calif.

Leathesia DIFFormis (Linnaeus) Areschoug

Smith, 1944

Bering Sea to San Pedro, Calif.

Leathesia nana Setchell \& Gardner

Smith, 1944

Monterey Peninsula, Calif.

\section{Fam. Myrionemataceae}

Myrionema attenuatum Setchell \& Gardner Smith, 1944

Monterey Peninsula, Calif.

Myrionema balticum f. Californicum Setchell \& Gardner Smith, 1944

Monterey Peninsula, Calif.

Myrionema balticum f. pedicellatum Setchell \& Gardner Setchell \& Gardner, 1925

Point Carmel, Calif.

Myrionema compsonematoides Setchell \& Gardner

Setchell \& Gardner, 1925

Friday Harbor, Wash.

Myrionema corunnae f. angulatum Setchell \& Gardner

Setchell \& Gardner, 1925

San Francisco, Calif.

Myrionema corunnae f. sterile Setchell \& Gardner

Smith, 1944

Carmel, Calif.

Myrionema corunnae f. uniforme Setchell \& Gardner Setchell \& Gardner, 1925

San Mateo Co., Calif.

Myrionema foecundum f. Ramulosum Setchell \& Gardner Setchell \& Gardner, 1925

Friday Harbor, Wash. 
Myrionema foecundum f. simplicissimum Setchell \& Gardner

Setchell \& Gardner, 1925

Kodiak Is., Alaska to central California

Myrionema foecundum f. subulatum Setchell \& Gardner

Setchell \& Gardner, 1925

San Francisco, Calif.

Myrionema globosum f. affine Setchell \& Gardner

Setchell \& Gardner, 1925

Sitka, Alaska to Point Carmel, Calif.

Myrionema minutissimum Setchell \& Gardner

Setchell \& Gardner, 1925

San Francisco, Calif.

Myrionema obscurum Setchell \& Gardner

Setchell \& Gardner, 1925

Moss Beach, San Mateo Co., Calif.

Myrionema phyllophyluum Setchell \& Gardner

Setchell \& Gardner, 1925

Sitka, Alaska

Myrionema primarium Setchell \& Gardner

Smith, 1944

Alaska to Carmel, Calif.

Myrionema Setiferum Setchell \& Gardner

Setchell \& Gardner, 1925

Sitka, Alaska

Myrionema strangulans Greville

Smith, 1944

Sitka, Alaska to Carmel, Calif.

Compsonema coniferum Setchell \& Gardner

Smith, 1944

Monterey Peninsula, Calif.

Compsonema dubium Setchell \& Gardner

Smith, 1944

Monterey Peninsula, Calif.

Compsonema fasciculatum Setchell \& Gardner

Smith, 1944

Pacific Grove, Calif.

Compsonema fructuosum Setchell \& Gardner

Setchell \& Gardner, 1925

Tomales Bay, Calif.

Compsonema immixtum Setchell \& Gardner

Dawson, 1944

Is. Partida, Gulf of Calif. 
Compsonema intricatum Setchell \& Gardner Smith, 1944

Carmel, Calif.

Compsonema myrionematoides Setchell \& Gardner Smith, 1944

Pacific Grove, Calif.

Compsonema nummuloides Setchell \& Gardner

Setchell \& Gardner, 1925

Moss Beach, San Mateo Co., Calif.

Compsonema pusillum Setchell \& Gardner

Smith, 1944

Carmel, Calif.

Compsonema ramulosum Setchell \& Gardner

Smith, 1944

Carmel, Calif.

Compsonema secundum Setchell \& Gardner

Smith, 1944

Moclips, Wash. to Carmel, Calif.

Compsonema Serpens Setchell \& Gardner

Smith, 1944

Monterey Peninsula, Calif.

Compsonema sessile Setchell \& Gardner

Setchell \& Gardner, 1925

Neah Bay, Wash.

Compsonema speciosum f. Piliferum Setchell \& Gardner Setchell \& Gardner, 1925

Moclips, Wash.

CompSOnEma sporangitferum Setchell \& Gardner

Setchell \& Gardner, 1925

Neah Bay, Wash.

Compsonema streblonematordes Setchell \& Gardner

Setchell \& Gardner, 1925

Tomales Bay, Calif.

Compsonema tenue Setchell \& Gardner

Setchell \& Gardner, 1925

Sitka, Alaska

\section{Fam. Chordariaceae}

Aegira virescens (Carmichael) Setchell \& Gardner

Setchell \& Gardner, 1925; Dawson, 1945

Shumagin Is. to Sitka, Alaska; La Jolla, Calif. 
Haplogloia Andersonit (Farlow) Levring

Smith, 1944; Dawson, 1945E

Sitka, Alaska to Cabo Colnett, Baja Calif.

Haplogloia Kuckuckir Kylin

Kylin, 1940

Sitka, Alaska to Friday Harbor, Wash.

Chordaria dissessa Setchell \& Gardner

Setchell \& Gardner, 1925

Orcas Is., Wash.

Chordaria flagelliformis (Müller) C. Agardh

Setchell \& Gardner, 1925

Bering Sea to Sitka, Alaska

Chordaria Gracilis Setchell \& Gardner

Setchell \& Gardner, 1925

Amaknak Is., Alaska

Saundersella simplex (Saunders) Kylin

Kylin, 1940

Cook Inlet, Alaska to Vancouver, B. C.

\section{Fam. Heterochordariaceae}

Heterochordaria abietina (Ruprecht) Setchell \& Gardner Smith, 1944

Bering Sea to Point Conception, Calif.

\section{Fam. Spermatochnaceae}

Neriacystus Brandegeei (Setchell \& Gardner) Kylin

Dawson. 1944

Punta Peñasco, Sonora; La Paz, Baja Calif.

\section{Order SPOROCHNALES}

Fam. Sporochnaceae

Sporochnus pedunculatus (Hudson) C. Agardh

Setchell \& Gardner, 1930

Is. Guadalupe, Baja Calif.

\section{Order DESMARESTIALES}

\section{Fam. Desmarestiaceae}

Desmarestia farcta Setchell \& Gardner

Setchell \& Gardner, 1925

Argyle, San Juan Co., Wash. 
Desmarestia filamentosa Dawson

Dawson, 1944

Is. Angel de la Guarda, Gulf of Calif.

Desmarestia foliacea Pease

Setchell \& Gardner, 1925

San Juan Co., Wash.

Desmarestia herbacea (Turner) Lamouroux

Smith, 1944; Setchell \& Gardner, 1930; Taylor, 1945;

$$
\text { Dawson, 1945E }
$$

Kodiak Is., Alaska to Is. Cedros, Baja Calif.

Desmarestia intermedia Postels \& Ruprecht

Setchell \& Gardner, 1925

Bering Sea to Puget Sound, Wash.

Desmarestia Jordanil Gardner

Gardner, 1940

Ventura, Calif.

Desmarestia Latifrons (Ruprecht) Kützing

Smith, 1944

Coos Bay, Oregon to Point Sur, Calif.

Desmarestia latissima Setchell \& Gardner

Setchell \& Gardner, 1925

San Juan Co., Wash.

Desmarestia ligulata (Lightfoot) Lamouroux

Setchell \& Gardner, 1925

San Juan Is., Wash.

Desmarestia linearis Gardner

Smith, 1944

Monterey Peninsula, Calif.

Desmarestia media (C. Agardh) Greville

Setchell \& Gardner, 1925

Unalaska, Alaska

Desmarestia media var. tenuis Setchell \& Gardner

Setchell \& Gardner, 1925

Juneau, Alaska to Puget Sound, Wash.

Desmarestia mexicana Dawson

Dawson, 1944

Is. Angel de la Guarda, Gulf of Calif.

Desmarestia Munda Setchell \& Gardner

Smith, 1944 ; Dawson, 1945A

Puget Sound, Wash. to Is. Cedros, Baja Calif. 
Desmarestia pacifica Setchell \& Gardner

Setchell \& Gardner, 1925; 1930

Santa Catalina Is,. Calif.; Is. Guadalupe, Baja Calif. ?

Desmarestia viridis (Müller) Lamouroux

Smith, 1944

Carmel, Calif.

\section{Order PUNCTARIALES}

\section{Fam. Punctariaceae}

Punctaria chartacea Setchell \& Gardner

Setchell \& Gardner, 1925

Sitka, Alaska

Punctaria expansa Setchell \& Gardner

Setchell \& Gardner, 1925

Whidbey Is., Wash.

Punctaria hesperia Setchell \& Gardner

Smith, 1944

Victoria, B. C.; Monterey; San Pedro, Calif.

Punctaria latifolia Greville

Setchell \& Gardner, 1925

Metlacatla; Baranoff Is., Alaska

Punctaria lobata (Saunders) Setchell \& Gardner

Setchell \& Gardner, 1925

Prince William Sound to Sitka, Alaska

Punctaria occidentalis Setchell \& Gardner

Smith, 1944

Monterey, Calif.

Punctaria orbiculata Jao

Jao, 1937

San Juan Is., Wash.

Punctaria plantaginea Greville

Saunders, 1901 ; Setchell \& Gardner, 1925

Yakutat Bay, Alaska?

Halorhipis Winstoniz (Anderson) Saunders

Smith, 1944

Monterey Peninsula, Calif.

\section{Fam. Asperococcaceae}

Soranthera ulvoidea Postels \& Ruprecht

Smith, 1944

Unalaska, Alaska to southern Calif. 
Soranthera ulvoidea f. DIFFormis Setchell \& Gardner Setchell \& Gardner, 1925

Bering Sea to Cape Flattery, Wash.

Myelophycus intestinale Saunders

Setchell \& Gardner, 1925

Shumagin Is., Alaska to Puget Sound, Wash.

Myelophycus intestinale f. Tenue Setchell \& Gardner Setchell \& Gardner, 1925

Coos Bay, Oregon to central Calif.

\section{Fam. Scytosiphonaceae}

Scytosiphon Lomentaria (Lyngbye) J. Agardh

Smith, 1944; Dawson, 1945E

Bering Sea to Punta Descanso, Baja Calif.

Scytosiphon Lomentaria f. Cylindricus M.iculatus Setchell \& Gardner

Setchell \& Gardner, 1925

San Francisco, Calif.

Scytosiphon Lomentaria f. typica Rosenvinge

Smith, 1944 ; Dawson, 1945E

Bering Sea to Punta Descanso, Baja Calif.

Scytosiphon Lomentaria var. complanatus Rosenvinge

Smith, 1944

Cape Arago, Oregon to Carmel, Calif.

Ilea Fascia (Müller) Fries

Smith, 1944 ; Dawson, 1945E

Unalaska, Alaska to Cabo Colnett, Baja Calif.

Ilea Fascia f. caespitosa Setchell \& Gardner

Setchell \& Gardner, 1925

Alaska

Ilea Fascia f. DEbilis Setchell \& Gardner

Setchell \& Gardner, 1925

San Juan Is., Wash.

Ilea Fascia f. Typica Setchell \& Gardner

Setchell \& Gardner, 1925

Puget Sound, Wash. to southern Calif.

Ilea Fascia f. zosterifolia Setchell \& Gardner Smith, 1944

Monterey Peninsula, Calif.

Endarachne Binghamiae J. Agardh

Setchell \& Gardner, 1925

Southern Calif. to Ensenada, Baja Calif. 
Colpomenta Ramosa Taylor

Taylor, 1945

Is. Cedros, Baja Calif.; Bahía Salinas; Port Parker, Costa Rica

Colpomenia sinuosa (Roth) Derbés \& Solier

Setchell \& Gardner, 1925; 1930; Smith, 1944; Dawson, 1944 ; Taylor, 1945

Yakutat Bay, Alaska to Port Parker, Costa Rica

Colpomenia sinuosa f. Deformans Setchell \& Gardner

Setchell \& Gardner, 1925; Dawson, 1944; Taylor, 1945; Scytosiphon bullosus in Smith, 1944.

Cook Inlet, Alaska to Bahía San Bartolomé, Baja Calif.; Gulf of Calif.

Colpomenia sinuosa f. expansa Saunders

Setchell \& Gardner, 1925

Avalon, Santa Catalina Is., Calif.

Colpomenia sinuosa f. tuberculata (Saunders) Setchell \& Gardner

Setchell \& Gardner, 1925 ; Dawson, 1944

Unalaska, Alaska to La Paz, Baja Calif.; Gulf of Calif.

Rosenvingea intricata (J. Agardh) Børgesen

Dawson, 1944; Taylor, 1945

Bahía Tepoca, Sonora to Is. Socorro, Revilla Gigedo Arch.

Hydroclathrus clathratus (Bory) Howe

Dawson, 1944; 1945B

Southern Calif. to central México; southern Gulf of Calif.

\section{Fam. Coilodesmaceae}

Coilodesme bulligera Stroemfelt

Setchell \& Gardner, 1925

Shumagin Is., Alaska to Coos Bay, Oregon

CoIlodesme Californica (Ruprecht) Kjellman

Smith, 1944; Connell, 1928; Dawson, 1945C

Departure Bay, B. C. to La Jolla, Calif.

Coilodesme corrugata Setchell \& Gardner

Setchell \& Gardner, 1925

Santa Catalina Is., Calif.

Coilodesme Cystoseirae (Ruprecht) Setchell \& Gardner

Setchell \& Gardner, 1925

Kukak Bay; Yakutat Bay, Alaska 
Coilodesme polygnampta Setchell \& Gardner Setchell \& Gardner, 1925

Amaknak Is., Unalaska, Alaska

Coilodesme rigida Setchell \& Gardner

Setchell \& Gardner, 1925

Redondo to San Diego, Calif.

Coilodesme sitchensis Setchell \& Gardner

Setchell \& Gardner, 1925

Sitka, Alaska

Phaeostrophion irregulare Setchell \& Gardner

Setchell \& Gardner, 1925

Coos Bay, Oregon; Bolinas, Calif.

\section{Fam. Striariaceae}

Stictyosiphon tortilis (Ruprecht) Reinke

Smith, 1944

Alaska; Monterey Peninsula, Calif.

\section{Fam. Chnoosporaceae}

Chnoospora pacifica J. Agardh

Dawson, 1944

La Paz, Baja Calif. to St. Augustin, Oaxaca

Chnoospora pannosa J. Agardh

Setchell \& Gardner, 1930

Is. Guadalupe, Baja Calif.

\section{Fam. Ishigiaceae}

ISHIGE FoliACEA Okamura

Dawson, 1944

Northern Gulf of Calif.

\section{Order DICTYOSIPHONALES}

\section{Fam. Dictyosiphonaceae}

Dictyosiphon foeniculaceus (Hudson) Greville

Setchell \& Gardner, 1925

Bering Sea to Puget Sound, Wash.

Dictyosiphon hippuroides (Lyngbye) Kützing

Setchell \& Gardner, 1925

Bering Sea to Unalaska, Alaska 
Dictyosiphon hispidus Kjellman

Setchell \& Gardner, 1925

Orca, Alaska

Dictyosiphon sinicola Gardner

Gardner, 1940

Vancouver Is., B. C.; Puget Sound, Wash.

Dictyosiphon tenuis Setchell \& Gardner

Setchell \& Gardner, 1925

Golofin Bay, Alaska

\section{Order LAMINARIALES}

\section{Fam. Chordaceae}

CHORDA FILUm (Linnaeus) Lamouroux

- Setchell \& Gardner, 1925

Bering Sea to Puget Sound, Wash.

\section{Fam. Laminariaceae}

Laminaria Andersonit Eaton

Smith, 1944

Whidbey Is., Wash, to Carmel, Calif.

Laminaria complanata (Setchell \& Gardner) Setchell

Setchell \& Gardner, 1925

Friday Harbor, Wash.

Laminaria Cuneifolia J. Agardh

Setchell \& Gardner, 1925

Bering Sea to Puget Sound, Wash.

Laminaria CUNEIFolia f. Amplissima Setchell \& Gardner

Setchell \& Gardner, 1925

Sitka, Alaska to Cape Flattery, Wash.

Laminaria cuneifolia f. angusta Setchell \& Gardner

Setchell \& Gardner, 1925

Cape Flattery; Whidbey Is., Wash.

LAMiNARIa CUneifolia f. Subsimplex Setchell \& Gardner

Setchell \& Gardner, 1925

Lower Puget Sound, Wash.

LAMINARIA DENTIGERA Kjellman

Setchell \& Gardner, 1925

Aleutian Islands, Alaska 
Laminaria ePHEmera Setchell

Smith, 1944

Puget Sound, Wash.; Monterey Peninsula, Calif.

Laminaria Farlowi Setchell

Smith, 1944; Dawson, 1945E

Santa Cruz, Calif. to Cabo Colnett, Baja Calif.

LAMINARIA LONGIPES Bory

Setchell \& Gardner, 1925

Agattu Is.; Kiska Is., Alaska

Laminaria personata Setchell \& Gardner

Setchell \& Gardner, 1925

Yakutat Bay to Sitka, Alaska

Laminaria platymeris De la Pylaie

Setchell \& Gardner, 1925

Bering Sea to Straits of Juan de Fuca

LAMINARIA SACCHARINA (Linnaeus) Lamouroux

Setchell \& Gardner, 1925

Alaska to Coos Bay, Oregon

Laminaria saccharina f. Linearis J. Agardh

Setchell \& Gardner, 1925

Unga, Alaska to Puget Sound, Wash.

Laminaria saccharini f. membranacea J. Agardh

Setchell \& Gardner, 1925

Alaska to Coos Bay, Oregon

Laminaria Sinclairii (Harvey) Farlow

Smith, 1944

Vancouver Is., B. C. to San Luis Obispo Co., Calif.

Pleurophycus Gardneri Setchell \& Saunders

Setchell \& Gardner, 1925

Yakutat Bay, Alaska to Coos Bay, Oregon

Cyamathere triplicata (Postels \& Ruprecht) J. Agardh

Setchell \& Gardne, 1925

Bering Sea to Puget Sound, Wash.

Costaria costata (Turner) Saunders

Smith, 1944

Shumagin Is., Alaska to San Pedro, Calif.

Thalassiophyllum clathrus (Gmelin) Postels \& Ruprecht

Setchell \& Gardner, 1925

Bering Sea to Straits of Juan de Fuca

Agarum cribrosum Boty

Setchell \& Gardner, 1925

liering Sea to San Juan Is., Wash. 
Agarum Fimbriatum Harvey

Setchell \& Gardner, 1925

Puget Sound, Wash. to central Calif.

Hedophyllum Sessile (C. Agardh) Setchell

Setchell \& Gardner, 1925

Yakutat Bay, Alaska to Point Sur, Calif.

Hedophyllum subsessile (Areschoug) Setchell

Sanborn \& Doty, 1946

Bering Sea; Coos Bay, Oregon

Arthrothamnus bifidus (Gmelin) J. Agardh

Setchell \& Gardner, 1925

Aleutian Islands, Alaska

Dictyoneurum CaLIFornicum Ruprecht

Smith, 1944

Vancouver Is., B. C. to San Luis Obispo Co., Calif.

Dictyoneuropsis Reticulata (Saunders) G. M. Smith

Smith, 1944

Monterey Peninsula, Calif.

Nereocystis Luetkeana (Mertens) Postels \& Ruprecht

Smith, 1944

Shumagin Is., Alaska to Santa Barbara. Calif.

Postelsia palmaeformis Ruprecht

Smith, 1944

Vancouver Is., B. C. to San Luis Obispo Co., Calif.

MaCrocystis Integrifolia Bory

Smith, 1944

Vancouver Is., B. C. to Carmel, Calif.

Macrocystis pyrifera (Linnaeus) C. Agardh

Smith, 1944; Taylor, 1945

Sitka, Alaska to Bahía Magdalena, Baja Calif.; cast ashore on Is. Clarion, Revilla Gigedo Arch.

Pelagophycus porra (Leman) Setchell

Setchell \& Gardner, 1925

Point Conception to San Diego, Calif.

Lessoniopsis LitToralis (Farlow \& Setchell) Reinke

Smith, 1944

Sitka, Alaska to Carmel, Calif.

\section{Fam. Alariaceae}

Pterygophora CALIfornica Ruprecht

Smith, 1944; Dawson, 1945E

Vancouver Is., B. C. to Punta Descanso, Baja Calif. 
Alaria dolichorhachis Kjellman

Setchell \& Gardner, 1925

Agattu Is., Alaska

Alaria fistulosa Postels \& Ruprecht

Setchell \& Gardner, 1925

Bering Sea to Wrangell, Alaska

Araria irstulosa f. Platyphylla Setchell

Setchell \& Gardner, 1925

Bering Sea to southeastern Alaska

Alaria fistulosa f. stenophylla Setchell

Setchell \& Gardner, 1925

Bering Sea to southeastern Alaska

Alaria lanceolata Kjellman

Setchell \& Gardner, 1925

Bering Sea to Sitka, Alaska

Alaria marginata Postels \& Ruprecht

Smith, 1944; Sanborn \& Doty, 1946

Coos Bay. Ore. to Carmel, Calif.

Alaria nana Schrader

Smith, 1944

Vanconver Is., B. C. to Carmel, Calif.

Alaria Pylail (Bory) Greville

Setchell \& Gardner, 1925

Prince William Sound to Kodiak Is., Alaska

Alaria tenuifolia Setchell

Setchell \& Gardner, 1925

Bering Sea to Puget Sound, Wash.

Alaria tenuifolia f. typica Setchell

Setchell \& Gardner, 1925

Unalaska, Alaska

Alaria tenuifolia f. Amplior Setchell \& Gardner

Setchell \& Gardner, 1925

Esquimault, B. C. to San Juan Is., Wash.

Alaria valida Kjellman \& Setchell

Setchell \& Gardner, 1925

Unga, Alaska to Puget Sound, Wash.

Alaria valida f. Longipes Setchell \& Gardner

Setchell \& Gardner, 1925

Whidbey Is., Wash.

Eisenia arborea Areschoug

Setchell \& Gardner, 1925

Redondo, Calif. to Cabo San Lazaro, Baja Calif. 
Eisenia ? DESMAREstroides Setchell \& Gardner

Setchell \& Gardner, 1930

Is. Guadalupe, Baja Calif.

Eisenia ? Masonir Setchell \& Gardner

Setchell \& Gardner, 1930

Is. Guadalupe, Baja Calif.

Egregia Laevigata Setchell

Smith, 1944; Dawson, 1945E; 1946

Monterey ; Point Conception, Calif. to Cabo Colnett, Baja

Calif.; Bahía Los Angeles, Gulf of Calif.

Egregia Menziesii (Turner) Areschoug

Smith, 1944

Vancouver Is., B. C. to Point Conception, Calif.

\section{Order FUCALES}

\section{Fam. Fucaceae}

Fucus edentatus De la Pylaie

Setchell \& Gardner, 1925

Sitka, Alaska to Coos Bay, Oregon

Fucus edentatus f. acutus Gardner

Setchell \& Gardner, 1925

Bellingham, Wash.

Fucus edentatus f. costatus Gardner

Setchell \& Gardner, 1925

Lower Puget Sound, Wash.

Fucus edentatus f. Divaricatus Gardner

Setchell \& Gardner, 1925

Vancouver Is., B. C.; Bellingham, Wash.

Fucus edentatus f. Divergens Gardner

Setchell \& Gardner, 1925

Kanaka Bay, San Juan Co., Wash.

Fucus edentatus f. hesperius Gardner

Setchell \& Gardner, 1925

Cape Arago, Oregon

Fucus evanescens C. Agardh

Setchell \& Gardner, 1925

Bering Sea to Coos Bay, Oregon

Fucus eVAnescens f. CORnutus Kjellman

Setchell \& Gardner, 1925

Yakutat Bay, Alaska 
Fucus evanescens f. cuneatus Gardner

Setchell \& Gardner, 1925

Coos Bay, Oregon

Fucus evanescens f. Dendroides Stroemfelt

Setchell \& Gardner, 1925

Agattu Is. to Sitka, Alaska

Fucus evanescens f. ecostatus Gardner

Setchell \& Gardner, 1925

Coos Bay, Oregon

Fucus evanescens f. Flabellatus Gardner

Setchell \& Gardner, 1925

Bellingham, Wash.

Fucus evanescens f. Longifructus Setchell \& Gardner

Setchell \& Gardner, 1925

Orca to Juneau, Alaska

Fucus evanscens f. macrocephalus Kjellman

Setchell \& Gardner, 1925; Connell, 1928

Bering Sea to Departure Bay, B. C.

Fucus evanscens f. Magnificus Gardner

Setchell \& Gardner, 1925

Juneau, Alaska to Puget Sound, Wash.

Fucus evanescens f. marginatus Gardner

Setchell \& Gardner, 1925

Sitka, Alaska

Fucus evanescens f. Nanus Kjellman

Setchell \& Gardner, 1925

Yakutat Bay, Alaska to Puget Sound, Wash.

Fucus evanescens f. oregonensis Gardner

Setchell \& Gardner. 1925

Coos Bay, Oregon

Fucus evanescens f. Pergrandis Kjellman

Setchell \& Gardner, 1925

Unalaska, Alaska to Puget Sound, Wash.

Fucus evanescens f. Robustus Setchell \& Gardner

Setchell \& Gardner, 1925

Bering Sea to Friday Harbor, Wash.

Fucus evanescens f. Rudis Kjellman

Setchell \& Gardner, 1925

Bering Sea to Skagway, Alaska

Fucus evanescens f. stellatus Gardner

Setchell \& Gardner, 1925

Sackman's Point, Kitsap Co., Wash. 
Fucus eVAnescens f. Typicus Kjellman

Setchell \& Gardner, 1925

Harvester and Kodiak Is., Alaska

Fucus furcatus C. Agardh

Smith, 1944

Sitka, Alaska to San Luis Obispo Co., Calif.

Fucus furcatus f. abbreviatus Gardner

Setchell \& Gardner, 1925; Sanborn \& Doty, 1946

San Juan Co., Wash. to Coos Bay, Oregon

Fucus furcatus f. angustus Gardner

Setchell \& Gardner, 1925

San Juan Is., Wash. to central Oregon

Fucus furcatus f. CONTORTUS Gardner

Setchell \& Gardner, 1925

Near Bellingham, Wash.

Fucus furcatus f. CORnutus Gardner

Setchell \& Gardner, 1925

Yakutat Bay, Alaska to Victoria, B. C.

Fucus furcatus f. elongatus Gardner

Setchell \& Gardner, 1925

San Juan Is., Wash. to Coos Bay, Oregon

Fucus furcatus f. Latifrons Gardner

Setchell \& Gardner, 1925

Ft. Ward, near Seattle, Wash.

Fucus furcatus f. Linearis Gardner

Setchell \& Gardner, 1925

Tracyton, Wash.

Fucus furcatus f. Luxurians Gardner

Setchell \& Gardner, 1925 ; Smith, 1944 ; Sanborn \& Doty, 1945

Coos Bay, Oregon to Oil Port, San Luis Obispo Co., Calif.

Fucus furcatus f. nigricans Gardner

Setchell \& Gardner, 1925

Cattle Point, San Juan Is., Wash.

Fucus furcatus f. Reflexus Gardner

Setchell \& Gardner, 1925

Pt. Defiance, Tacoma, Wash.

Fucus furcatus f. RIGIDUs Gardner

Setchell and Gardner, 1925; Connell, 1928

Horswell Channel, B. C. to Whidbey Is., Wash. 
Fucus furcatus f. Typicus Gardner

Setchell \& Gardner, 1925

Straits of Juan de Fuca to Fort Ross, Calif.

Fucus furcatus f. variabilis Gardner

Setchell \& Gardner, 1925 ; Connell, 1928

Sitka, Alaska; Campbell River, B. C.

Fucus membranaceus Gardner

Setchell \& Gardner, 1925

Bering Sea to Puget Sound, Wash.

Fucus membranaceus f. abbreviatus Gardner

Setchell \& Gardner, 1925

Sitka, Alaska

Fucus membranaceus f. acuminatus Gardner

Setchell \& Gardner, 1925

Sitka, Alaska

Fucus membranaceus f. Latissimus Gardner

Setchell \& Gardner, 1925

Kodiak Is. to Sitka, Alaska

Fucus membranaceus f. Limitatus Gardner

Setchell \& Gardner, 1925

Pt. Defiance, Tacoma, Wash.

Fucus membranaceus f. obtusus Gardner

Setchell \& Gardner, 1925

Sitka, Alaska

Fucus membranaceus f. Typicus Gardner

Setchell \& Gardner, 1925

Sitka, Alaska

Fucus nitens Gardner

Setchell \& Gardner, 1925

San Francisco Bay, Calif.

Fucus Parksir Gardner

Gardner, 1940

Humbolt Bay; Eurelia, Calif.

Pelvetia fastigiata (J. Agardh) DeToni

Smith, 1944; Sanborn \& Doty, 1946; Dawson, 1945E; Connell, 1928

Horswell Channel, B. C.; Coos Bay, Oregon to Ensenada, Baja Calif.

Pelvetia fastiginta f. gracilis Setchell \& Gardner

Smith, 1944

Monterey Peninsula; Santa Catalina Is., Calif. 
Pelvetiopsis arborescens Gardner

Gardner, 1940

Point Carmel, Calif.

Pelvetiopsis limitata (Setchell) Gardner

Smith, 1944

Vancouver Is., B. C. to Carmel, Calif.

Pelvetiopsis limitata f. Lata Gardner

Smith, 1944

Tomales Point to Monterey, Calif.

Pelvetiopsis limitata f. typica Gardner

Setchell \& Gardner, 1925

Vancouver Is., B. C. to central Calif.

Hesperophycus Harveyanus (Decaisne) Setchell \& Gardner

Smith, 1944; Dawson, 1945E

Santa Cruz, Calif. to Ensenada, Baja Calif.

\section{Fam. Sargassaceae}

Blossevillea Brandegeei Setchell \& Gardner

Setchell \& Gardner, 1930; Dawson, 1945C

La Jolla, Calif. to Is. Guadalupe, Baja Calif.

Cystophyllum geminatum (C. Agardh) J. Agardh

Setchell \& Gardner, 1925

Bering Sea to Puget Sound, Wash.

Halidrys dioica Gardner

Setchell \& Gardner, 1925 ; Taylor, 1945 ; Dawson, $1945 \mathrm{E}$

Redondo, Calif. to Is. Cedros, Baja Calif.

Cystoseira neglecta Setchell \& Gardner

Setchell \& Gardner, 1925; Dawson, 1945C; 1945E

Santa Catalina Is.; La Jolla, Calif.; Cabo Colnett, Baja Calif.

Cystoseira osmundacea (Menzies) C. Agardh

Smith, 1944; Taylor, 1945; Dawson, 1945E

Seaside, Oregon to Punta San Bartolomé, Baja Calif.

Cystoseira Setchelli Gardner

Setchell \& Gardner, 1925

Redondo to San Diego, Calif.

Sargassum acinacifolium Setchell \& Gardner

Dawson, 1944

Puerto Libertad to Guaymas, Sonora

Sargassum Agardhianum Farlow

Setchell \& Gardner, 1925; Dawson, 1945E

Southern Calif. to Ensenada, Baja Calif. 
SARGASSUM ASYMMETRICUM Dawson

Dawson, 1944

Punta Peñasco, Sonora to Is. Tiburón, Gulf of Calif.

Sargassum Brandegeei Setchell \& Gardner

Dawson, 1944; Taylor, 1945

Puerto Libertad to Guaymas, Sonora; Golfo Dulce, Costa Rica ?

Sargassum Camouir Dawson

Dawson, 1944

Is. Tiburón, Gulf of Calif.

Sargassum herporhizUm Setchell \& Gardner

Dawson, 1944

George Is.; Is. San Pedro Martir, Gulf of Calif.

SARGASSUM HORRIDUm Setchell \& Gardner

Dawson, 1944

Vicinity of La Paz, Baja Calif.

SaRgassum Howellir Setchell \& Gardner

Setchell, 1937; Taylor, 1945

Is. Soccoro; Is. Clarion, Revilla Gigedo Arch.

Sargassum Johnstonir Setchell \& Gardner

Dawson, 1944

Punta Peñasco, Sonora to Bahía Agua Verde, Baja Calif.

Sargassum Johnstonir f. gracile Setchell \& Gardner

Dawson, 1944

Punta Peñasco to Guaymas, Sonora

Sargassum Lapazeanum Setchell \& Gardner

Dawson, 1944

Guaymas, Sonora to La Paz, Baja Calif.

Sargassum Liebmanni J. Agardh

Taylor, 1945

Is. Maria Magdalena, Nayarit to Bahía Honda, Panamá

Sargassum Macdougalit Dawson

Dawson, 1944

Puerto Libertad; Guaymas, Sonora

Sargassum Palmeri Grunow

Setchell \& Gardner, $1925 ; 1930$

Santa Cruz, Calif. to Is. Guadalupe, Baja Calif.

Sargassum sinicola Setchell \& Gardner

Dawson, 1944

Punta Peñasco, Sonora to La Paz, Baja Calif.; Is. Guadalupe, Baja Calif. 


\section{R H O D O P H C E A E \\ (RED ALGAE)}

\section{Order BANGIALES}

\section{Fam. Goniotrichaceae}

GONIOTRICHUM CORNU-CERVI (Reinsch) Hauck

Kylin, 1925

Friday Harbor, Wash.

Goniotrichum elegans (Chauvin) Zanardini

Smith, 1944; Dawson, 1944; Goniotrichum Alsidii in Taylor, 1945

Friday Harbor, Wash. to Is. María Madre, Nayarit

Goniotrichopsis sublittoralis G. M. Smith

Smith, 1944

Monterey, Calif.

\section{Fam. Erythrotrichiaceae}

Erythropeltis discigera (Berthold) Schmitz

Dawson, 1944

Is. Tiburón, Gulf of Calif.

Erythrotrichia CALIFornica Kylin

Smith, 1.944 ; Dawson, 1944

Monterey, Calif.; Is. Tiburón, Gulf of Calif.

Erythrotrichia carnea (Dillwyn) J. Agardh

Smith, 1944; Dawson, 1944; 1945B

Monterey; San Diego, Calif.; Gulf of Calif.

Erythrotrichia ceramicola (Lyngbye) Areschoug

Collins, 1913

Ucluelet, Vancouver Is., B. C.

Erythrotrichia Kylinit Gardner

Gardner, 1927

Bering Sea to Puget Sound, Wash.

Erythrotrichia Parksir Gardner

Gardner, 1927

Eureka, Calif.

ERythrotrichia Parksil var. Minor Gardner

Gardner, 1927

Neah Bay, Wash. 
ERythrotrichia POLYMORPHA Howe

Setchell \& Gardner, 1924

Gulf of Calif.

ERythrotrichia PORPhyroIDEs Gardner

Gardner, 1927

San Francisco, Calif.

Erythrotrichia pulvinata Gardner

Smith, 1944

Monterey, Calif.

Erythrotrichia tetraseriata Gardner

Gardner, 1927

San Pedro, Calif.

Erythrotrichia Welwitschil (Ruprecht) Batters

Smith, 1944

Monterey, Calif.

ERythrocladia IRrEgularis Rosenvinge

Smith, 1944; Dawson, 1944

Friday Harbor, Wash.; Monterey. Calif.; Turner's Is. Gulf of Calif.

Erythrocladia subintegra Rosenvinge

Smith, 1944 ; Dawson, 1945 E

Friday Harbor, Wash.; Monterey, Calif.; Punta Descanso, Baja Calif.

\section{Fam. Bangiaceae}

Bangia fuscopurpurea (Dillwyn) Lyngbye

Kylin, 1925; Taylor, 1945

Orcas Is., Wash.; Port Parker, Costa Rica

Bangia maxima Gardner

Gardner, 1927

Bolinas, Calif.

Bangin tenuis Gardner

Gardner, 1927

Orcas Is., Wash.

Bangia Vermicularis Harvey

Smith, 1944; Sanborn \& Doty. 1946

Coos Bay, Oregon to Carmel, Calif.

Porphyra abyssicola Kjellman

Kylin, 1925

Friday Harbor, Wash.

Porpiyra amplissima (Kjellman) Setchell \& Hus

Kylin, 1925 ; Setchell \& Gardner, 1903

Amaknak Is., Alaska to Friday Harbor, Wash. 
Porphyra laciniata (Lightfoot) C. Agardh

Setchell \& Gardner, 1903

Amaknak Is. to Sitka, Alaska

Porphyra lanceolata (Setchell \& Hus) G. M. Smith Smith, 1944

Chehalis Bay, Wash. to Carmel, Calif.

Porphyra miniata f. cuneiformis Setchell \& Hus

Smith, 1944

Gulf of Alaska; Coupeville, Wash.; Monterey, Calif.

Porphyra natadum Anderson

Smith, 1944; Taylor, 1945; Dawson, 1945E

Vancouver Is., B. C. to Cabo San Lazaro, Baja Calif. Port Parker, Costa Rica

Porphyra Nereocystis Anderson

Smith, 1944

Uyak Bay, Alaska to San Pedro, Calif.

Porphyra occidentalis Setchell \& Hus

Smith, 1944; Sanborn \& Doty, 1946

Coos Bay, Oregon; Carmel Bay, Calif.

Porphyra perforata J. Agardh

Smith, 1944; Dawson, 1944; 1945E

Shumagin Is., Alaska to Cabo Colnett, Baja Calif. ; Bahía Agua Verde, Baja Calif.

Porphyra perforata f. segregata Setchell \& Hus

Kylin, 1925

Washington to northern Calif.

Porphyra pulchra Hollenberg

Smith, 1944

Santa Cruz to Monterey, Calif.

Porphyra schizophylla Hollenberg

Smith, 1944

Pescadero Point, Calif.

Porphyra Thureti Setchell \& Dawson

Dawson, 1944; Smith, 1944

Santa Cruz; Monterey, Calif.; Bahía San Felipe, Baja Calif.

Porphyra tenuissima (Stroemfelt) Setchell \& Hus

Setchell \& Gardner, 1903

Shumagin Is.; Yakutat Bay, Alaska

Porphyra umbilicalis (Setchell \& Gardner) Collins

Collins, 1913; Porphyra laciniata f. umbilicalis in Setchell \& Gardner, 1903

Victoria, B. C. ? 
Porphyra variegata Kjellman

Smith, 1944

Puget Sound, Wash.; Monterey, Calif.

Porphyrella californica Hollenberg

Hollenberg, 1945

Lady's Harbor, Santa Cruz Is., Calif.; Southern Calif

Porphyrella Gardneri Smith \& Hollenberg

Smith, 1944; Hollenberg, 1945

Cape Arago, Oregon; Duxbury Reef to Monterey, Calif.

Porphyropsis coccinea ( $\mathrm{J}$. Agardh) Rosenvinge

Kylin, 1925

Friday Harbor, Wash.

\section{Order NEMALIONALES}

\section{Fam. Acrochaetiaceae}

Acrochaetium Amphiroae (Drew) Papenfuss

Papenfuss, 1945; Dawson, 1945E; Rhodochorton Amphiroae in Dawson, 1945B

Monterey, Calif. to Cabo Colnett, Baja Calif.

Acrochaetium angustum (Drew) Papenfuss

Papenfuss, 1945

Santa Catalina Is., Calif.

Acrochaetium Bornetil Papenfuss

Papenfuss, 1945

San Pedro, Calif.

Acrochaetium coccineum (Drew) Papenfuss

Papenfuss, 1945

Marin Co.; San Francisco, Calif.

Acrochaetium Daviesil (Dillwyn) Nägeli

Papenfuss, 1945 ; Taylor, 1945

Carmel, Calif. to Is. Clarion, Revilla Gigedo Arch.

Acrochaetium densum (Drew) Papenfuss

Papenfuss, 1945

San Francisco, Calif.

Acrocifaetium Desmarestiae Kylin

Papenfuss, 1945

San Juan Co., Wash.

Acrochaetium Dictyotae Collins

Papenfuss, 1945

San Diego Co., Calif. 
Acrochaetium Eastwoodae (Setchell \& Gardner) Papenfuss

Papenfuss, 1945

Is. Clarion, Revilla Gigedo Arch.

Acrochaetium elegans (Drew) Papenfuss

Papenfuss, 1945

La Jolla, Calif.

Acrochaetium Erythrophyllum Jao

Jao, 1937

Port Angeles, Wash.

Acrochaetium Gymnogongri (Drew) Papenfuss

Papenfuss, 1945

San Francisco, Calif.

Acrochaetium Hancockil (Dawson) Papenfuss

Papenfuss, 1945

Is. Angel de la Guarda, Gulf of Calif.

Acrochaetium Macounit (Collins) Hamel

Papenfuss, 1945

Vancouver Is., B. C. to Carmel Bay, Calif.

Acrochaetium magnificum (Drew) Papenfuss

Papenfuss, 1945

La Jolla, Calif.

Acrochaetium obscurum (Drew) Papenfuss

Papenfuss, 1945

Marin Co. to Carmel, Calif.

Acrochaetium pacificum Kylin

Papenfuss, 1945

San Juan Co., Wash.

Acrochaetium penetrale (Drew) Papenfuss

Papenfuss, 1945; Taylor, 1945

La Jolla, Calif.; Port Parker, Costa Rica

Acrochaetium plumosum (Drew) G. M. Smith

Papenf uss, 1945 ; Dawson, 1945E

Tomales Bay to Carmel, Calif.; Punta Descanso, Baja Calif.

Acrochaetium rhizoideum (Drew) G. M. Smith

Papenfuss, 1945

Washington to southern Calif.

Acrochaetium rhizoideum var. patens (Drew) G. M. Smith

Smith, 1944

Carmel, Calif. 
Acrochaetium simplex (Drew) Papenfuss

Papenfuss, 1945

Santa Monica, Calif.

Acrochaetium sinicolum (Dawson) Papenfuss

Papenfuss, 1945

Turner's Is., Gulf of Calif.

Acrochaetium subimmersum (Setchell \& Gardner) Papenfuss

Papenfuss, 1945

Puget Sound, Wash. to Carmel, Calif.

Acrochaetium tenuissimum (Collins) Papenfuss

Papenfuss, 1945

San Pedro, Calif.

Acrochaetium Thuretil var. agama (Rosenvinge) Dawson

Dawson, 1945D

San Pedro, Calif.

Acrochaetium vagum (Drew) Jao

Jao, 1937 ; Papenfuss, 1945

Cape Flattery; San Juan Is., Wash.; Moss Beach, San Mateo Co., Calif.

Acrochaetium variabile (Drew) G. M. Smith

Papenfuss, 1945

San Juan Is., Wash. to San Pedro, Calif.

Chromastrum arcuatum (Drew) Papenfuss

Papenfuss, 1945; Rhodochorton arcuatum in Dawson, 1944

Cape Flattery, Wash. to Moss Beach, San Mateo Co., Calif.; Turner's Is., Gulf of Calif.

Cinronastrum hirsutum (Drew) Papenfuss

Papenfuss, 1945

Vancouver, B. C.

- Chromastrum implicatum (Drew) Papenfuss

Papenfuss, 1945

Moss Beach, San Mateo Co., Calif.

Chromastrum microscopicum (Nägeli) Papenfuss

Papenfuss, 1945 ; Rhodochorton microscopicum in Dawson, 1944

La Jolla, Calif.; Turner's Is., Gulf of Calif.

Chromastrum moniliforme (Rosenvinge) Papenfuss

Papenfuss, 1945

Vancouver Is., B. C. 
Chromastrum Porphyrae (Drew) Papenfuss

Papenfuss, 1945

San Francisco; Monterey, Calif.

Rhodochorton CONCRESCEns Drew

Papenfuss, 1945

Carmel Bay, Calif.

Rhodochorton penicilliforme (Kjellman) Rosenvinge

Papenfuss, 1945

Spruce Is., Alaska to San Juan Co., Wash.

RHODOCHORTON PURPUREUM (Lightfoot) Rosenvinge

Papenfuss, 1945

Bering Sea to San Diego, Calif.

Rhodochorton tenue Kylin

Papenfuss, 1945

San Juan Is., Wash.; Santa Cruz, Calif.

Audouinella membranaceum (Magnus) Papenfuss

Papenfuss, 1945

San Juan Co., Wash.

Conchocelis rosea Batters

Jao, 1937

Puget Sound, Wash.

\section{Fam. Helminthocladiaceae}

Nemalion elminthoides (Velley) Batters

Dawson, 1945B; Nemalion lubricum in Smith, $194+$

Sitka, Alaska to San Diego, Calif.

Nemalion virens J. Agardh

Agardh, 1852

E:

Pacific coast of México, probably Oaxaca

Helminthora Saundersii Gardner

Smith, 1944

Monterey, Calif.

Helminthora stricta Gardner

Gardner, 1926

La Jolla, Calif.

Helminthocladia californica (J.Agardh) Kylin

Kylin, 1941

Santa Barbara to San Diego, Calif.

Helminthocladia GRACILIS Gardner

Gardner, 1926

Santa Barbara, Calif. 
Cumagloia Andersonit (Farlow) Setchell \& Gardner

Smith, 1944 ; Dawson, 1945E

Vancouver Is., B. C. to San Diego, Calif.; Cabo Colnett, Baja Calif.

Liagora CALIFornica Zeh

Zeh, 1912; Dawson, 1945D

Santa Catalina Is., Calif. to Is. Guadalupe, Baja Calif.

Liagora Ceranoides Lamouroux

Taylor, 1945

Golfo Dulce, Costa Rica

Liagora Valida Harvey

Taylor, 1945

Golfo Dulce, Costa Rica

\section{Fam. Chaetangiaceae}

Glotophloea confusa Setchell

Smith, 1944

Vancouver Is., B. C. to San Diego, Calif.

Scinaia articulata Setchell

Setchell, 1914A

Santa Barbara, Calif.

Scinaia complanata (Collins) Cotton

Taylor, 1945

Is. María Magdalena, Nayarit; Puerto Culebra, Costa Rica

Scinain Johnstoniae Setchell

Dawson, 1944; Taylor, 1945

Southern Calif. to Puerto Culebra, Costa Rica; Gulf of Calif.

Scinaia latifrons Howe

Dawson, 1944; Taylor, 1945

Southern Calif. to Is. María Magdalena, Nayarit; Gulf of Calif.

Scinaia minima Dawson

Dawson, $1945 \wedge$

Is. Cedros, Baja Calif.

Pseudoscinaia Snyderae Setchell

Setchell. 1914A ; Dawson, 1945B

San Pedro to San Diego, Calif.

Wijubeyella Cartitaginea Setchell \& Gardner

Kylin, 1925

Whidbey Is., Wash. 
Galaxaura fastigiata Decaisne

Dawson, 1944

Punta Peñasco, Sonora; Is. Tiburón, Gulf of Calif.

Galaxaura filamentosa Chou

Taylor, 1945

Is. Clarion, Revilla Gigedo Arch.; Puerto Culebra, Costa Rica

Galaxaura marginata (Solander) Kjellman

Dawson, 1944

San Jose del Cabo, Baja Calif.

Galaxaura oblongata (Ellis \& Solander) Lamouroux

Taylor, 1945

Is. María Madre, Nayarit

Galaxaura ramulosa Kjellman

Taylor, 1945

Is. Jacarita, Panamá

GalaXaura sQualida Kjellman

Taylor, 1945

Bahía Honda, Panamá

Galaxaura stupocaulon Kjellman

Taylor, 1945

Golfo Dulce, Costa Rica

Galaxaura subfruticulosa Chou

Taylor, 1945

Is. Clarion, Revilla Gigedo Arch.

Galaxaura ventricosa Kjellman

Taylor, 1945

Is. María Magdalena, Nayarit

Galaxaura VEPRECUla Kjellman

Taylor, 1945

Golfo Dulce, Costa Rica

\section{Fam. Bonnemaisoniaceae}

Bonnemaisonia CALIFornica Buffham

Smith, 1944

Vancouver Is., B. C. to Ventura, Calif.

Bonnemaisonia geniculata Gardner

Smith, 1944

Carmel Bay to Point Sur, Calif. 
Bonnemaisonia hamifera Hariot

Feldman, 1942; Asparagopsis hamifera in Kylin, 1925; 1941; Dawson, 1945E

Victoria, B. C. to Punta Descanso, Baja Calif.

Asparagopsis Sanfordiana Harvey

Setchell \& Gardner, 1930; Dawson, 1944; Taylor, 1945 ; see Asparagopsis taxiformis in Feldmann, 1942

Is. Angel de la Guarda, Gulf of Calif. to Is. Clarion, Revilla Gigedo Arch.

Asparagopsis Sanfordiana f. amplissima Setchell \& Gardner

Setchell \& Gardner, 1924 ; Taylor, 1945

La Paz, Baja Calif.; Revilla Gigedo Arch.

\section{Order GELIDIALES}

\section{Fam. Gelidiaceae}

GELIDIUM ARBOREscens Gardner

Smith, 1944

Monterey to Cambria, Calif.

Gelidiun caloglossoides Howe

Smith, 1944

Monterey to southern Calif.

Gelidium cartilagineum (Linnaeus) Greville

Kylin, 1925; Dawson, 1945E

San Juan Is., Wash. and southward

Gelidium Cartilagineum var. Robustum Gardner

Smith, 1944; Taylor, 1945

San Francisco, Calif. to Puerto San Bartholomé, Baja Calif.

Gelidium Coulteri Harvey

Smith, 1944; Sanborn \& Doty, 1946; Dawson, 1945E

Coos Bay, Oregon to Punta Descanso, Baja Calif.

Gelidium crinale (Turner) Lamouroux

Dawson, 1944 ; 1945B ; Collins, 1913

Victoria, B. C. to La Jolla, Calif.; Bahía Gonzaga, Baja Calif. to Turner's Is., Gulf of Calif.

Gelidium crinale var. Luxurians Collins

Gardner, 1927E

Southern Calif.

Gelidium decompositum Setchell \& Gardner

Dawson, 1944

Bahía San Francisquito, Baja Calif. 
Gelidium densum Gardner

Gardner, 1927E; Taylor, 1945

San Pedro, Calif.; Is. Cedros, Baja Calif.

Gelidium Johnstonit Setchell \& Gardner

Dawson, 1944

Is. Angel de la Guarda, Gulf of Calif. to Guaymas, Sonora

Gelidium microphysa Setchell \& Gardner

Setchell \& Gardner, 1930; Dawson, 1944

Is. Guadalupe, Baja Calif.; Turner's Is., Gulf of Calif.

Gelidium nudifrons Gardner

Gardner, 1927E

Southern Calif.

Gelidium polystichum Gardner

Gardner, 1927E

White's Point, San Pedro, Calif.

Gelidium pulchrum Gardner

Kylin, 1941 ; Sanborn \& Doty, 1946; Dawson, 1945E

Coos Bay, Oregon; Orange County, Calif. to Cabo Colnett, Baja Calif.

Gelidium purpurascens Gardner

Smith, 1944

Bolinas to San Diego, Calif.

Geididium pusillum (Stackhouse) Le Jolis

Smith, 1944 ; Dawson, 1944; Taylor, 1945

Monterey, Calif. to Panamá

Gelidium Ramuliferum Gardner

Gardner, 1927E

San Pedro, Calif.

Gelidium sclerophyllum Taylor

Taylor, 1945

Golfo Dulce, Costa Rica

Gelidium Setchelli Gardner

Gardner, 1927E

Marin Co., Calif.

Gelidium sinicola Gardner

Smith, 1944

San Francisco Bay; Monterey, Calif.

Pterocladia mexicana Taylor

Taylor, 1945

Cabo San Lazaro, Baja Calif. 
Pterocladia musciformis Taylor

Taylor, 1945

Golfo Dulce, Costa Rica

Pterocladia Okamurai (Setchell \& Gardner) Taylor Taylor, 1945

Is. Clarion, Revilla Gigedo Arch.

Pterocladia Pyramidale (Gardner) Dawson

Dawson, 1945D; 1945E

Southern Calif.; Punta Descanso, Baja Calif.

Gelidiocolax microsphaerica Gardner

Gardner, 1927A

Balboa, Calif.

Gelidiella acerosa (Forsskål) Feldmann \& Hamel

Dawson, 1944

Southern Gulf of Calif. to Central America

Gelidiella Hancockin Dawson

Dawson, 1944

Is. Angel de la Guarda, Gulf of Calif.; Kino, Sonora

Gelidiella mexicana Dawson

Dawson, 1944

Bahía Gonzaga, Baja Calif. to Guaymas, Sonora

Gelidiella ? Refugiensis Dawson

Dawson, 1944

Is. Angel de la Guarda, Gulf of Calif.

Wurdemannia miniata (Draparnaud) Feldmann \& Hamel

Dawson, 1944; Taylor, 1945

Is. Carmen, Gulf of Calif. to Panama City, Panamá

Gelidiopsis tenuis Setchell \& Gardner

Dawson, 1944

Guaymas, Sonora to San Jose del Cabo, Baja Calif.; Is.

Clarion, Revilla Gigedo Arch.

Gelidiopsis variabilis (Greville) Schmitz

Dawson, 1944

Guaymas, Sonora

\section{Order CRYPTONEMIALES}

\section{Fam. Dumontiaceae}

Cryptosiphonia Woodi J. Agardh

Smith, 1944

Unalaska, Alaska to Venice, Calif. 
Thuretellopsis Peggiana Kylin

Kylin, 1925

Friday Harbor, Wash.

Dumontia filiformis (Lyngbye) J. Agardh

Setchell \& Gardner, 1903

Alaska

Baylesia plumosa Setchell

Smith, 1944

Santa Cruz; Monterey, Calif.

SARCOPH YlLis ARCTICA Kjellman

Setchell \& Gardner, 1903

Alaska

Pikea Californica Harvey

Smith, 1944

Vancouver Is., B. C. to La Jolla, Calif.

Pikea pinnata Setchell

Smith, 1944; Dawson, 1945D

Bolinas to Coronado, Calif.

Farlowia COM PRessa J. Agardh

Smith, 1944

Tomales Bay to Carmel Bay, Calif.

Farlowia CRassa J. Agardh

Smith, 1944

Port Orford, Oregon to San Diego, Calif.

Farlowia mollis (Harvey \& Bailey) Farlow \& Setchell

Smith, 1944

Vancouver, B. C. to Carmel, Calif.

Dilsea Californica (J. Agardh) Schmitz

Kylin, 1941; Sanborn \& Doty, 1946

Coos Bay, Oregon to San Francisco, Calif.

Leptocladia Binghamiae J. Agardh

Setchell, 1912; Kylin, 1941; Dawson, 1945E

Santa Cruz, Calif. to Cabo Colnett, Baja Calif.

Leptocladia conferta Setchell

Smith, 1944

Crescent City to Carmel Bay, Calif.

Leptocladia Laxa Taylor

Taylor, 1945

Cabo San Lazaro, Baja Calif.

Weersia Fryeana Setchell

Kylin, 1925

San Juan Co., Wash. 
Weeksia Howellii Setchell \& Gardner

Setchell \& Gardner, 1937

Is. Natividad, Baja Calif.

WeEksia Reticulata Setchell

Smith, 1944; Dawson, 1945E

Monterey Peninsula, Calif.; Cabo Colnett, Baja Calif.

Weeksia Templetoni Setchell \& Gardner

Setchell \& Gardner, 1937

Is. Cedros, Baja Calif.

Constantinea rosa marina (Gmelin) Postels \& Ruprecht

Setchell \& Gardner, 1903; Setchell, 1906

Western Aleutian Is. to Sitka, Alaska

Constantinea simplex Setchell

Smith, 1944

Neah Bay, Wash. to Carmel, Calif.

Constantinea subulifera Setchell

Setchell, 1906; Kylin, 1925

Esquimalt, B. C. to San Juan Is., Wash.

\section{Fam. Gloiosiphoniaceae}

Gloiopeltis Furcata (Postels \& Ruprecht) J. Agardh

Setchell \& Gardner. 1903; Kylin, 1925

Aleutian Islands, Alaska to Puget Sound, Wash.

Gloiopeltis miniata Kylin

Kylin, 1941

Santa Catalina Is., Calif.

Glotosiphonia CALIFornica (Farlow) J. Agardh

Smith, 1944

Sitka, Alaska to Carmel Bay, Calif.

Gloiosiphonia Capillaris (Hudson) Carmichael

Collins, 1913

Vancouver Is., B. C.

Gloiosiphonia verticillaris Farlow

Smith, 1944

Sitka, Alaska to Carmel Bay, Calif.

\section{Fam.Endocladiaceae}

Endocladia muricata (Postels \& Ruprecht) J. Agardh Smith, 1944

Shumagin Is., Alaska to La Jolla, Calif. 


\section{Fam. Squamariaceae}

Peyssonnelia calcea Heydrich

Taylor, 1945

Is. Socorro, Revilla Gigedo Arch.

Peyssonnelia Clarionensis Taylor

Taylor, 1945

Is. Clarion, Revilla Gigedo Arch.

Peyssonnelta pacifica Kylin

Smith, 1944 ; Dawson, 1945A

San Juan Is., Wash. to Is. Cedros, Baja Calif.

Peyssonnelia rubra (Greville) J. Agardh

Setchell \& Gardner, 1930; Taylor, 1945

Is. Guadalupe, Baja Calif. ?; Is. Clarion; Is. Socorro, Revilla Gigedo Arch.

Rhododermis elegans Crouan

Smith, 1944

Marin Co. to Monterey, Calif.

Asymmetria expansa Setchell \& Gardner

Smith, 1944

Monterey, Calif.

Hildenbrandia occidentalis Setchell

Smith, 1944

Puget Sound, Wash. to Carmel Bay, Calif.

Hildenbrandia prototy pus Nardo

Smith, 1944; Taylor, 1945

Alaska to Panamá

Hildenbrandia Rosea Kützing

Kylin, 1925 ; Dawson, 1944

San Juan Co., Wash.; Turner's Is., Gulf of Calif.

Cruoriella Dubyi Crouan

Taylor, 1945

Is. Isabel, Nayarit; Is. Socorro; Is. Clarion, Revilla Gigedo Arch.

\section{Fam. Cruoriaceae}

Petrocelis franciscana Setchell \& Gardner

Smith, 1944

Puget Sound, Wash. to San Luis Obispo Co., Calif. 
Petrocelis haematis Hollenberg

Hollenberg, 1943

Southern Calif.

Petrocelis Middendorffin (Ruprecht) Kjellman

Kylin, 1925

Bering Sea to Whidbey Is., Wash.

\section{Fam. Corallinaceae}

Choreonema Thureti (Bornet) Schmitz

Setchiell \& Gardner, 1930

Is. Guadalupe, Baja Calif.

Melobesia marginata Setchell \& Foslie

Smith, 1944; Taylor, 1945

Whidbey Is., Wash. to Is. Cedros, Baja Calif.

Melobesia mediocris (Foslie) Setchell \& Mason

Smith, 1944; Taylor, 1945

Fort Bragg, Calif. to Cabo San Lazaro, Baja Calif.

Archeolithotham nium Howei Lemoine

Lemoine, 1929

Is. Coiba, Panamá

Lithotham nium aculeiferum Mason

Setchell \& Mason, 1943

Pacific Grove to La Jolla, Calif.

Lithothamnium australe f. americana Foslie

Dawson, 1944; Taylor, 1945

Is. Angel de la Guarda, Gulf of Calif. to Bahía Honda, Panamá

Lithotham niUm australe f. minutula Foslie Mesophyllum australe var. minutula in Lemoine, 1929

Is. Coiba, Panamá

Lithotham nium australe f. TUalensis Foslie

Dawson, 1944; Taylor, 1945; Mesophyllum australe var. tualensis in Lemoine, 1929

Is. Angel de la Guarda, Gulf of Calif. to Bahía Honda, Panamá

Lithotham NiUm CALIFornicum Foslie

Smith, 1944

San Juan Is., Wash. to San Diego, Calif.

Lithothamnium conchatum Setchell \& Foslie

Smith, 1944

San Juan Is., Wash. to Carmel, Calif. 
Lithothaminim crassiusculum (Foslie) Mason

Setchell \& Mason, 1943

San Pedro to La Jolla, Calif.

Lithothamnium giganteum Mason

Setchell \& Mason, 1943

La Jolla, Calif.

Lithothamnium indicum Foslie

Taylor, 1945

Is. Socorro; Is. Clarion, Revilla Gigedo Arch.; Is. Secas, Panamá

Lithotham nium Lamellatum Setchell \& Foslie

Smith, 1944

Monterey, Calif.

Lithotham nium montereyicum Foslie

Smith, 1944

Monterey, Calif.

Lithothamnium muricatum (Foslie) G. DeToni G. DeToni, 1924; Lithophyllum muricatum in Foslie,

Vancouver Is., B. C.

Lithothaminium pacificum Foslie

Smith, 1944

Whidbey Is., Wash. to Carmel, Calif.

Lithothamnium parcum Setchell \& Foslie

Smith, 1944

San Juan Is., Wash. to Carmel, Calif.

Iithothamaium phymatodeum Foslie

Foslie, 1929

Puget Sound, Wash. to Bolinas, Calif.

Lithothamnium Reclinatum Foslie

Foslie, 1929; Collins, 1913

Vancouver Is., B. C. to Tomales Bay, Calif.

Lithothamnium validum Foslie

Taylor, 1945

Bahía Petatlán, Guerrero; Puerto Culebra, Costa Rica

Clathromorphum compactum f. circumscriptum Strömfelt) Foslie

Foslie, 1929

Unalaska, Alaska

Hydrolithon Setchelli (Foslie) Setchell \& Mason

Setchell \& Mason, 1943

Redondo to La Jolla, Calif. 
Fosliella ascripticia (Foslie) G. M. Smith

Smith, 1944

Monterey to La Jolla, Calif.

Fosliella dispar (Foslie) G. M. Smith

Smith, 1944

Whidbey Is., Wash.; Bolinas; Monterey, Calif.

Fosliella intermedia (Foslie) G. M. Smith

Smith, 1944

Pacific Grove to La Jolla, Calif.

Fosliella minuta Taylor

Taylor, 1945

Bahía Honda, Panamá

Fosliella Nicholsii (Setchell \& Mason) G. M. Smith Smith, 1944

Monterey to San Diego, Calif.

Fosliella paschalis (Lemoine) Setchell \& Gardner

Setchell \& Gardner, 1930

Is. Guadalupe, Baja Calif.

Litholepis accola Foslie

Setchell \& Gardner, 1930

Is. Guadalupe, Baja Calif.; Is. Clarion, Revilla Gigedo Arch.

Litholepis fertilis (Lemoine) Setchell \& Mason

Setchell \& Mason, 1943

Is. Coiba, Panamá

Litholepis sonorensis Dawson

Dawson, 1944

Is. Espiritu Santo, Gulf of Calif.

Lithoporella pacifica (Heydrich) Foslie

Setchell \& Gardner, 1930

Is. Clarion, Revilla Gigedo Arch.

Heteroderma corallinicola Dawson

Dawson, 1944

Guaymas, Sonora

Heteroderma Gibbsil (Foslie \& Setchell) Foslie

Dawson, 1944

Is. Angel de la Guarda, Gulf of Calif. to San Jose del Cabo, Baja Calif.

Dermatolithon saxicolum (Lemoine) Setchell \& Mason

Setchell \& Mason, 1943

Is. Cocos, Costa Rica 
Dermatolithon veleroae Dawson

Dawson, 1944

Bahía Agua Verde, Baja Calif.

Porolithon cocosicum Lemoine

Lemoine, 1929

Is. Cocos, Costa Rica

Porolithon sonorensis Dawson

Dawson, 1944

Is. Angel de la Guarda, Gulf of Calif. to Guaymas, Sonora

Lithophyllum BRACchiatum (Heydrich) Lemoine

Taylor, 1945; Lemoine, 1929

Is. María Magdalena, Nayarit; Is. Socorro ; Is. Clarion, Revilla Gigedo Arch.; Is. Secas; Is. Coiba, Panamá

Lithophyllum (?) CoIbense Lemoine

Lemoine, 1929

Is. Coiba, Panamá

Lithophyllum decipiens Foslie

Dawson, 1944; Foslie, 1929

Bodega Bay to San Diego, Calif.; Is. Angel de la Guarda,

Gulf of Calif. to Guaymas, Sonora

Lithophyllum Digueti (Hariot) Heydrich

Dawson, 1944

Is. Angel de la Guarda; Is. Espíritu Santo, Gulf of Calif.

LithopHyLlum DivARICATUM Lemoine

Taylor, 1945

Is. Socorro, Revilla Gigedo Arch.; Bahía Petatlán, Guerrero; Is. Jicarita, Panamá

Lithophyllum (?) Fetum Foslie

Lemoine, 1929

Is. Cocos, Costa Rica

Lithophyllum grumosum Foslie

Smith, 1944

Pacific Grove to San Diego, Calif.

Lithophyllum Hancocim Dawson

Dawson, 1944

Is. Espíritu Santo, Gulf of Calif.

Lithophyllum imitans Foslie

Foslie, 1929

Southern Calif.

Lithophyllum Lithophylloides Heydrich

Dawson, 1944

Is. Angel de la Guarda to Is. Espíritu Santo, Gulf of Calif. 
Lithophyllum (?) LIVIDUM Lemoine

Lemoine, 1929

Is. Cocos, Costa Rica

Lithophyllum Margaritae (Hariot) Heydrich

Dawson, 1944; Lithophyllum elegans in Setchell \& Mason, 1943

La Paz, Baja Calif.

Lithophyllum neofarlowi Setchell \& Mason

Smith, 1944

Fort Bragg to Carmel Bay, Calif.

Lithophyllum pallescens (Foslie) Heydrich

Dawson, 1944

Is. Espiritu Santo, Gulf of Calif.

Lithophyllum proboscidium Foslie

Smith, 1944

Monterey; San Pedro, Calif.

Lithophyllum (?) PROPINQUUm var. cocosica Lemoine

Lemoine, 1929

Is. Cocos, Costa Rica

Lithophyllum trichotomum (Heydrich) Lemoine

Dawson, 1944; Taylor, 1945; Neogoniolithon trichotomum in Setchell \& Mason, 1943A

Is. Angel de la Guarda, Gulf of Calif. to Is. Clarion, Revilla Gigedo Arch.

Lithophyllum veleroae Dawson

Dawson, 1944

Is. Espíritu Santo, Gulf of Calif.

Lithophyllun Whidbeyense Foslie

Setchell \& Mason, 1943

Vancouver Is., B. C.; Puget Sound, Wash.

Corallina chilensis Decaisne

Smith, 1944 ; Taylor, 1945; Dawson, 1945E

Vancouver Is., B. C. to Cabo San Lazaro, Baja Calif.

Corallina Cubensis (Montagne) Kützing

Setchell \& Gardner, 1930

Is. Guadalupe, Baja Calif.

Corallina gracilis Lamouroux

Dawson, 1945B; Taylor, 1945

Southern Calif. to Is. Cedros, Baja Calif.

Corallina gracilis var. Densa Collins

Smith, 1944; Dawson, 1945B; 1945E

Marin Co., Calif. to Cabo Colnett, Baja Calif. 
CORAllina GRACILIS var. LYCOPODIOIDES Taylor

Taylor, 1945

Is. Cedros, Baja Calif.

Corallina pilulifera Postels \& Ruprecht

Dawson, 1944; Corallina officinalis f. pilulifera in Setchell \& Gardner, 1903

Alaska; Gulf of Calif. ?

Corallina subulata Solander

Setchell \& Gardner, 1930

Is. Guadalupe, Baja Calif. ?

Corallina vancouveriensis Yendo

Yendo, 1902; Taylor, 1945

Port Renfew, Vancouver Is., B. C.; Cabo San Lazaro, Baja Calif.

Pachyarthron cretaceum (Postels \& Ruprecht) Manza

Manza, 1940

Unalaska, Alaska

Lithothrix Aspergillum J. E. Gray

Smith 1944; Taylor, 1945; Dawson, 1945E

Vancouver Is., B. C. to Is. Cedros, Baja Calif.

Joculator pinnatifolius Manza

Manza, 1940

Orange and San Diego Counties, Calif.

Bossea angustata Taylor

Taylor, 1945

Is. San Benito, Baja Calif.

Bossea Californica (Decaisne) Manza

Smith, 1944

Monterey, Calif.

Bossea corymbifera Manza

Smith, 1944

Point Lobos, Carmel Bay, Calif.

Bossea dichotoma Manza

Smith, 1944

Moss Beach, San Mateo Co.; Monterey Peninsula, Calif.

Bossea frondifera Manza

Manza, 1940; Dawson, 1945E

Moss Beach, San Mateo Co., Calif.; Punta Descanso, Baja Calif.

Bossea Gardneri Manza

Smith, 1944; Taylor, 1945

Duxbury Reef, Marin Co., Calif. to Is. Cedros, Baja Calif. 
Bossea interrupta Manza

Smith, 1944

Pacific Grove, Calif.

Bossea Orbigniana (Decaisne) Manza

Smith, 1944; Dawson, 1945E

Cape Arago, Oregon; Monterey, Calif. to Cabo Colnett, Baja Calif.

Bossea pachyclada Taylor

Taylor, 1945

Is. Cedros, Baja Calif.

Bossea plumosa Manza

Smith, 1944

Moss Beach, San Mateo Co.; Monterey Peninsula, Calif.

JANIA ADHAERENS Lamouroux

Setchell \& Gardner, 1930

Is. Guadalupe, Baja Calif.

Jania CAPIllacea Harvey

Taylor, 1939; 1945

Is. Socorro, Revilla Gigedo Arch.; Clipperton Is.

Jania MeXiCANa Taylor

Taylor, 1945

Bahía Tangola-Tangola, Oaxaca; Bahía Petatlán. Guerrero

JANIA RUBENS Lamouroux

Setchell \& Gardner, 1930; Dawson, 1944

Is. Guadalupe, Baja Calif.; Pond Is., Gulif of Calif. to Guaymas, Sonora

Amphiroa annulata Lemoine

Taylor, 1945

Is. Socorro, Revilla Gigedo Arch.; Golfo Dulce, Costa Rica

Amphiroa compressa var. tenuis Taylor

Taylor, 1945

Is. María Magdalena, Nayarit

Amphiroa Crosslandi Lemoine

Taylor, 1945; Lemoine, 1929

Is. Socorro, Revilla Gigedo Arch.; Tangola-Tangola, Oaxaca; Is. Gorgona, Gulf of Panamá

Amphiroa dimorpina Lemoine

Taylor, 1945

[s. Isabel, Nayarit 
AmphiRoA Foliacea Lamouroux

Taylor, 1945

Is. María Magdalena, Nayarit

Amphiroa fragilissima (Linnaeus) Lamouroux

Setchell \& Gardner, 1930

Is. Guadalupe, Baja Calif.

Amphiroa Franciscana Taylor

Taylor, 1945

Is. María Magdalena, Nayarit

Amphiroa mexicana Taylor

Taylor, 1945

Morro de Petatlán, Guerrero

Amphiroa minutissima Taylor

Taylor, 1945

Golfo Dulce, Costa Rica

Amphiroa peninsularis Taylor

Taylor, 1945

San Diego, Calif.; Is. Cedros, Baja Calif.; Is. María Magdalena, Nayarit; Bahía Petatlán, Guerrero

Amphiroa polymorpha Lemoine

Taylor, 1945

Golfo Dulce, Costa Rica

Amphiroa pusilla Yendo

Dawson, 1944

Is. Angel de la Guarda, Gulf of Calif. to Guaymas, Sonora

AMPHIROA RIGIDA Lamouroux

Dawson, 1944

Bahía Tepoca to Guaymas, Sonora

Amphiroa zonata Yendo

Dawson, 1944

Is. Angel de la Guarda, Gulf of Calif. to Guaymas, Sonora

Calliarthron cheilosporioides Manza

Smith, 1944

Bolinas to San Pedro, Calif.

Calliarthron pinnulatum Manza

Manza, 1940

Puget Sound, Wash.; ?; Moss Beach, San Mateo Co., Calif.

Calliarthron Regenerans Manza

Manza, 1940

Moss Beach, San Mateo Co., Calif. 
Calliarthron Setchelliae Manza

Smith, 1944

Moss Beach, San Mateo Co.; Monterey, Calif.

Calliarthron Schmittil Manza

Manza, 1940

San Diego, Calif.

\section{Fam. Dermocorynidaceae}

Dermocorynus occidentalis Hollenberg Hollenberg, 1940

Los Angeles Co., Calif. to Punta Banda, Baja Calif.

\section{Fam. Grateloupiaceae}

Grateloupia abreviata Kylin

Kylin, 1941

La Jolla, Calif.

Grateloupia acroidalea Setchell \& Gardner

Dawson, 1944

Guaymas, Sonora

Grateloupia californica Kylin

Smith, 1944 ; Dawson, 1945E

Puget Sound, Wash. to Cabo Colnett, Baja Calif.

Grateloupia cerrosiana Taylor

Taylor, 1945

Is. Cedros, Baja Calif.

Grateloupia filicina (Wulfen) C. Agardh

Taylor, 1945; Dawson, 1945E

Punta Descanso; Cabo Colnett, Baja Calif.; Bahía Petatlán, Guerrero

Grateloupia (?) Hancockin Dawson

Dawson, 1944

Kino, Sonora

Grateloupia Howeir Setchell \& Gardner

Dawson, 1944

Is. San Esteban, Gulf of Calif.

Grateloupia Johnstonir Setchell \& Gardner

Dawson, 1944

Is. Angel de la Guarda, Gulf of Calif. 
Grateloupia maxima (Gardner) Kylin

Kylin, 1941

San Francisco; La Jolla, Calif.

Grateloupia pinnata (Postels \& Ruprecht) Setchell

Kylin, 1925

Sitka, Alaska to Tracyton, Wash.

Grateloupia prolongata J. Agardh

Dawson, 1944; 1945C; 1945E

La Jolla, Calif. to central Mexico

Grateloupia Setchellit Kylin

Smith, 1944

Monterey, Calif.

Grateloupia sQuarrulosa Setchell \& Gardner

Dawson, 1944

Smith Is., Gulf of Calif.

Cryptonemia borealis Kylin

Kylin, 1925

San Juan Co., Wash.

Cryptonemia decolorata Taylor

Taylor, 1945

Is. María Magdalena, Nayarit

Cryptonemia obovata J. Agardh

Kylin, 1941 ; Dawson, 1945B

San Francisco; La Jolla, Calif.

Cryptonemia ovalifolia Kylin

Smith, 1944 ; Sanborn \& Doty, 1946

Coos Bay, Oregon; Pacific Grove, Calif.

Aeodes Gardneri Kylin

Smith, 1944

Puget Sound, Wash. to San Pedro, Calif.

Estebania conjuncta Setchell \& Gardner

Dawson, 1944

Is. Angel de la Guarda, Gulf of Calif, to Guaymas, Sonora

Polyopes Bushiae Farlow

Kylin, 1941 ; Taylor, 1945

San Pedro, Calif. to Is. Cedros, Baja Calif.

Polyopes clarionensis Setchell \& Gardner

Setchell \& Gardner, 1937A

Is. Clarion, Revilla Gigedo Arch. 
Polyopes sinicola Setchell \& Gardner

Dawson, 1944

Northern Gulf of Calif.

Halymenia (?) abyssicola Dawson

Dawson, 1944

Is. Partida, Gulf of Calif.

Halymenia actinophysa Howe

Dawson, 1944; Taylor, 1945

Punta Peñasco, Sonora; Is. Tiburón, Gulf of Calif.; Is. Clarion; Is. Socorro, Revilla Gigedo Arch.

Halymenia Agardhit DeToni

Tavlor, 1945

Is.María Magdalena, Nayarit

Halymenia Californica Smith \& Hollenberg

Smith, 1944

Monterey Peninsula, Calif.

Halymenia (?) Refugiensis Dawson

Dawson, 1944

Is. Angel de la Guarda, Gulf of Calif.

Zanardinula abbreviata (Setchell \& Gardner) J. DeToni

J. DeToni, 19.36; Prionitis abbreviata in Dawson, 1944

Is. San Esteban, Gulf of Calif. to Guaymas, Sonora

Zanardinula Andersoniana (Eaton) Papenfuss

Papenfuss, 1943 ; Dawson, 1945B ; 1945E; Prionitis Andersoniana in Smith, 1944; Sanborn \& Doty, 1946

Coos Bay, Oregon to Cabo Colnett, Baja Calif.

Zanardinula australis ( $J$. Agardh) Papenfuss

Papenfuss, 1943; Prionitis australis in Smith. 1944

Monterey, Calif.

ZnNardinula filiformis (Kylin) Papenfuss

Papenfuss, 1943; Prionitis filiformis in Smith. 1944; Taylor, 1945

Cape Arago, Oregon to Is. Cedros, Baja Calif.

Zanardinula Filiformis var. Delicatula (Taylor) Dawson

Dawson, 1945D; Prionitis filiformis var. delicatula in Taylor, 1945

Is. Cedros, Baja Calif.

Zanardinula guaymasensis (Dawson) Dawson

Dawson, 1945D; Prionitis guaymasensis in Dawson, 1944

Is. Angel de la Guarda, Gulf of Calif. to Guaymas, Sonora 
ZaNARDinula KINOENSIS (Dawson) Dawson

Dawson, 1945D; Prionitis kinoensis in Dawson, 1944

Kino, Sonora

Zanardinula lanceolata (Hatvey) J. DeToni

J. DeToni, 1936; Prionitis lanceolata in Smith, 1944

Vancouver Is., B. C. to San Pedro, Calif.

Zanardinula linearis (Kylin) Papenfuss

Papenfuss, 1943; Dawson, 1945E; Prionitis lincaris in Smith, 1944

San Mateo Co., Calif. to Punta Descanso, Baja Calif.

Zanardinula Lyalli (Harvey) J. DeToni

J. DeToni, 1936; Prionitis Ly'allii in Smith, 1944; Taylor, 1945

Vancouver Is., B. C. to Carmel Bay. Calif.; Bahía Magdalena, Baja Calif. ?

Zanardinula Mexicana (Dawson) Dawson

Dawson, 1945D ; Prionitis mexicana in Dawson. 1944

Bahía Santa María; San Jose del Cabo; Baja Calif.

Zanardinula Sternbergit (C. Agardh) J. DeToni

J. DeToni, 1936; Prionitis Sternbergii in Dawson. 1944

Georges Is., Gulf of Calif. to central Mexico

LoBOCOLAX DEFORMANS Howe

Smith, 1944; Taylor, 1945 ; Dawson, $1945 \mathrm{E}$

Monterey, Calif.; Punta Descanso; Is. Cerlros, Baja Calif.

\section{Fam. Kallymeniaceae}

Kallymenia angustata Setchell \& Gardner

Dawson, 1944; 1945C; Setchell \& Gardner, 1937

Mission Beach, Calit.; Bahía Santa María, Baja Calif.; Bahía Tepoca, Sonora

Kallymenia gUaymasensis Dawson

Dawson, 1944

Guaymas, Sonora

Kallymenia oblongifructa Setchell

Kylin, 1925 ; Setchell, 1912

Sitka; Seldovia, Alaska to Puget Sound, Wash.

Kallymenia ornata (Postels \& Ruprecht) J. Agardh

Setchell \& Gardner, 1903; Collins, 1913

Yakutat Bay, Alaska to Vancouver Is., B. C. 
Kallymenia pertusa Setchell \& Gardner

Dawson, 1944

Is. San Pedro Martir, Gulf of Calif.

Kallymenia RENiformis (Turner) J. Agardh

Setchell \& Gardner, 1903; Collins, 1913

Esquimault, B. C.

Kallymenia Reniformis f. cuneata J. Agardh

Setchell \& Gardner, 1903

Unalaska; Morzhovoi Bay, Alaska

Kallymenia tenuifolia Taylor

Taylor, 1945

Is. Socorro, Revilla Gigedo Arch.

Kallymenia veleroae Dawson

Dawson, 1944

Guaymas, Sonora

Meredithia Californica J. Agardh

Kylin, 1941; J. Agardh, 1899

California (locality unknown)

Pugetia firma Kylin

Smith, 1944

Monterey Peninsula, Calif.

Pugetia fragilissima Kylin

Kylin, 1925; Sanborn \& Doty, 1946

Friday Harbor, Wash.; Coos Bay, Oregon

Callophyllis acrocarpa Setchell

Setchell, 1923A

Santa Cruz to Santa Barbara, Calif.

Callophyllis crassifolia Setchell \& Swezy

Smith, 1944

San Mateo Co. to Carmel, Calif.

Callophyllis crenulata Setchell

Smith, 1944

Whidbey Is., Wash.; Pacific Grove, Calif.

Callophyllis dissecta Setchell \& Swezy

Kylin, 1941

La Jolla, Calif.

Callophiyllis edentata Kylin

Kylin, 1925

Friday Harbor, Wash. 
Callophyllis filicina Setchell \& Swezy

Setchell, 1923A

Venice to La Jolla, Calif.

Callophyllis flabellulata Harvey

Kylin, 1925; Sanborn \& Doty, 1946

Esquimault, B. C. to Coos Bay, Oregon

Callophyllis Gardneri Setchell

Setchell, 1923A

Venice to Redondo, Calif.

Callophyllis heanophylla Setchell

Kylin, 1925; Sanborn \& Doty, 1946

Friday Harbor, Wash. to Coos Bay, Oregon

Callophyllis Johnstonit Setchell \& Gardner

Dawson, 1944

Is. Tortuga, Gulf of Calif.

Callophyllis marginifructa Setchell \& Swezy

Smith, 1944; Sanborn \& Doty, 1946

Coos Bay, Oregon to San Diego, Calif.

Callophyllis megalocarpa Setchell \& Swezy

Smith, 1944; Dawson, 1945E

Whidbey Is., Wash. to Santa Barbara, Calif.; Punta Descanso, Baja Calif.

Callophyllis obtusifolia J. Agardh

Smith, 1944

Santa Cruz to San Pedro, Calif.

Callophyllis odonthalioides Setchell

Setchell, 1923A

Santa Cruz to San Diego, Calif.

Callophyllis pinnata Setchell \& Swezy

Smith, 1944 ; Dawson, 1945E

Marin Co. to Carmel, Calif.; Punta Descanso; Cabo Colnett, Baja Calif.

Callophyllis plumosa Setchell \& Swezy

Setchell, 1923A

San Pedro to La Jolla, Calif.

Callophyllis stenophylla Setchell

Setchell, 1923A

Bolinas, Calif.

Callophyllis Thompsonit Setchell

Setchell, 1923A

San Juan Co., Wash. 
Callophyllis violacea J. Agardh

Kylin, 1941; Taylor, 1945; Dawson, 1945E

Santa Barbara, Calif. to Cabo San Lazaro, Baja Calif.

Callocolax fungiformis Kylin

Kylin, 1925

Friday Harbor, Wash.

Callocolax globulosis Dawson

Dawson, 1945D

San Diego, Calif.

Callocolax neglectus Schmitz

Smith, 1944

Monterey, Calif.

\section{Fam. Choreocolaceae}

Choreocolax Polysiphoniae Reinsch

Smith, 1944 ; Dawson, 1945E

Sitka, Alaska; Monterey, Calif.; Cabo Colnett. Baja Calif.

\section{Order GIGARTINALES}

\section{Fam. Nemastomaceae}

Predaea Masonit (Setchell \& Gardner) J. DeToni

J. DeToni, 1936; Clarionea Masonii in Setchell \& Gardner, 1930

Is. Clarion, Revilla Gigedo Arch.

Schizymenia epiphytica (Setchell \& Lawson) Smith \& Hollenberg

Smith, 1944; Papenfuss, 1944A

Monterey Peninsula, Calif.

Schizymenia Johnstonir Setchell \& Gardner

Dawson, 1944

Is. San Esteban, Gulf of Calif.

Schizymenia pacifica Kylin

Smith, 1944 ; Dawson, 1945E

Unga Is., Alaska to Punta Descanso, Baja Calif. 


\section{Fam. Solieriaceae}

Turnerella Mertensiana (Postels \& Ruprecht) Schmitz Setchell \& Gardner, 1903; Collins, 1913

Shumagin Is., Alaska to Victoria, B. C. ?

Eucheuma uncinatum Setchell \& Gardner

Dawson, 1944

Is. Angel de la Guarda, Gulf of Calif. to Mazatlán, Sinaloa

Agardhiella Coulteri (Harvey \& Bailey) Setchell

Smith, 1944 ; Dawson, 1945E

Vancouver Is., B. C. to Cabo Colnett, Baja Calif.

Agardhiella mexicana Dawson

Dawson, 1944 ; 1945E

Bahía Gonzaga, Baja Calif.; Is. Angel de la Guarda, Gulf of Calif.; Cabo Colnett, Baja Calif.

Agardhiella tenera (J. Agardh) Schmitz

Dawson, 1944 ; Taylor, 1945

San Jose del Cabo, Baja Calif.; Is. Clarion, Revilla Gigedo Arch.

Gardneriella tubifera Kylin

Smith, 1944 ; Dawson, 1945E

Monterey Peninsula, Calif.; Punta Descanso ; Cabo Colnett, Baja Calif.

Opuntiella californica (Farlow) Kylin

Smith, 1944

Unga Is., Alaska to San Diego, Calif.

Sarcodiotheca cuneata Setchell \& Gardner

Setchell \& Gardner, 1937A

Is. San Martin, Baja Calif.

Sarcodiotheca dichotoma (Howe) Dawson

Dawson, 1944

Guaymas, Sonora to La Paz, Baja Calif.

Sarcodiotheca ecuadoreana Taylor

Taylor, 1945

Is. María Magdalena, Nayarit; Puerto Culebra, Costa Rica

Sarcodiotheca elongata (Setchell \& Gardner) Setchell

Dawson, 1944

Is. Tiburón; Is. San Pedro Martir, Gulf of Calif.

Sarcodiotheca Furcata (Setchell \& Gardner) Kylin

Kylin, 1932

Friday Harbor, Wash. 
SarcodiotheCa linearis Setchell \& Gardner

Dawson, 1944

Cape district, Baja Calif.

Sarcodiotheca meridionalis Setchell \& Gardner

Setchell \& Gardner, 1937A

Is. San Martin, Baja Calif.

\section{Fam. Hypneaceae}

Hypnea adunca J. Agardh

Kylin, 1941

Santa Barbara; San Diego, Calif.

HYPNEA CALIFORNICA Kylin

Kylin, 1941 ; Taylor, 1945

La Jolla, Calif.; Bahía Petatlán, Guerrero

Hypnea Esperi Bory

Dawson, 1944 ; 1946

La Jolla, Calif.; Ensenada, Baja Calif.; Is. Tiburón, Gulf of Calif. to Bahía Agua Verde, Baja Calif.

Hypnea Evermanir Setchell \& Gardner

Setchell \& Gardner, 1930

Is. Guadalupe, Baja Calif.

Hypnea Joh nstoniI Setchell \& Gardner

Dawson, 1944; Taylor, 1945

Cabo San Lazaro; Bahía Santa María, Baja Calif.; Pond Is., Gulf of Calif. to Guaymas, Sonora

Hypnen nidifica J. Agardh

Dawson, 1944

Punta Peñasco, Sonora to Costa Rica

Hypnea nidulans Setchell

Dawson, 1944

Pond Is., Gulf of Calif. to Bahía Agua Verde, Baja Calif.

Hypnea pannosa J. Agardh

Dawson, 1944; Taylor, 1945

Is. Tiburón, Gulf of Calif. to Is. Secas, Panamá

Hypnea spinella (C. Agardh) Kützing

Taylor, 1945

Bahía Petatlán, Guerrero

Hypnea variabilis Okamura

Dawson, 1946

La Jolla, Calif.; Ensenada, Baja Calif. 


\title{
Fam. Rhodophyllidaceae
}

\author{
Euthora CRistata (Linnaeus) J. Agardh \\ Setchell \& Gardner, 1903 \\ Shumagin Is. to Cook Inlet, Alaska \\ Euthora Fruticulosa (Ruprecht) J. Agardh \\ Kylin, 1925 \\ Vancouver Is., B. C. to Friday Harbor, Wash. \\ Rhodophyllis dichotoma f. SETACEA Kjellman \\ Setchell \& Gardner, 1903 \\ Unalaska, Alaska
}

\section{Fam. Plocamiaceae}

Plocamium pacificum Kylin

Smith, 1944; Taylor, 1945 ; Dawson, 1945E

Vancouver Is., B. C. to Is. Clarion, Revilla Gigedo Arch.

Plocamium tenue Kylin

Kylin, 1925

Friday Harbor, Wash.

Plocamium violaceum Farlow

Smith, 1944

Vancouver Is., B. C. to San Diego, Calif.

Plocamiocolax pulvinata Setchell

Smith, 1944; Dawson, 1945C

San Juan Is., Wash. to La Jolla, Calif.

\section{Fam. Gracilariaceae}

Corallopsis Salicornia (C. Agardh) Greville

Kylin, 1932

Unalaska, Alaska (a very doubtful record)

Gracilaria Andersonit (Grunow) Kylin

Kylin, 1941; Dawson, 1945E

La Jolla, Calif. to Cabo Colnett, Baja Calif.

Gracilaria cerrosiana Taylor

Taylor, 1945

Is. Cedros, Baja Calif.

Gracilaria compressa (C. Agardh) Greville

Dawson, 1944

Vicinity of Guaymas, Sonora 
Gracilaria confervoides (Linnaeus) Greville

Dawson, 1944; 1945B; Taylor, 1945

San Diego, Calif.; Gulf of Calif.; Is. Clarion, Revilla Gigedo Arch.

Gracilaria Crispata Setchell \& Gardner

Dawson, 1944

Is. Tiburón, Gulf of Calif.; Is. Clarion, Revilla Gigedo Arch.; Bahía Banderas

Gracilaria guaymasensis Dawson

Dawson, 1944

Guaymas, Sonora

Gracilaria Hancockit Dawson

Dawson, 1944

Is. Angel de la Guarda; Is. Tiburón, Gulf of Calif.

Gracilaria Johnstonil Setchell \& Gardner

Dawson, 1944; Taylor, 1945

Punta Turloe, Baja Calif. to Is. Isabel, Nayarit; Gulf of Calif.

Gracilaria lacerata Setchell \& Gardner

Dawson, 1944

Santa Rosalia, Baja Calif.; Guaymas, Sonora

Gracilaria lichenoides (Linnaeus) Harvey

Dawson, 1944

Bahía Concepción, Baja Calif. (doubtful)

Gracilaria linearis Kylin

Smith, 1944; Dawson, 1945B ; 1945E

Monterey Peninsula; San Pedro, Calif.; Punta Descanso, Baja Calif.

Gracilaria pachydermatica Setchell \& Gardner

Dawson, 1944

Is. Tortuga, Gulf of Calif.

Gracilaria panamensis Taylor

Taylor, 1945

Puerto Culebra, Costa Rica; Is. Taboga, Panamá

Gracilaria pinnata Setchell \& Gardner

Dawson, 1944; Taylor, 1939; 1945

Bahía Magdalena, Baja Calif.; Is. Angel de la Guarda, Gulf of Calif. to Is. María Magdalena, Nayarit

Gracilaria robusta Setchell

Smith, 1944

Monterey Peninsula, Calif. 
Gracilaria Sjoestedti Kylin

Smith, 1944; Dawson, 1944; 1945E

Vancouver Is., B. C. to Cabo Colnett, Baja Calif.; Bahía Tepoca, Sonora

Gracilaria subsecundata Setchell \& Gardner

Dawson, 1944

Guaymas, Sonora

Gracilaria tenuifolia Taylor

Taylor, 1945

Is. Socorro; Is. Clarion, Revilla Gigedo Arch.

Gracilaria veleroae Dawson

Dawson, $1944 ; 1946$

Bahía San Felipe, Baja Calif. to Guaymas, Sonora; La Jolla ; Coronado, Calif.; Is. Socorro; Is. Clarion, Revilla Gigedo Arch.

Gracilaria Vivesit Howe

Dawson, 1944

Guaymas, Sonora to La Paz, Baja Calif.

Gracilariophila Gardneri Setchell

Setchell, 1923; Dawson, 1945C

Santa Monica to La Jolla, Calif.

Gracilariophila oryzoides Setchell \& Wilson

Smith, 1944 ; Dawson, 1945E

Coos Bay, Oregon to Cabo Colnett, Baja Calif.

Tylotus Cunninghamil (J. Agardh) Kylin

Kylin, 1941; Dawson, 1945C

Santa Barbara to La Jolla, Calif.

\section{Fam. Dicranemaceae}

Dicranema rosaliae Setchell \& Gardner

Dawson, 1944

Is. Angel de la Guarda to Is. Espiritu Santo, Gulf of Calif.

\section{Fam. Phyllophoraceae}

Phyllophora Californica (J. Agardh) Kylin

Kylin, 1932

San Francisco, Calif.

Phyllophora Clevelandi Farlow

Smith, 1944

Bolinas, Calif. to near Rosarita Beach, Baja Calif. 
Petroglossum pacificum Hollenberg

Hollenberg, 1943 ; 1945

Coos Bay, Oregon to La Jolla, Calif.

Petroglossum parvum Hollenberg

Hollenberg, 1945

Laguna Beach; La Jolla, Calif.

Ahnfeltia gigartinoides J. Agardh

Smith, 1944 ; Taylor, 1945

Vancouver Is. B. C. to San Agustin, Oaxaca

Ahnfeltia Plicata (Hudson) Fries

Smith, 1944

Bering Sea to Carmel, Calif.

Gymnogongrus Carnosus Setchell \& Gardner

Dawson, 1944

Is. San Pedro Martir, Gulf of Calif.

GyM NOGONGRUS DIVARICATUS Holmes

Dawson, 1944

Turner's Is., Gulf of Calif.

Gymnogongrus Hancockin Dawson

Dawson, 1944

Kino, Sonora

Gymagongrus Leptophyllus J. Agardh

Smith, 1944; Dawson, 1945E

San Francisco to San Diego, Calif.; Cabo Colnett, Baja Calif.

Gymnogongrus Linearis (Turner) J. Agardh

Smith, 1944

Coos Bay, Oregon to San Luis Obispo Co., Calif.

Gymnogongrus martinensis Setchell \& Gardner

Setchell \& Gardner, 1937A; Taylor, 1945

Is. San Martin, Bahía San Bartolomé, Baja Calif.; Is. Socorro, Revilla Gigedo Arch.

Gymagongrus noRvegicus (Turner) J. Agardh

Collins, 1913

Ucluelet, Vancouver, B. C.

Gym NOGONGRUS PLATyphyLlus Gardner

Smith, 1944

Bolinas, Calif. to Ensenada, Baja Calif.

Gymnogongrus sinicola Dawson

Dawson, 1944

Is. Angel de la Guarda, Gulf of Calif. to Guaymas, Sonora 
Stenogramme californica Harvey

Smith, 1944

San Juan Is., Wash. to San Diego, Calif.

Stenogramme interrupta (C. Agardh) Montagne

Taylor, 1945

Is. Clarion; Is. Socorro, Revilla Gigedo Arch.

\section{Fam. Gigartinaceae}

Chondrus CRISpus (Linnaeus) Lyngbye

Setchell \& Gardner, 1903

Bering Sea to Unalaska, Alaska

Gigartina Agardhit Setchell \& Gardner

Smith, 1944 ; Sanborn \& Doty, 1946

Coos Bay, Oregon to La Jolla, Calif.

Gigartina armata J. Agardh

Setchell \& Gardner, 1933; Taylor, 1945

San Diego, Calif. to Is. Cedros, Baja Calif.

Gigartina asperifolia J. Agardh

Setchell \& Gardner, 1933

Santa Barbara to La Jolla, Calif.

Gigartina Binghamiae J. Agardh

Setchell \& Gardner, 1933; Sanborn \& Doty, 1946

Coos Bay, Oregon; Southern Calif.; Puget Sound ?

Gigartina Boryi Setchell \& Gardner

Smith, 1944

Pacific Grove to San Diego, Calif.

Gigartina Californica J. Agardh

Smith, 1944; Sanborn \& Doty, 1946; Dawson. 1945E

Coos Bay, Oregon to Carmel, Calif.; Punta Descanso; Cabo Colnett, Baja Calif.

Gitartina canaliculata Harvey

Smith, 1944; Dawson, 1945E

Coos Bay, Oregon to Cabo Colnett, Baja Calif.

Gigartina Corymbifera (Kützing) J. Agardh

Smith, 1944

Fort Ross to San Diego, Calif.

Gigartina CRIstata (Setchell) Setchell \& Gardner

Smith, 1944 ; Dawson, 1945E

Westport, Wash. to Point Sur, Calif.; Punta Descanso, Baja Calif. 
Gigartina dichotoma Gardner

Setchell \& Gardner, 1933

Duxbury Reef, Marin Co. to Point Sur, Calif.

Gigartina Eatoniana J. Agardh

Setchell \& Gardner, 1933; Dawson, 1944

Santa Barbara to La Jolla, Calif.; Puerto Libertad, Sonora to Is. Tiburón, Gulf of Calif.

Gigartina echinata Gardner

Setchell \& Gardner, 1933

Santa Cruz (?) ; Santa Catalina Is. ; La Jolla, Calif.

Gigartina exasperata Harvey \& Bailey

Setchell \& Gardner, 1933

Vancouver Is., B. C. to northen Calif.

Gigartina Harveyana (Kützing) Setchell \& Gardner

Smith, 1944; Dawson, 1945E

Santa Cruz, Calif. to Punta Descanso, Baja Calif.

Gigartina Jardinit J. Agardh

Setchell \& Gardner, 1933

Monterey; Santa Barbara, Calif.

Gigartina Johnstonit Dawson

Dawson, 1944

Bahía Gonzaga, Baja Calif. to Turner's Is., Gulf of Calif.

Gigartina latissima (Harvey) Eaton

Setchell \& Gardner, 1933

Near Esquimault, B. C.

Gigartina leptorhynchos J. Agardh

Smith, 1944; Taylor, 1945; Dawson, 1945E

Santa Cruz, Calif. to Is. Cedros, Baja Calif.

Gigartina Macdougali Dawson

Dawson, 1944

Puerto Libertad, Sonora

Gigartina mamillosa (Goodenough \& Woodward) I. Agardh

Setchell \& Gardner, 1933

Westport, Wash.; Seal Rocks, Oregon

Gigartina multidichotoma Dawson

Dawson, 1946

La Jolla, Calif. ; Punta Descanso, Baja Calif.

Gigartina obovata J. Agardh

Setchell \& Gardner, 1933

San Francisco, Calif. 
Gigartina Papillata (C. Agardh) J. Agardh

Smith, 1944; Dawson, 1945E

Tomales Bay to Carmel, Calif.; Punta Descanso, Baja Calif.

Gigartina pectinata Dawson

Dawson, $1944 ; 1946$

Punta Peñasco, Sonora; Bahía Los Angeles; Is. Angel de la Guarda, Gulf of Calif.

Gigartina serrata Gardner

Setchell \& Gardner, 1933; Taylor, 1945

Balboa, Calif. to Is. Cedros, Baja Calif.

Gigartina Sitchensis Ruprecht

Setchell \& Gardner, 1933

Sitka, Alaska to Whidbey Is., Wash.

Gigartina spinosa (Kützing) Harvey

Smith, 1944; Dawson, 1945E

Monterey, Calif. to Punta Descanso, Baja Calif.

Gigartina stellata (Stackhouse) Batters

Setchell \& Gardner, 1933

West Coast of Vancouver Is., B. C.

Gigartina tepida Hollenberg

Hollenberg, 1945; Dawson, 1944 as G. Tecdii

Balboa Harbor, Calif.; Guaymas, Sonora

Gigartina Turneri Setchell \& Gardner

Setchell \& Gardner, 1933; Dawson. 1945B

Southern Calif.?

Gigartina UnAlaschCEnsis (Ruprecht) Ruprecht

Setchell \& Gardner, 1933

Bering Sea to Whidbey Is., Wash.

Rhodoglossum AfFine (Harvey) Kylin

Smith, 1944; Sanborn \& Doty, 1946; Dawson, 1945E

Coos Bay, Oregon to Punta Descanso, Baja Calif.

Rhodoglossum americanum Kylin

Smith, 1944; Dawson, 1945B ; 1946

Bolinas to Carmel; Coronado, Calif.; Cabo Colnett, Baja Calif.

Rhodoglossum CORIACEum Dawson

Dawson, 1946

Punta Banda; Punta Descanso, Baja Calif.

Rhodoglossum Hancockin Dawson

Dawson, 1944

Is. San Esteban, Gulf of Calif. 
Rhodoglossum latissimum J. Agardh

Kylin, 1925

Whidbey Is., Wash.

RHodoglossum PARvum Smith \& Hollenberg

Smith, 1944

Monterey, Calif.

Rhodoglossum roseum (Kylin) G. M. Smith

Smith, 1944; Dawson, 1946

Monterey Peninsula, Calif.; Punta Descanso, Baja Calif.

Iridophycus CAliforíncum ( J. Agardh) Dawson

Dawson, 1945D; Iridea californica in Kylin, 1941

Santa Barbara, Calif.

IRIDOPHYCUS CORDATUM (Turner) Setchell \& Gardner

Setchell, 1940; Setchell \& Gardner, 1937

Table and Calvert Is.; Vancouver Is., B. C.; Whidbey Is., Wash.

IRIDOPHyCUS CORIACEUM Setchell \& Gardner

Smith, 1944

Neah Bay, Wash. to Carmel, Calif.

Iridophycus flaccidum Setchell \& Gardner

Smith, 1944; Sanborn \& Doty, 1946

Coos Bay, Oregon to Point Sur, Calif.

Iridophycus Fulgens Setchell \& Gardner

Setchell \& Gardner, 1937

Trinidad, Humboldt Co. to central Calif.

IRIDOPHyCUS FURCATUM Setchell \& Gardner

Setchell \& Gardner, 1937

Sitka, Alaska

IRIDOPHyCUS HETEROCARPUm (Postels \& Ruprecht) Setchell \& Gardner

Smith, 1944

Vancouver Is., B. C. to Point Sur, Calif.

Iridophycus lineare Setchell \& Gardner

Smith, 1944

Sunset Bay, Oregon to Ventura, Calif.

IRIDOPhycus PARKsII Setchell \& Gardner

Setchell \& Gardner, 1937

Trinidad, Calif.

Iridophycus parvulum (Kjellman) Setchell \& Gardner

Setchell \& Gardner, 1937

Unalaska; Kodiak Is., Alaska 
Iridophycus Reediae Setchell \& Gardner Setchell \& Gardner, 1937

Bushnell's Beach, San Luis Obispo Co., Calif.

IrIDophycus Sanguineum Setchell \& Gardner

Smith, 1944

Cape Arago, Oregon to Pacific Grove, Calif.

IRIDOPHYCUS SINICOLA Setchell \& Gardner

Setchell \& Gardner, 1937

San Francisco Bay, Calif.

IRIDOPhyCUS SPLENDEns Setchell \& Gardner

Smith, 1944

Cape Kiawandi, Oregon to southern Calif.

IRIDOPHYCUS WhidBEYANUM Setchell \& Gardner

Setchell \& Gardner, 1937

Whidbey Is., Wash.

Erythrophyllum delesserioides J. Agardh

Smith, 1944

Departure Bay, Alaska to San Luis Obispo Co.. Calif.

Erythrophyllum Gmelini (Grunow) Yendo

Setchell \& Gardner, 1903

Agattu Is., Alaska

Besa papillaeformis Setchell

Smith, 1944

Lands End, San Francisco; Monterey, Calif.

\section{Order RHODYMENIALES}

\section{Fam. Rhodymeniaceae}

FaUChea CRISpa Taylor

Taylor, 1945

Is. María Magdalena, Nayarit

Fauchea Fryeana Setchell

Kylin, 1925

Vicinity of Friday Harbor, Wash.

Fauchea laciniata J. Agardh

Setchell, 1912; Kylin, 1941

Santa Barbara, Calif. 
FaUchea Media Kylin

Smith, 1944

Monterey Peninsula, Calif.

Fauchea mollis Howe

Dawson, 1944

La Paz, Baja Calif.

Fauchea pyguaea (Setchell \& Gardner) Kylin

Kylin, 1941

San Pedro, Calif.

Fauchea Sefreri Howe

Dawson, 1944

La Paz, Baja Calif.

Faucheocolax attenuata Setchell

Smith, 1944

Monterey Peninsula, Calif.

Sciadophycus stellatus Dawson

Dawson, 1945A

San Diego, Calif.; Is. Cedros, Baja Calif.

Leptofauchea pacifica Dawson

Dawson, 1945A

Is. Cedros, Baja Calif.

Fryella Gardneri (Setchell) Kylin

Kylin, 1931

Friday Harbor to Point Defiance, Wash.

Botryocladia Hancocki Dawson

Dawson, 1944

Bahía Agua Verde, Baja Calif.

Botryocladia pSEUdodichotoma (Farlow) Kylin

Smith, 1944; Taylor, 1945

Vancouver Is., B. C. to Is. María Magdalena, Nayarit; Is. Socorro, Revilla Gigedo Arch.

BotryoCladia PSEUDODICHOTOMA var. DATILENSIS Dawson

Dawson, 1944

Is. Tiburón, Gulf of Calif.

Botryocladia uvarioides Dawson

Dawson, 1944

San Jose del Cabo; Cabo San Lucas, Baja Calif.

Hatosaccion gi,andiforme (Gmelin) Ruprecht

Smith, 1944

Westernmost Aleutian Islands, Alaska to Baja Calif. 
Halosaccion ramentaceum (Linnaeus) J. Agardh

Setchell \& Gardner, 1903

Sannak Is. to Cook Inlet, Alaska

Halosaccion Tilesii Kjellman

Setchell \& Gardner, 1903

Kukak Bay to Wrangel, Alaska

Rhodymenia arborescens Dawson

Dawson, 1941

Laguna Beach, Calif.

Rhodymenia attenuata Dawson

Smith, 1944

Monterey to San Pedro, Calif.

Rhodymenia CALIFornica Kylin

Smith, 1944; Dawson, 1945; Sanborn \& Doty, 1946

Coos Bay, Oregon to San Diego, Calif.

Rhodymenia Dawsonit Taylor

Taylor, 1945

Cabo San Lazaro; Bahía Santa María, Baja Calif.

Rhodymenia divaricata Dawson

Davson, 1944

Guaymas. Sonora; Is. Angel de la Guarda, Gulf of Calif.

Rhodymenia Hancockin Dawson

Dawson, 1944

Is. Angel de la Guarda, Gulf of Calif.

Rhodymenia lobata Dawson

Smith, 1944 ; Dawson, 1944

Monterey, Calif.; near Is. Isabel, Nayarit

Rhodymenia lobulifera Dawson

Smith, 1944

Bolinas; Carmel; San Pedro, Calif.

Rhodymenia pacifica Kylin

Smith, 1944; Dawson, 1945D

Coos Bay, Oregon to San Diego, Calif.

Rhodymenia palmata (Linnaeus) Greville

Dawson, 1941

Aleutian Is., Alaska; British Columbia; Puget Sound, Wash.

Rhodymenia palmata f. mollis Setchell \& Gardner

Smith, 1944

Agattu Is., Alaska to Pacific Grove, Calif. 
Rhodymenia palmata f. Sarniensis (Mertens) J. Agardh Setchell \& Gardner, 1903

Kodiak Is. to Orca, Alaska

Rhody MENIA PALMETTIFormis Dawson

Dawson, $1941 ; 1945 ; 1945 \mathrm{E}$

La Jolla, Calif.; Cabo Colnett, Baja Calif.

Rhodymenia pertusa (Postels \& Ruprecht) J. Agardh

Kylin, 1925; Dawson, 1941; Sanborn \& Doty, 1946

Alaska to Coos Bay, Oregon

Rhodymenia RHizordes Dawson

Dawson, $1941 ; 1945$

San Pedro to San Diego, Calif.

Rhodymenia rosea Dawson

Dawson, 1944

Is. Angel de la Guarda, Gulf of Calif.

Rhodymenia stipitata Kylin

Dawson, 1941

British Columbia; Puget Sound, Wash.

Rhodymenia (?) tepocensis Dawson

Dawson, 1944

Bahía Tepoca, Sonora; Pond Is.; Gulf of Calif.

Rhodymeniocolax botryoidea Setchell

Dawson, 1945D

San Pedro to San Diego, Calif.

\section{Fam. Champiaceae}

Binghamiella californica Setchell \& Dawson

Setchell \& Dawson, 1941

Santa Barbara to Santa Monica, Calif.

Binghamiella Forkit Dawson

Dawson, 1945

La Jolla, Calif.

Lomentaria Baileyana (Harvey) Farlow

Taylor, 1945

Revilla Gigedo Arch.; Puerto Culebra, Costa Rica

Lomentaria Caseae Dawson

Dawson, 1946

Del Mar, Calif. 
Lomentaria catenata Harvey

Dawson, 1944

Pond Is. to Is. Tortuga, Gulf of Calif.

Lomentaria Drouetil Dawson

Dawson, 1944

Guaymas, Sonora

Lomentaria hakodatensis Yendo

Dawson, 1944

Is. Guadalupe, Baja Calif.; Is. Angel de la Guarda, Gulf of Calif.; Guaymas, Sonora

Champia caespitosa Dawson

Dawson, 1944

Is. Angel de la Guarda, Gulf of Calif.

Champia disticha Dawson

Dawson, 1944

Is. Angel de la Guarda; Is. San Esteban, Gulf of Calif.

Champia parvula (C. Agardh) Harvey

Dawson, 1944

Is. Tiburón, Gulf of Calif. to San Jose del Cabo, Baja Calif.; Is. Clarion, Revilla Gigedo Arch.

Gastroclonium clavatum (Roth) Ardissone

Dawson, 1944

Bahía San Bartholomé, Baja Calif.; Punta Peñasco to Guaymas, Sonora

Gastroclonium Coulteri (Harvey) Kylin

Smith, 1944; Dawson, 1945E

Nootka Sound, B. C. to Cabo Colnett, Baja Calif.

Coeloseira compressa Hollenberg

Smith, 1944

Pacific Grove, Calif. to Punta Banda, Baja Calif.

Coeloseira parva Hollenberg

Hollenberg, 1940

Redondo to La Jolla, Calif.

\section{Order CERAMIALES}

\section{Fam. Ceramiaceae}

Trailliella intricata (J. Agardh) Batters

Kylin, 1925

Friday Harbor, Wash. 
Antithamnion alternans Gardner

Gardner, 1927B

Cook Inlet, Alaska

Antithamnion asymmetricum Gardner

Gardner, 1927C

Sitka, Alaska

Antithamnion Baylesiae Gardner

Smith, 1944

Monterey Peninsula, Calif.

Antithamnion Defectum Kylin

Smith, 1944; Sanborn \& Doty, 1946

Friday Harbor, Wash. to Monterey, Calif.

Antithamnion Dendroideum Smith \& Hollenberg

Smith, 1944

Monterey, Calif.

Antithamaion Densiusculum Gardner

Smith, 1944

Vancouver, B. C. ; Puget Sound, Wash.; Pacific Grove, Calif.

Antithamnion floccosum (Müller) Kleen

Kylin, 1925

Friday Harbor, Wash.

Antithamnion Gardneri J. DeToni

J. DeToni, 1935; Antithamnion temissimum in Gardner $1927 \mathrm{~B}$

La Jolla, Calif.

Antithamaion glanduliferum Kylin

Smith, 1944

Puget Sound, Wash. to Carmel, Calif.

Antithamnion Kylinil Gardner

Smith, 1944

Victoria, B. C. ; Monterey, Calif.

Antithaminion nigricans Gardner

Gardner, 1927C

Vancouver Is., B. C.

Antithamaion occidentale Kylin

Smith, 1944; Dawson, 1945B

Puget Sound, Wash.; Carmel; La Jolla, Calif.

Antithamnion pacificum (Harvey) Kylin

Smith, 1944; Dawson, 1944

Yakutat Bay, Alaska to La Jolla, Calif.; Bahía Tepoca;

Guaymas, Sonora 
Antithaminion pulchellum Gardner

Gardner, 1927C

Santa Monica, Calif.

Antithamnion pygmaeum Gardner

Smith, 1944

Pacific Grove to San Diego, Calif.

Antithamnion secundatum Gardner

Gardner, 1927C

San Diego, Calif.

Antithaninion setaceum Gardner

Gardner, 1927B

San Diego, Calif.

Antithamnion simulans Gardner

Gardner, 1927B

Sitka, Alaska

Antithamnion sublittorale Setchell \& Gardner

Dawson, 1944

San Jose del Cabo, Baja Calif.

Antithamnion subulatum (Harvey) J. Agardh

Smith, 1944

Puget Sound, Wash.; Monterey, Calif.

Antithamnion uncinatum Gardner

Smith, 1944

Puget Sound, Wash. to Carmel, Calif.

Platythamnion meteromorphum J. Agardh

Smith, 1944

San Francisco to San Pedro, Calif.

Platythamnion pectinatum Kylin

Smith, 1944; Dawson, 1945E

Puget Sound, Wash. to San Pedro, Calif.; Cabo Colnett, Baja Calif.

Platytham nion pectinatum var. Laxum Taylor

Taylor, 1945

Is. Clarion, Revilla Gigedo Arch.

Platythamion reversum (Setchell \& Gardner) Kylin

Kylin, 1925

Whidbey Is., Wash.

Platythamion tepocensis Dawson

Dawson, 1944

Bahía Tepoca, Sonora 
Platythamnion villosum Kylin

Smith, 1944

Sitka, Alaska; Puget Sound, Wash. to Monterey, Calif.

Callithamnion acutum Kylin

Kylin, 1925

San Juan Is., Wash.

Callithamnion arborescens Gardner

Gardner, 1927 B

Sitka, Alaska

Callithamnion biseriatum Kylin

Smith, 1944

Friday Harbor, Wash.; Monterey, Calif.

Callithamnion bisporum Gardner

Gardner, 1927C

San Juan Is., Wash.

Callithamnion breviramosum Gardner

Gardner, 1927C

La Jolla, Calif.

Callithamion byssoides Arnott

Setchell \& Gardner, 1930

Is. Guadalupe, Baja Calif.

Callithamnion californicum Gardner

Smith, 1944

Monterey Peninsula, Calif.

Callithaminion endovaginum Setchell \& Gardner

Kylin, 1941; Dawson, 1944

La Jolla, Calif.; Guaymas, Sonora

Callithamion Laxum Setchell \& Gardner

Gardner, $1927 \mathrm{C}$

Straits of Juan de Fuca; San Juan Co., Wash.

Callithamnion pacificum Taylor

Taylor, 1945

Is. Socorro, Revilla Gigedo Arch.

Callithamnion Pikeanum Harvey

Smith, 1944

Vallenar Point, Alaska to Carmel, Calif.

Callithamnion Pikennum var. pacificum (Harvey)

Setchell \& Gardner

Gardner, 1927C

Shumagin Is., Alaska to Straits of Juan de Fuca 


\section{Callithamnion Ramosissimum Gardner}

Gardner, 1927C

La Jolla, Calif.

Callithamnion rupicolum Anderson

Smith, 1944

Fort Ross to La Jolla, Calif.

Callithamnion soccoriense Taylor

Taylor, 1945

Is. Socorro, Revilla Gigedo Arch.

Callithamion squarrulosum Harvey

Harvey, 1853; J. Agardh, 1876

Golden Gate (San Francisco) Calif.

Callithamaion veleroae Dawson

Dawson, 1944

Is. Angel de la Guarda, Gulf of Calif.; Bahía Tepoca, Sonora

Spyridia filamentosa (Wulfen) Harvey

Setchell \& Gardner, 1930; Kylin, 1941 ; Taylor, 1945

Southern Calif.; Is. Guadalupe, Baja Calif.; Is. Taboga, Panamá

Crounania attenuata (Bonnemaison) J. Agardh

Setchell \& Gardner, 1930

Is. Guadalupe, Baja Calif. ?

Gymothamnion elegans (Schousboe) J. Agardh

Setchell \& Gardner, 1930

Is. Clarion, Revilla Gigedo Arch.

Haloplegma mexicanum Taylor

Taylor, 1945

Is. María Magdalena, Nayarit

Pleonos porium abysicola Gardner

Gardner, 1927B

Friday Harbor, Wash.

Pleonosporium dasyoides ( $\mathrm{J}$. Agardh) DeToni

Smith, 1944; Dawson, 1946

Tomales Bay to San Pedro, Calif.; Punta Descanso, Baja Calif.

Pleonosporium polycarpum Gardner

Gardner, 1927B

La Jolla, Calif. 
Pleonosporium pygmaeum Gardner

Gardner, 1927B

La Jolla, Calif.

Pleonosporium squarrosum Kylin

Kylin, 1925

San Juan Is., Wash.

Pleonosporium squarrosum var. obovatum Gardner

Gardner, 1927C; Dawson, 1945D

Sidney, Vancouver Is., B. C.

Pleonosporium vancouverianum J. Agardh

Smith, 1944

Vancouver Is., B. C.; Puget Sound, Wash.; Monterey, Calif.

Spermothamnion saccorhiza (Setchell \& Gardner) Feldmann-Mazoyer

Feldmann-Mazoyer, 1942; Pleonosporium saccorhiza in Setchell \& Gardner, 1930

Is. Guadalupe, Baja Calif.

Spermothamnion Snyderae Farlow

Smith, 1944 ; Dawson, 1945E

Bolinas, Calif. to Punta Descanso, Baja Calif.

Griffithsia multiramosa (Setchell \& Gardner) Taylor

Dawson, 1944 ; 1945B

San Diego, Calif.; Is. Angel de la Guarda, Gulf of California to San Jose del Cabo, Baja Calif.

Grifitithsia multiramosa var. balboensis Hollenberg

Hollenberg, 1945

Balboa Harbor, Calif.

GrifFithisia MULTiRamosa var. Minor Taylor

Taylor, 1939

Punta Gorda, Baja Calif.

Griffithisia paCifica Kylin

Sinith 1944; Dawson, 1944; Taylor, 1945

Puget Sound, Wash. to San Diego, Calif.; Bahía Tepoca; Guaymas, Sonora; Is. Clarion, Revilla Gigeda Arch.?

Griffithisia Schoesboei Montagne

Collins, 1913

Vancouver Is., B. C. (?) (probably G. pacifica)

Grimithisia tenuis C. Agardh

Dawson, 1944

Punta Peñasco, Sonora to Is. Tiburón, Gulf of Calif. 
Ceramium affine Setchell \& Gardner

Dawson, 1944

Is. Guadalupe, Baja Calif.; Is. Angel de la Guarda, Gulf of Calif.

Ceramium californicum J. Agardh

Kylin, 1941

Puget Sound, Wash. to southern Calif.

Ceramium Camoum Dawson

Dawson, 1944

Turner's Is., Gulf of Calif.

Ceramium caudatum Setchell \& Gardner

Dawson, 1944

Is. Angel de la Guarda, Gulf of Calif. to La Paz, Baja Calif.

Ceramium clarionensis Setchell \& Gardner

Setchell \& Gardner, 1930

Is. Clarion, Revilla Gigedo Arch.

Ceramium codicola J. Agardh

Smith, 1944; Dawson, 1944; 1945E

Sitka, Alaska to San Jose del Cabo, Baja Calif.

Ceramium codiophila Setchell \& Gardner

Setchell \& Gardner, 1937; Dawson, 1945C

La Jolla, Calif.; Is. Guadalupe, Baja Calif.

Ceramium Eatonianum (Farlow) DeToni

Smith, 1944; Taylor, 1945; Dawson, 1945E

Coos Bay, Oregon to Is. Cedros, Baja Calif.

Ceramium equisetoides Dawson

Dawson, 1944

Bahía Tepoca, Sonora to Mazatlán, Sinaloa

Ceramium Evermannir Setchell \& Gardner

Setchell \& Gardner, 1931; Dawson, 1945E

Is. Guadalupe, Cabo Colnett, Baja Calif.

Ceramium fastigiatum Harvey

Taylor, $1939 ; 1945$

Cabo San Lucas, Baja Calif.; Bahía Petatlán, Guerrero

Ceramium fimbriatum Setchell \& Gardner

Dawson, 1944

Is. Angel de la Guarda, Gulf of Calif. to San Jose del Cabo, Baja Calif. 
Ceramium Gardneri Kylin

Smith, 1944

Coos Bay, Oregon to Carmel, Calif.

Ceramium gracillimum Griffiths \& Harvey

Dawson, 1944

Is. Guadalupe, Baja Calif.; Turner's Is., Gulf of Calif.; San Jose del Cabo, Baja Calif.

Ceramium horridum Setchell \& Gardner

Dawson, 1944

Is. Angel de la Guarda, Gulf of Calif. to Guaymas, Sonora

Ceramium ornatum Setchell \& Gardner

Setchell \& Gardner, 1930

Is. Guadalupe, Baja Calif.

Ceramium pacificum (Collins) Kylin

Smith, 1944; Dawson, 1945E

Vancouver Is., B. C. to Santa Barbara, Calif.; Punta Descanso, Baja Calif.

Ceramium paniculatum Okamura

Dawson, 1944

Guaymas, Sonora

Ceramium personatum Setchell \& Gardner

Setchell \& Gardner, 1930; Taylor, 1945

Is. Guadalupe, Baja Calif.; Port Parker, Costa Rica

Ceramium procumbens Setchell \& Gardner

Dawson, 1944

Bahía San Francisquito, Baja Calif.; Is. Partida, Gulf of Calif.

Ceramium rubrum (Hudson) C. Agardh

Setchell \& Gardner, 1903; Collins, 1913

Bering Sea to Puget Sound, Wash.

Ceramium serpens Setchell \& Gardner

Dawson, 1944

Is. Angel de la Guarda, Gulf of Calif. to La Paz, Baja Calif.

Ceramium sinicola Setchell \& Gardner

Dawson, 1944

Is. Angel de la Guarda, Gulf of Calif. to Guaymas, Sonora

Ceramium sinicola var. interruftum (Setchell \& Gardner) Dawson

Dawson, 1944

Near La Paz, Baja Calif. 
Ceramium sinicola var. Johnstonit (Setchell \& Gardner) Dawson

Dawson, 1944

Is. San Esteban; Is. San Pedro Martir, Gulf of Calif.

Ceramium strictum Hatvey

Collins, 1913

Vancouver Is., B. C.

Ceramium washingtoniense Kylin

Kylin, 1925

San Juan Is., Wash.

Ceramium zacae Setchell \& Gardner

Setchell \& Gardner, 1937A; Dawson, 1945E

Cabo Colnett; Bahía San Bartolomé, Baja Calif.

Ceramium zebrinum J. Agardh

J. Agardh, 1894

Santa Cruz, Calif.

Centroceras bellum Setchell \& Gardner

Dawson, 1944

Guaymas, Sonora

Centroceras clavulatum (C. Agardh) Montagne

Smith, 1944; Dawson, 1944; 1945E; Taylor, 1945

Santa Cruz, Calif. to Panamá

Microcl $A$ DIA BOREALIs Ruprecht

Smith, 1944

Unalaska, Alaska to San Simeon, Calif.

Microcladia Californica Farlow

Smith, 1944

San Francisco to San Diego, Calif.

Microcladia Coulteri Harvey

Smith, 1944; Dawson, 1945E

Vancouver Is., B. C. to Punta Descanso, Baja Calif.

Ptilota aspleñiomes (Turner) C. Agardh

Setchell \& Gardner, 1903

Alaska to Puget Sound, Wash.

Ptilota Californica Ruprecht

Smith, 1944

Cape Arago, Oregon to San Diego, Calif.

Ptilota densa C. Agardh

Smith, 1944; Dawson, 1945B

Tomales Bay to San Diego, Calif. 
Ptilota filicina (Farlow) J. Agardh

Smith, 1944

Bering Sea to Carmel, Calif.

Ptilota hypnoides Harvey

Smith, 1944

Sitka, Alaska to San Luis Obispo Co., Calif.

Ptilota Pectinata (Gunner) Kjellman

Setchell \& Gardner, 1903; Kylin, 1925

Bering Sea to Puget Sound, Wash.

Ptilota tenuis Kylin

Kylin, 1925

Friday Harbor, Wash.

\section{Fam. Delesseriaceae}

Branchioglossum Woodir (J. Agardh) Kylin

Smith, 1944; Dawson, 1944

Vancouver Is., B. C.; Monterey to Santa Barbara, Calif.; Puerto Libertad to Guaymas, Sonora

Hypoglossum Abyssicolum Taylor

Taylor, 1945

Is. Las Tres Marías, Nayarit; Puerto Culcbra, Costa Rica

Hypoglossum attenuatum Gardner

Dawson, 1944

Puerto Libertad to Guaymas, Sonora

Hypoglossum Retusum Dawson

Dawson, 1945A

Is. Cedros, Baja Calif.

Membranoptera denticulata (Montagne) Kylin

Kylin, 1924; Pteridium spimulosum in Setchell \& Gardner, 1903

Bering Sea to Morzhovoi Bay, Alaska

Membranoptera dimorpha Gardner

Gardner, 1926; Sanborn, \& Doty, 1946

Queen Charlotte Is., B. C. to Coos Bay, Oregon

Membranoptera multiramosa Gardner

Smith, 1944

San Mateo Co. to Monterey, Calif. 
Membranoptera platyphyla (Setchell \& Gardner) Kylin Kylin, 1925

Puget Sound to Pleasant Beach, Wash.

Membranoptera Setcheliti Gardner

Gardner, 1926

Morzhovoi Bay, Alaska

Membranoptera tenuts Kylin

Kylin, 1925

Friday Harbor, Wash.

Membranoptera Weeksiae Setchell \& Gardner

Jao, 1937; Smith, 1944; Dawson, 1946

Seattle, Wash.; San Francisco to San Diego, Calif.

Holmesia californica (Dawson) Dawson

Dawson, 1945D

San Diego, Calif.

Delesseria decipiens J. Agardh

Smith, 1944

Prince William Sound, Alaska to Carmel, Calif.

Platysiphonia Clevelandi (Farlow) Papenfuss

Papenfuss, 1944

Pacific Grove to San Diego, Calif.

Taenioma perpusillum J. Agardh

Dawson, 1944 ; Papenfuss, 1944

Bahía Gonzaga to Bahía Agua Verde, Baja Calif.

Erythroglossum californicum J. Agardh

Smith, 1944

Monterey to Santa Barbara, Calif.

Erythroglossum intermedium (J. Agardh) Kylin

Kylin, 1944

Esquimault, B. C.

Sorella Delicatula (Gardner) Hollenberg

Hollenberg, 1943

San Pedro, Calif.

Sorella delicatula var. Californica Hollenberg

Hollenberg, 1943

Southern Calif.

Sorella divaricata (Setchell \& Gardner) Hollenberg

Hollenberg, 1943; Erythroglossum divaricata in Smith. 1944

Pacific Grove, Calif. 
Sorella pinnata Hollenberg

Hollenberg, 1943; Dawson, 1944

Southern Calif.; Is. Angel de la Guarda, Gulf of Calif.

Grinnellia lanceolata Dawson

Dawson, 1944

Punta Gorda, Cape district, Baja Calif.

Polyneura latissima (Harvey) Kylin

Smith, 1944; Dawson, 1945A

Vancouver, B. C. to Is. Cedros, Baja Calif.

Polyneurella Hancockin Dawson

Dawson, 1944

Is. Angel de la Guarda, Gulf of Calif.

Nienburgia Andersoniana (J. Agardh) Kylin

Smith, 1944; Taylor, 1945; Dawson, 1945E

Santa Cruz, Calif. to Is. Cedros, Baja Calif.

Nienburgta borealis (Kylin) Kylin

Kylin, 1935; Heteronema boreale in Kylin, 1925

Friday Harbor, Wash.

Phycodrys ambigua Gardner

Gardner, 1927A

Sitka, Alaska

Phycodrys bullata Gardner

Gardner, 1927A

$\Lambda$ gattu Is. to Sitka, Alaska

Phycodrys RiggiI Gardner

Gardner, 1927A

Kukak Bay to Prince William Sound, Alaska

Phycodrys Setchellit Skottsberg

Smith, 1944; Dawson, 1945A ; 1945E

Bolinas, Calif. to Is. Cedros, Baja Calif.

Polycoryne Gardneri Setchell

Smith, 1944

Marin Co.; Monterey Peninsula, Calif.

Polycoryne phycodricola Dawson

Dawson, 1945A

Is. Cedros, Baja Calif.

Anisocladella pacifica Kylin

Smith, 1944; Dawson, 1945E

Santa Cruz, Calif. to Cabo Colnett, Baja Calif.

Mrrtogramme DIVARICATa Dawson

Dawson, 1944

Is. Angel de la Guarda, Gulf of Calif. 
Myriogramme Hollenbergit Kylin

Smith, 1944

Monterey, Calif.

Myriogramme pulchra Gardner

Gardner, 1926

Puget Sound to Tacoma, Wash.

Myriogramme repens Hollenberg

Hollenberg, 1945

Point Vicente, Calif.

Myriogramme spectabilis (Eaton) Kylin

Smith, 1944

Santa Cruz to Redondo, Calif.

Acrosorium uncinatum (J. Agardh) Kylin

Kylin, 1941; Taylor, 1945; Dawson, 1945A ; 1945E

Southern Calif. to Bahía Santa María, Baja Calif.

Pantoneura Baeris (Ruprecht) Kylin

Kylin, 1924

Sitka, Alaska

Pantoneura Juergensir ( J. Agardh) Kylin

Kylin, 1924

Bering Sea to Unalaska, Alaska

Nitor' fiyldum mirabile Kylin

Kylin, 1925

Friday Harbor, Wash.

Hymenena flabelligera (J. Agardh) Kylin

Smith, 1944

Puget Sound, Wash. to Carmel, Calif.

Hymenena Kylinir Gardner

Smith, 1944

San Francisco to Monterey, Calif.

Hymentana multiroba (J. Agardh) Kylin

Smith, 1944

Cape Mendocino to Carmel, Calif.

Hymenena Setchellit Gardner

Smith, 1944

Puget Sound, Wash. to Carmel, Calif.

Hymenena Smithir Kylin

Smith, 1944

Carmel, Calif.

Cryptopleura brevis Gardner

Gardner, 1927

Moss Beach, San Mateo Co., Calif. 
Cryptopleura corallinara (Nott) Gardner Gardner, 1927

San Diego Co., Calif.

Cryptopleura crispa Kylin

Kylin, 1941; Dawson, 1945E

La Jolla, Calif.; Punta Descanso, Baja Calif.

Cryptopleura dichotoma Gardner

Gardner, 1927

San Pedro, Calif.

Cryptopleura lobulifera ( $\mathrm{J}$. Agardh) Kylin

Smith, 1944; Taylor, 1945

Tomales Bay to Morro Bay, Calif.; Bahía Santa María, Baja Calif.

Cryptopleura Ruprechtiana (J. Agardh) Kylin

Kylin, 1925

Sitka, Alaska to northern Calif.

Cryptopleura spatulata Gardner

Gardner, 1927

Santa Barbara; San Pedro, Calif.

Cryptopleura violacea ( $J$. Agardh) Kylin

Smith, 1944; Dawson, 1945B ; 1945E

Vancouver Is., B. C. to Cabo Colnett, Baja Calif.

Botryogiossum Farlowianum (J. Agardh) G. DeToni

Snith, 1944; Dawson, 1945B

Puget Sound, Wash. to San Diego, Calif.

Gonimophyllum Skottsbergit Setchell

Smith, 1944; Dawson, 1945C

Friday Harbor, Wash. to San Diego, Calif.

\section{Fam. Dasyaceae}

DASYA CALIFORNICA Gardner

Gardner, 1927A ; Dawson, 1945B

Southern Calif.

Dasya Eastwoodae Setchell \& Gardner

Setchell \& Gardner, 1930

Is. Guadalupe, Baja Calif.

Dasya pedicellata C. Agardh

Dawson, 1944

Is. Angel de la Guarda, Gulf of Calif. to Guaymas, Sonora 
Dasya Stanfordiana Farlow

Setchell \& Gardner, 1930; Taylor, 1945

Is. Guadalupe, Baja Calif.; Is. Las Tres Marías, Nayarit

Dasyopsis Densa G. M. Smith

Smith, 1944

Santa Cruz to Carmel, Calif.

Dasyopsis plumosa (Harvey \& Bailey) Schmitz

Kylin, 1925 ; Collins, 1913

Vancouver Is., B. C. to northern Calif.

Pogonophora CAlifornica J. Agardh

Kylin, 1941 ; Dawson, 1945B ; 1945E

Santa Barbara, Calif. to Punta Descanso, Baja Calif.

Heterosiphonia Asymmetria Hollenberg

Hollenberg, 1945

Corona del Mar, Calif.

Heterosiphonia densiuscula Kylin

Kylin, 1925

Friday Harbor, Wash.

Heterosiphonia erecta Gardner

Gardner, 1927D; Setchell \& Gardner, 1937A; Taylor, 1945

Santa Monica, Calif. to Bahía Santa María, Baja Calif.

Heterosiphonia laxa Kylin

Kylin, 1925

Friday Harbor, Wash.

Heterosiphonia sinicola Setchell \& Gardner

Dawson, 1944

Near La Paz, Baja Calif.

\section{Fam. Rhodomelaceae}

OrCasia senticulosa (Harvey) Kylin

Kylin, 1941

Orcas Is., Wash.; Monterey, Calif.

Polysir'honia acuminata Gardner

Hollenberg, 1942A ; Smith, 1944

Monterey to La Jolla, Calif.

Polysiphonia bifurcata Hollenberg

Taylor, 1945

Playa Blancas, Costa Rica 
Polysiphonia Brodiaei (Dillwyn) Greville

Hollenberg, 1944; Smith, 1944

Sausalito to Santa Monica, Calif.

Polysiphonia Collinsit Hollenberg

Hollenberg, 1944; Dawson, 1945E

San Juan Co., Wash. to Cabo Colnett, Baja Calif.

Polysiphonia Collinsir var. compacta Hollenberg

Hollenberg, 1944

Pacific Grove to southern Calif.

Polysiphonia Collinsin var. Deliquescens Hollenberg

Hollenberg, 1944

Prince William Sound, Alaska to Friday Harbor, Wash.

Polysiphonia Collinsi var. luxurians Hollenberg

Hollenberg, 1944

Cape Flattery; Friday Harbor, Wash.

Polysiphonia concinna Hollenberg

Hollenberg, 1944

Santa Catalina Is.; La Jolla, Calif.

Polysiphonia decussata Hollenberg

Hollenberg, 1942A

Los Angeles Co. to San Diego Co., Calif.

Polysiphonia dichotoma Hollenberg

Hollenberg, 1944

Santa Cruz; San Diego, Calif.

Polysiphonia Eastwoodae Setchell \& Gardner

Setchell \& Gardner, 1930

Is. Guadalupe, Baja Calif.

Polysiphonia flaccidissima Hollenberg

Hollenberg, 1942A

Southern Calif.

Polysiphonia flaccidissima var. Smithir Hollenberg

Hollenberg, 1942A ; Smith, 1944

San Francisco to San Diego, Calif.

Porysiphonia guadalupensis Setchell \& Gardner

Hollenberg, 1944

Is. Guadalupe, Baja Calif.

Polysiphonia Hancockin Dawson

Dawson, 1944

San Jose del Cabo, Baja Calif. 
Polysiphonia Hendryi Gardner

Smith, 1944; Hollenberg, 1944; Taylor, 1945

Cape Arago, Oregon to Is. Cedros, Baja Calif.

Polysiphonia homoia Setchell \& Gardner

Hollenberg, 1944 ; Taylor, 1945

Is. Guadalupe, Baja Calif.; Is. Socorro, Revilla Gigedo Arch.

Polysiphonia Howei Hollenberg

Taylor, 1945

Bahía de Panamá, Panamá

Polysiphonia inconspicua Hollenberg

Hollenberg, 1944

Southern Calif.

Polysiphonia Johnstonir Setchell \& Gardner

Hollenberg, 1944

Is. Angel de la Guarda; Is. San Esteban, Gulf of Calif.

Polysiphonia Macouni Hollenberg

Hollenberg, 1942A

Vancouver, B. C.

Polysiphonia Marchantae Setchell \& Gardner

Hollenberg, 1944

La Paz, Baja Calif.

Polysiphonia Masonit Setchell \& Gardner

Hollenberg, 1942A

Is. Guadalupe, Baja Calif.

Polysiphonia minutissima Hollenberg

Hollenberg, 1942A ; Dawson, 1945B

Santa Catalina Is., Calif. to Punta Banda, Baja Calif.

Polysiphonia pacifica Hollenberg

Hollenberg, 1942A ; Smith, 1944

Sitka, Alaska to Baja Calif.

Polysiphonia pacifica var. Delicatula Hollenberg

Hollenberg, 1942A

Central Calif. to Gulf of Calif.

Polysiphonia Pacifica var. Determinata Hollenberg

Hollenberg, 1942A

Alaska to central Calif.

Polysiphonia pacifica var. Disticha Hollenberg

Hollenberg, 1942A

Vancouver Is., B. C. to central Calif. 
Polysiphonia PaCifica var. GRACILIS Hollenberg

Hollenberg, 1942A

British Columbia to central Calif.

Polysiphonia paniculata Montagne

Hollenberg, 1944; Polysiphonia californica in Smith, 1944 ; Dawson, 1944

Port Holmes, B. C. to Baja Calif.; Punta Peñasco, Sonora

Polysiphonia pungens Hollenberg

Hollenberg, 1942A

Alaska to Vancouver, B. C.

Polysiphonia simplex Hollenberg

Hollenberg, 1942A ; Dawson, 1944

Southern Calif.; Bahía Gonzaga to Bahía Agua Verde, Baja Calif.

Polysiphonia Snyderae Kylin

Hollenberg, 1942A; Dawson, 1944

Washington to central Mexico

Polysiphonia Snyderae var. heteromorpha Hollenberg

Hollenberg, 1942A

Vancouver, B. C. ; coast of Washington

Polysiphonia Snyderae var. intricata Hollenberg

Hollenberg, 1942A

Guaymas, Sonora

Polysiphonia sonorensis Hollenberg

Hollenberg, 1942A; Dawson, 1944

Guaymas; Empalme, Sonora

Bryocladia dictyurus (J. Agardh) Taylor

Taylor, 1945

Bahía Petatlán, Guerrero

Rhodosiphonia CALIFoRnica Hollenberg

Hollenberg, 1943

Santa Barbara to San Diego, Calif.

Lophosiphonia mexicana Dawson

Dawson, 1944

Is. Angel de la Guarda, Gulf of Calif.; Is. Clarion, Revilla Gigedo Arch.

Lophosiphonia obscura (C. Agardh) Falkenberg

Kylin, 1925

Friday Harbor, Wash.?

Lophosiphonia villum (J. Agardh) Setchell \& Gardner

Smith, 1944; Dawson, 1944; Taylor, 1945

Pacific Grove, Calif. to Golfo Dulce, Costa Rica 
Brogniartella mucronata (Harvey) Schmitz

Taylor, 1945

Is. María Magdalena, Nayarit

Veleroa subulata Dawson

Dawson, 1944

Bahía Tepoca, Sonora

Falkenbergia Hillebrandtii (Bornet) Falkenberg

Setchell \& Gardner, 1930

Is. Guadalupe, Baja Calif.

Pterosiphonia arctica Setchell \& Gardner

Kylin, 1925

Alaska to Puget Sound, Wash.

Pterosiphonia Baileyi (Harvey) Falkenberg

Smith, 1944; Taylor, 1945; Dawson, 1945E

Crescent City, Calif. to Is. Cedros, Baja Calif.

Pterosiphonia bipinnata (Postels \& Ruprecht) Falkenberg

Smith, 1944

Shumagin Is., Alaska to San Pedro, Calif.

Pterosiphonia californica Kylin

Kylin, 1941

La Jolla, Calif.

Pterosiphonia dendroidea (Montagne) Falkenberg

Smith, 1944; Dawson, 1944; 1945E; Taylor, 1945

Vancouver Is., B. C. to San Jose del Cabo, Baja Calif.

Pterosiphonia gracilis Kylin

Kylin, 1925; Sanborn \& Doty, 1946

Friday Harbor, Wash. to Coos Bay, Oregon

Pterosiphonia pennata (Roth) Falkenberg

Dawson, 1944

Bahía Tepoca, Sonora

Pterosiphonia robusta Gardner

Gardner, 1927D

Northern to central Calif.

Pterosiphonia robusta var. divaricata Gardner

Gardner, 1927D

Sitka, Alaska

Pterosiphonia robusta var. Inermis Gardner

Gardner, 1927D

Neah Bay, Wash. to San Francisco Bay, Calif.

Stromatocarpus Gardneri Setchell

Setchell, 1923; Dawson, 1945C

Santa Monica to La Jolla, Calif. 
Pterochondria pygmaea (Setchell) Hollenberg Hollenberg, 1942

Southern Calif.

Pterochondria Woodi (Harvey) Hollenberg

Smith, 1944; Dawson, 1945E

Vancouver, B. C. to San Pedro, Calif.; Cabo Colnett, Baja Calif.

HERPOSIPHONIA GRANDIS Kylin

Kylin, 1925; Sanborn \& Doty, 1946

Friday Harbor, Wash. to Coos Bay, Oregon

Herposiphonia parva Hollenberg

Hollenberg, 1943; Herposiphonic pygmaea (by error) in Smith, 1944

Monterey, Calif. to Punta Banda, Baja Calif.

Herposiphonia rigida Gardner

Smith, 1944

Puget Sound, Wash. to Santa Monica, Calif.

Herposiphonia Rigida var. Laxa Setchell \& Gardner

Setchell \& Gardner, 1930

Is. Gradalupe, Baja Calif.

Herposiphonia secunda (C. Agardh) Ambronn

Taylor, 1945

Is. Jicarita, Panamá

Herposiphonia subdisticila Okamura

Dawson, 1944

Is. San Esteban, Gulf of Calif.

Herposiphonia tenella (C. Agardh) Nägeli

Dawson, 1944 ; Taylor, 1945

Kino, Sonora to Is. Las Tres Marías, Nayarit

Herposiphonia verticillata (Harvey) Kylin

Smith, 1944

San Francisco, Calif. to Ensenada, Baja Calif.

Amplisiphonia pacifica Hollenberg

Smith, 1944 ; Dawson, 1945C

Moss Beach, San Mateo Co., Calif. to Bahía de Todos Santos, Baja Calif.

Jantinella sinicola (Setchell \& Gardner) Kylin

Dawson, 1944; Setchell \& Gardner, 1930

La Pas, Baja Calif.; Is. Clarion, Revilla Gigedo Arch.

Jantinella verrucaeformis (Setchell \& McFaddlen) Kylin

Kylin, 1941

San Pedro, Calif. 
Chondria acror hizophora Setchell \& Gardner

Setchell \& Gardner, 1924

Near La Paz, Baja Calif.

Chondria arcuata Hollenberg

Hollenberg, 1945

Corona del Mar; Laguna Beach, Calif.

Chondria Californica (Collins) Kylin

Kylin, 1941; Taylor, 1945; Dawson, 1944; 1945E

La Jolla, Calif. to Puerto Culebra, Costa Rica; Gulf of Calif.

Chondria Clarionensis Setchell \& Gardner

Setchell \& Gardner, 1930

Is. Clarion, Revilla Gigedo Arch.

Chondria cuscutoides Dawson

Dawson, 1946

La Jolla, Calif.

Chondria dasyphylla (Woodward) C. Agardh

Dawson, 1944; 1946

Bahía Gonzaga, Baja Calif. to Guaymas, Sonora

Chondria decipiens Kylin

Smith, 1944; Dawson, 1945B

Santa Cruz to La Jolla, Calif.

Chondria nidifica Harvey

Kylin, 1941 ; Dawson, 1945E

La Jolla, Calif.; Cabo Colnett, Baja Calif.

Chondria oppositiclada Dawson

Dawson, 1946

La Jolla, Calif.

Chonidra pacifica Setchell \& Gardner

Setchell \& Gardner, 1937A

Bahía San Bartholomé, Baja Calif.

Chondria platyclada Taylor

Taylor, 1945

Puerto Culebra, Costa Rica

Chondria secundata (J. Agardh) DeToni

DeToni, 1903

Santa Barbara, Calif.

Chondria telmoensis Dawson

Dawson, 1946

La Jolla, Calif.; Cabo Colnett, Baja Calif.

Laurencia clarionensis Setchell \& Gardner

Setchell \& Gardner, 1937A ; Taylor, 1945

Is. Clarion, Revilla Gigedo Arch. 
LaUrencia Crispa Hollenberg

Smith, 1944

Monterey Peninsula, Calif.

Laurencia diegoensis Dawson

Dawson, 1944A; 1945E

Santa Monica to Cabo Colnett, Baja Calif.

Laurencia estebaniana Setchell \& Gardner

Dawson, 1944

Smith Is.; Is. San Esteban, Gulf of Calif.

Laurencia Gardneri Hollenberg

Smith, 1944

Monterey Peninsula, Calif.

Laurencia Hancockin Dawson

Dawson, 1944

Bahía Agua Verde, Baja Calif.

Laurencia humilis Setchell \& Gardner

Setchell \& Gardner, 1930

Is. Clarion, Revilla Gigedo Arch.

LAURENCIA INTRICATA Lamouroux

Taylor, 1945

Bahía Petatlán, Guerrero

Laurencia Johnstonim Setchell \& Gardner

Dawson, 1944

Bahía San Francisquito, Baja Calif.; Is. San Marcos: Is. Tiburón, Gulf of Calif.

Laurencia Miasonit Setchell \& Gardner

Setchell \& Gardner, 1930

Is. Guadalupe, Baja Calif.

Laurencia obtusiuscula Setchell \& Gardner

Dawson, 1944

Guaymas, Sonora to San Jose del Cabo, Baja Calif.

LaURencia pacifica Kylin

Smith, 1944; Dawson, 1945E

Pacific Grove, Calif. to Punta Descanso, Baja Calif.

Laurencia paniculata (C. Agardh) J. Agardh

Dawson, 1944

Bahía Gonzaga to Bahía Agua Verde, Baja Calif.

Laurencia papillosa var. pacifica Setchell \& Gardner

Dawson, 1944 ; Setchell \& Gardner, 1930

Is. Guadalupe; La Paz. Baja Calif.; Is. Tiburón, Gulf of Calif. 
LaURencta PEnINSUlaris Taylor

Taylor, 1945

Cabo San Lazaro, Baja Calif.

LAURENCIA SCRIPPSENSIS Dawson

Dawson, 1944

La Jolla, Calif.

Laurencia sinicola Setchell \& Gardner

Dawson, 1944

Is. San Marcos, Gulf of Calif.; Eureka, near La Paz, Baja Calif.

Laurencia Snyderae Dawson

Dawson, 1945

La Jolla, Calif.

Laurencia spectabilis Postels \& Ruprecht

Smith, 1944 ; Dawson, 1944A

Sitka, Alaska to Santa Monica, Calif.

LaURENCIA SPLEndENS Hollenberg

Smith, 1944; Dawson, 1945E

Santa Cruz, Calif. to Cabo Colnett, Baja Calif.

Laurencia subopposita (J. Agardh) Setchell

Dawson, 1944A; Kylin, 1941

La Jolla to San Diego, Calif.

LaURencia voragina Taylor

Taylor, 1945

White Friars Is., Guerrero

Ricardia saccata (J. Agardh) Kylin

Snith, 1944

Pacific Grove to La Jolla, Calif.; Is. Guadalupe, Baja Calif.

Janczewskia Gardneri Setchell \& Guernsey

Smith, 1944; Dawson, 1945B ; 1945E

Vancouver Is.. B. C. to Cabo Colnett, Baja Calif.

Jan CZEWS Kia LAPpaCEa Setchell

Kylin, 1941 ; Dawson, 1945E

San Pedro, Calif. to Cabo Colnett, Baja Calif.

JANCZEWSKIA MORIFORMIS Setchell

Setchell, 1914

Santa Monica, Calif.

JancZEWskia Solmsir Setchell \& Guernsey

Setchell, 1914; Setchell \& Gardner, 1930; Dawson, 1945B

Redondo to San Diego, Calif.; Is. Guadalupe, Baja Calif. 
Digenia simplex (Wulfen) C. Agardh

Dawson, 1944; Taylor, 1945

Gulf of Calif. to Costa Rica

Bryothamnion pacificum Taylor

Taylor, 1945

Is. María Magdalena, Nayarit

Rhodomela larix (Turner) C. Agardh

Smith, 1944

Bering Sea to San Luis Obispo Co., Calif.

Rhodomela lycopodioides (Linnaeus) C. Agardh

Setchell \& Gardner, 1903; Collins, 1913

Alaska to Vancouver, B. C.

Odonthalia dentata (Linnaeus) Lyngbye

Setchell \& Gardner, 1903

Alaska to Victoria, B. C.

Odonthalia floccosa (Esper) Falkenberg

Smith, 1944

Puget Sound, Wash. to Santa Barbara, Calif.

Odonthalia kamtşchatica (Ruprecht) J. Agardh

Kylin, 1925

Alaska to Puget Sound, Wash.

Odonthalia Lyallim (Harvey) J. Agardh

Kylin, 1925

Puget Sound, Wash.

Odonthatia Washingtoniensis Kylin

Kylin, 1925 ; Sanborn \& Doty, 1946

Victoria, B. C. to Coos Bay, Oregon

Bostrychia Calliptera (Montagne) Montagne

Taylor, 1945

Panamá

Bostrychia radicans Montagne

Dawson, 1944

Guaymas, Sonora

Bostrychin tenella J. Agardh

Taylor, 1945

Golfo Dulce, Costa Rica 


\section{LITERATURE CITED}

Agardh, J. G. 1852. Species genera et ordines algarum. Vol. 2, Pt. 2, pp. 337-720. Lund.

1876. Spccies genera et ordines algarum. Vol. 3, Pt. 1.

Epicrisis systematis floridearum. 724 pp. Lund.

1894. Analecta algologica: observationes de speciebus minus cognitis ealumque dispositione, Continuatio II. Actis Soc. Physiog. Lundensis, 30: 1-98.

1899. Analecta algologica: observationes de speciebus minus cognitis earumque dispositione, Continuatio V. Ibid., N. S. 10: 1-160.

Collins, F. S. 1913. The marine algae of Vancouver Island. Bull. Victoria Memorial Museum, 1: 99-137.

Connell, R. 1928. Notes on marine algae collected at Departure Bay, B. C. Can. Field Nat., 42(4):99-100.

Dawson, E. Y. 1941. A review of the genus Rhodymenia witl descriptions of new species. Allan Hancock Pacific Exped., 3: 123. 180. 13 pls.

1944. The marine algae of the Gulf of California. Ibid., 3: 189-454. 47 pls.

1944a. Some new Laurenciae from southern California. Madroño, $7(8): 233-240.3$ pls.

1944b. A new parasitic red alga from southern California. Bull. Torrey Bot. Club, 77(6): 655-657. 1 pl.

1945. Notes on Pacific Coast marine algae, I. Bull. So. Calif. Acad. Sci., $43(3):$ 95-101. 1 pl.

1945a. Some new and nnreported sublittoral algae from Cerros Island,* Mexico. Ibid.. 43(3): 102-112. 3 pls.

1945b. An annotated list of the marine algae and marine grasses of San Diezo County, California. Occas. Papcrs San Diego Soc. Nat. Hist., (7): 1-87.

1945c. Notes on Pacific Coast marine algae, II. Bull so. Calif. Acad. Sci., $44(1)$ : 22-27. 2 pls.

1945d. Notes on Pacific Coast marine algae, Irr. Madroño. 8(3): 93-97. 1 pl.

1945e. Marine algae associated with upwelling along the northwestern coast of Baja California, Mexico., Bull. So. Calif. Acad. Sci., 44(2): 57-71. 3 pls.

1946 New and unreported marine algae from southern California and northwestern Mexico. Ibid., 44 (3): 75-91. 20 figs.

De Toni, G. B. 1897-1924. Sylloge algarum omnium hucusque cognitarum. 4 (Sylloge Floridcarum) (1): I-XX, I-LXI, 1-388. 1897 ; (2): 387-776. 1900; (3) 775-1522. 1903; (4): 15231973. 1905; 6 (Sylloge Floridearum) (5 Additimenta): I-XI, 1-767. 1924. Patavii.

De Toni, J. 1935. Noterelle di nomenclature algologica. $\nabla$. L'Antithamnion tenuissimum Gardner 192\%. Published by the author. Brescia.

1936. Noterelle di nomenclature algologica, VII. Primo clenco di Floridee omonime. Published by the author. Brescia.

Feldmann, J. et G. 1942. Recherches sur les Bonnemaisoniacées et leur alternance de generations. Ann. des Sci. Nat., Bot., ser. 11, 3: 75-175. 26 figs.

"According to Mexican authorities the spelling should be "Cedros." 
Feldmann-Mazoyer, G. 1942. A propos de quelques Spermothamnion a polysporanges. Bull. Soc. d'Hist. Nat. de l'Afrique Nord, 33: 15-18.

Foslie, M. H. 1929. Contributions to a monograph of the Lithothamnia. 60 pp. 75 pls. Trondhjem.

Gardner, N. L. 1926. New Rhodophyceae from the Pacific Coast of North America. I. Univ. Calif. Publ. Bot., 13: 205-226. 7 pls.

1927. New Rhodophyceae from the Pacific Coast of North America. II. Ibid., 13:235-272. 12 pls.

1927a. New Rhodophyceae from the Pacific Coast of North America. III. Ibid., 13:333-368. 13 pls.

1927b. New Rhodophyceae from the Pacific Coast of North America. IV. Ibid., 13:373-402. 11 pls.

1927c. New Rhodophyceae flom the Pacific Coast of North America. V. Ibid., 13:403-434. 10 pls.

1927d. New Rhodophyceae from the Pacific Coast of North America. VI. Ibid., 14:99-138. 17 pls.

1927e. New species of Gelidium on the Pacific Coast of North America. Ibid., 13:273-318. 19 pls.

1940. New species of Melanophyceae from the Pacific Coast of North America. Ibid., 19:267-286. 6 pls.

Harvey, W. H. 1853. Nereis Boreali-Americana. Part II. Rhodospermae. Smithsonian Contr. to Knowledge, 3(5): 1-258. 24 pls.

Hollenberg, G. J. 1940. New marine algae from southern California. I. Amer. Journ. Bot., 27 (10):868-877. 17 figs.

1941. Culture studies of marine algae. II. Hapterophycus canaliculatus S. \& G. Ibid., 28(8):676-683. 16 figs.

1942. Phycological notes-I. Bull. Torrey Bot. Club, 69: 528-538. 15 figs.

1942a. An account of the species of Polysiphonia on the Pacific Coast of North America. I. Oligosiphonia. Amer. Journ. Bot.. $29: 772-785.21$ figs.

1943. New marine algae from southern California. II. Ibid.. 30:571-579. 16 figs.

1944. An account of the species of Polysiphonia on the Pacific Coast of North America. II. Polysiphonia. Ibid., 31:474-483. 12 figs.

1945. New marine algae from southern California. III. Ibid., 32:447-451. 9 figs.

Jao, C. 1937. New marine algae from Washington. Pap. Mich. Acad. Sci., Arts and Letters, 22:99-116. 3 pls.

Kylin, H. 1924. Studien über die Delesseriaceen. Lunds Univ. Ärsskr.. N. F., 20(6):1-111. 80 figs.

1925. The marine algae in the vicinity of the biological station at Friday Harbor, Wash. Ibid., $21(9): 1-87.47$ figs.

1932. Die Florideenordnung Gigartinales. Ibid., 28(8): 1-88. 22 figs. $28 \mathrm{pls}$.

1935. '/ur Nomenclature einigen Delesseriaceen. Förhanal. Kgl. Fysiografistca Sällsk. i Lund, 5(23):1-5.

1940. Die Phaeophyceenorduung Chordariales. Lunds Univ. Arsskr.. N. $F ., 36(9): 1-67.30$ figs. 8 pls.

1941. Californische Rhodophyceen. Ibid., 37(2):1-51. 7 figs. 13 pls.

Lemoine, Mme. P. 1929. Les Col'allinacées de l'Archipel des Galapagos et du Golfe de Panama. Arch. du Mus. d'Hist. Nat. VI, 4: 37-88. 35 figs., 4 pls. 
Levring, T. 1940. Die Phaeophyceengattungen Chlanidophora, Distromium und Syringoderma. Kgl. Fysiografiska Sällsk. i Lund, $10(20): 1-11$.

Manza, A. V. 1937. Some north Pacific species of articulated corallines. Proc. Nat. Acad. Sci. of U. S. A., 23:561-567.

1940. A revision of the genera of alticulated corallines. Philippine Journ. Sci., 71:239-316. 20 pls.

Papenfuss, G. 1943. Notes on algal nomenclature. III. Miscellaneous species of Chlorophyceae, Phaeophyceae and Rhodophyceae. Farlowia, 1.(3) :337-346.

1944. Structure and taxonomy of Taenioma, including a discussion on the phylogeny of the Ceramiales. Madroño, $7(7): 193-214$. 2 pls. 1 fig.

1944a. Marine algae of the Monterey Peninsula. A review. Ibid., $7(7): 226-231$.

1945. Review of the Acrochaetium-Rhodochorton complex of the red algae. Univ. Calif. Publ. Bot., 18(14):299-334.

Sanborn, E. I. and M. S'. Doty. 1946. The marine algae of the Coos BayCape Arago Region. Oregon State Monographs. Studies in Botany (7): in press.

Saunders, De A. 1901. The algae. Papers from the Harriman Alaska Exped. XXV. Proceed. Wash. Acad. Sci. 3:391-486. 20 pls.

Schmidt, O. C. 1935. Pringsheimia Reinke jetzt Pringsheimiella v. Hoehn. Hedwigia, 74:29.

Setchell, W. A. 1906. A revision of the genus Constantinea. Nuova Notarisia, 17:162-173.

19.12. Algae novae et minus cognitae. Univ. Calif. Publ. Bot., 4:229268. 7 pls.

1914. Parasitic Florideae. I. Ibid., 6:1-34. 6 pls.

1914a. The Scinaia assemblage. 1bid., 6:79-152. 7 pls.

1923. Parasitic Florideae. II. Ibid., 10:393-396.

1923a. A revision of the west North American species of Callophyllis. Ibid., 10:397-401.

1933. Some early algal confusions. II. Ibia., 17:187-254. 20 pls.

1937. Report on the Sargassums. The Templeton Crocker Expedition of the Califolnia Acadamy of S'ciences, 1932, no. 34. Proc. Calif. Acad. Sci. iv, 22 (5): 127-158. 6 pls.

1940. Fucus cordatus Turner. Proceed. N'at. Acad. Sci. of U. S. A., 26(11) :643-651. 2 figs.

Setchell, W. A. and E. Y. Dawson. 1941. Binghamia, the alga, vs. Binghamia, the cactus. Proc. Nat. Acad. Sci. of U. S. A., $27(8): 376$. 381. 1 pl.

Setchell, W. A. and N. L. Gardner. 1903. Algae of Northwestern Amelica. Univ. Calif. Publ. Bot. 1:165-418. 21 pls.

1920. The marine algae of the Pacific Coast of North America. Part 2, Chlorophyceae. Ibid., 8:139-381. 25 pls.

1924. The marine algae. Expedition of the California Academy of Sciences to the Gulf of California in 1921. Proc. Calif. Acad. Sci. iv, $12: 695-949.77$ pls.

1925. The marine algae of the Pacific Coast of North America, Part 3, Melanophyceae. Univ. Calif. Publ. Bot., 8:383-898, 20 pls.

1930. Marine algae of the Revillagigedo Islands Expedition of 1925. Proc. Calif. Acad. Sci, iv, 19:109-215. 15 pls. 
1933. A preliminary survey of Gigartina, with special reference to its Pacific North American species. Univ. Calif. Publ. Bot., 17:255-340. 20 pls.

1937. Iridophycus in the northern hemisphere. Proc. Nat. Acad, of Sci. of U. S. A., 23:169-174.

1937a. A preliminary report on the algae. The Templeton Crocker Expedition of the California Academy of Sciences. iv. 21:6598. 1 fig. 23 pls.

Setchell, W. A. and L. R. Mason. 1943. New or little-linown crustose corallines of Pacific North America. Proc. Nat. Acad. of Sci. of U. S. A., 29:92-97.

1943a. Goniolithon and Neogoniolithon: two genera of crustaceous coralline algae. Ibid., 29:87-92.

Smith, G. M. 1944. Marine algae of the Monterey Peninsula, California. ix +622 pp., $9 S$ pls. Stanford Univ.

Taylor, W. R. 1939. Algae collected on the Presidential cruise of 1938 . Smithsonian Contr. Knoul., Miscell. Ser. 98(9):1-1S. 2 pls. 14 figs.

1945. Pacific marine algae of the Allan Hancock Expeditions to the Galapagos Islands. Allan Hancock Pac. Exped. 12:1-52S. 100 pls. 3 figs.

Fendo, K. 1902. Corallinae verae of Port Renfew. Iinnesota Bot. Stud. $2(40): 711-720.6$ pls.

Zeh, W. 1912. Neue Arten der Gattung Liagora. Berlin Notizbl. bot. Garten, 5 (49):268-273. 


\section{N D E X}

Synonyms are in italics

PAGE

PAGE

Acetabularia

parvula ................ 15

v. americana ........... 15

Acrochaetium

Amphiroae ............. 52

angustum ............. 52

Bornetii ............... 52

coccineum ............. 52

Daviesii .............. 52

densum ............... 52

Desmarestiae ............ 52

Dictyotae ............. 52

Eastwoodae ............ 53

elegans ............... 53

Erythrophyllum ......... 53

Gymnogongri ........... 53

Hancockii .............. 53

Macounii ............... 53

magnificum ............ 53

obscurum ............. 53

pacificum ............... 53

penetrale ............ 53

plumosum .............. 53

rhizoideum ........... 53

v. patens............. 53

simplex ............... 54

sinicolum ............ 54

subimmersum ............ 54

tenuissimum $\ldots \ldots \ldots \ldots \ldots . \ldots 54$

Thurettii

v. agama..............54

vagum ............... 54

variabile ............... 54

Acrosorium

uncinatum ............105

Aegira

virescens .............. 32

Aeodes

Gardneri .............. 73

Agardhiella

Couiteri .............. 79

mexicana $\ldots \ldots \ldots \ldots \ldots \ldots \ldots \ldots 79$

tenera ................ 79

Agarum

cribrosum ............. 40

fimbriatum $\ldots \ldots \ldots \ldots \ldots \ldots \ldots 41$

Ahnfeltia

gigartinoides ........... 84

plicata ............... 84

Alaria

dolichorhachis .......... 42

fistulosa ............... 42

f. platyphylla ........... 42

f. stenophylla .......... 42

lanceolata ............. 42

marginata $\ldots \ldots \ldots \ldots \ldots \ldots \ldots \ldots 42$

nana ................. 42

Pylail $\ldots \ldots \ldots \ldots \ldots \ldots \ldots \ldots \ldots 42$

tenuifolia ............ 42

f. typica ............ 42

f. amplior ............. 42

valida ............... 42

f. longipes ............. 42

Amphiroa

annulata ............. 70

v. tenuis ........... 70

Crosslandii ................ 70

dimorpha ............. 70

ioliacea .................. 71

1ragilissima ............ 71

franciscana ............ 71

mexicana ................... 71

minutissima $\ldots \ldots \ldots \ldots \ldots . \ldots 71$

peninsularis $\ldots \ldots \ldots \ldots \ldots . \ldots 71$

polymorpha ............ 71

pusilla ................ 71

rigida $\ldots \ldots \ldots \ldots \ldots \ldots \ldots \ldots 71$

zonata .............. 71

Amplisiphonia

pacifica ................112

Anisocladella

pacifica ...............104

Antithamnion

alternans ............. 94

asymmetricum .......... 94

Baylesiae .............. 94

defectum ................. 94

dendroideum .............. 94

densiusculum ........... 94

floccosum .............. 94

Gardneri .............. 94

glanduliferum .......... 94

Kylinii .............. 94

nigricans .............. 94

occidentale ............. 94

pacificum ............ 94

pulchellum ............ 95

pygmaeum ............ 95

secundatum ........... 95

setaceum .............. 95

simulans .............. 95

sublittorale ............ 95

subulatum ............ 95

tenuissimum ............94

uncinatum ............. 95

Archeolithothamnium

Howei ................ 64

Arthrothamnus

bifidus ..............41

Asparagopsis

hamifera ............ 58

Sanfordiana ........... 58

f. amplissima.......... 58

taxiformis ............. 58 
Asymmetria expansa

Audouinella membranaceum .......... 55

Bangia

fuscopurpurea ........... 50

maxima .............. 50

tenuis ............... 50

vermicularis .......... 50

Baylesia

plumosa ..............61

Besa

papillaeformis .......... 89

Binghamiella

calitornica ..............92

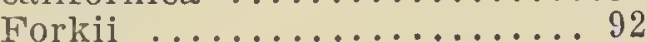

Blossevillea

Brandegeei ..............47

Bonnemaisonia

californica ............. 57

geniculata $\ldots \ldots \ldots \ldots \ldots \ldots \ldots . \ldots 57$

hamifera .............. 58

Boodlea

composita .............. 15

Bossea

angustata ............6 69

californica ............... 69

corymbifera .............6 69

dichotoma .............. 69

frondifera ............. 69

Gardneri ............... 69

interrupta ............ 70

Orbigniana ............. 70

pachyclada ............ 70

plumosa ............... 70

Bostrychia

Calliptera ..............116

radicans ..................116

tenella ................116

Botryocladia

Hancockii ............. 90

pseudodichotoma ......... 90

v. datilensis............ 90

uvarioides .............. 90

Botryoglossum

Farlowianum

Branchioglossum Woodii

Brogniartella

mucronata

Bryocladia

dictyurus ...............110

Bryopsis

corticulans ............. 16

galapagensis ............. 16

hypnoides ............. 16

pennatula ............. 16

plumosa ............... 16

v. pennata............ 16

Bryothamnion

pacificum

.116

Bulbocoleon

piliferem

\section{Calliarthron}

cheilosporioides ..........71

pinnulatum ............ 71 regenerans ............ 71

Schmittii ............. 72

Setchelliae ............ 72

Callithamnion

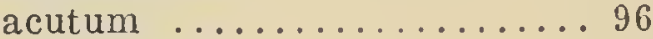

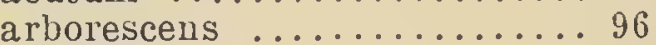

biseriatum ............ 96

bisporum ............. 96

breviramosum .......... 96

byssoides .............. 96

californicum ........... 96

endovaginum .......... 96

laxum ................ 96

pacificum ............ 96

Pikeanum ............. 96

v. pacificum .......... 96

ramosissimum .......... 97

lupicolum ............... 97

soccoriense ............ 97

squarrulosum ........... 97

veleroae .............. 97

Callocolax

fungiformis .......... 78

globulosis .............. 78

neglectus ............. 78

Callophyllis

acrocarpa ............. 76

crassifolia ............. 76

crenulata ............ 76

dissecta ............... 76

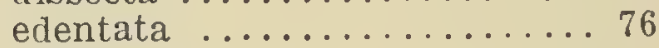

filicina ............... 77

flabellulata ............. 77

Gardneri .............. 77

heanophylla ........... 77

Johnstonii ............. 77

marginifructa .......... 77

megalocarpa ............ 77

obtusifolia ............. 77

odonthalioides ............. 77

pinnata ............... 77

plumosa .............. 77

stenophylla ........... 77

Thompsonii ........... 77

violacea ................ 78

Caulerpa

peltata ................ 17

pinnata

f. pectinata ......... 17

racemosa

v. chemnitzia .......... 17

v. clavifera

f. macrophysa ......... 17

racemosa

v. laeteirens

f. cylindraceae ....... 18

f. typica ............ 18

v. occidentalis ............... 18

v. uvifera ............. 18

sertularioides $\ldots \ldots \ldots \ldots \ldots \ldots . . \ldots 18$

Vanbosseae ............. 18

Centroceras

bellum ..................101

clavulatum ................ 101

Ceramium

affine ............... 99

californicum ............ 99

Camouii ............... 99 
Ceramium

caudatum ............. 99

clarionensis ............ 99

codicola ................ 99

codiophila .............. 99

Eatonian um ........................ 99

equisetoides ................. 99

Evermannii .............. 99

fastigiatum .................... 99

fimbriatum ............... 99

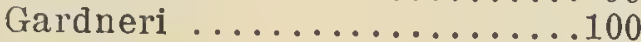

gracillimum .............100

horridum ..............100

ornatum ..............100

pacificum ...............100

paniculatum ..............100

personatum ..........................

procumbens ..............100

rubrum ................100

serpens .................100

sinicola ...................100

v. interruptum $\ldots \ldots \ldots \ldots 100$

v. Johnstonii ............... 101

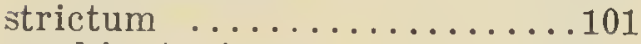

washingtoniense ............101

zacae .................101

zebrinum ................101

Chaetomorpha

aerea ................ 11

antennina .............. 11

californica ............ 11

cannabina ............. 11

clavata .............. 11

crassa ............... 11

melangonium ........... 12

tenuissima ............. 12

torta $\ldots \ldots \ldots \ldots \ldots \ldots \ldots \ldots 12$

Champia

caespitosa ............. 93

disticha .............. 93

parvula .............. 93

Chlanidophora

abyssicola ............. 29

Chlorochytrium

inclusum ............. 15

Porphyrae $\ldots \ldots \ldots \ldots \ldots \ldots 15$

Schmitzii ............. 16

Chlorodesmis

comosa ............... 19

mexicana .............. 19

Chnoospora

pacifica ............... 38

pannosa .............. 38

Chondria

acrorhizophora ...........113

arcuata ................113

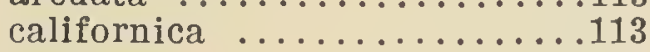

clarionensis ..............113

cuscutoides ..............113

dasyphylla ..............113

decipiens .................113

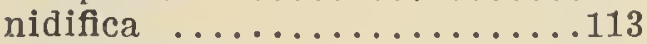

oppositiclada .............113

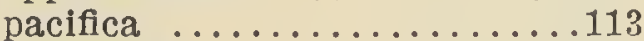

platyclada ...............113

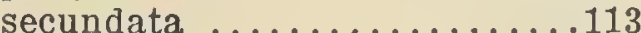

telmoensis $\ldots \ldots \ldots \ldots \ldots \ldots \ldots 113$
PAGE

Chondus

crispus ............... 85

Chorda

Filum ............... 39

Chordaria

dissessa ............... 33

flagelliformis .......... 33

gracilis .............. 33

Choreocolax

Polysiphoniae ........... 78

Choreonema

Thureti .............6 64

Chromastrum

arcuatum ........... 54

hirsutum ............ 54

implicatum ........... 54

micloscopicum ......... 54

moniliforme ............. 54

Porphyrae ........... 55

Cladophora

albida ............... 12

amphibia $\ldots \ldots \ldots \ldots \ldots \ldots \ldots 12$

Bertolonii

v. hamosa ............ 12

delicatula ............... 12

flexuosa .............. 12

glaucescens ............ 12

gracilis .............. 12

f. expansa............. 12

graminea ............. 12

hemisphaerica ........... 12

hesperia ............ 13

Hutchinsiae ............. 13

$\mathrm{v}$, distans ............. 13

laetevirens ............ 13

MacDougalii ............ 13

microcladioides ........... 13

f. stricta ............. 13

ovoidea .............. 13

panamensis ........... 13

prolifera .............. 13

Rudolphiana ............ 13

f. eramosa ........... 13

Stimpsonii ........... 13

tiburonensis ................ 13

trichotoma ............. 14

f. elongata ............. 14

Cladophoronsis

robusta ................ 15

Clarionea

Masonii.............. 78

Clathromorphum

compactum

f. circumscriptum ....... 65

Codiolum

gregarium ............. 16

Petrocelidis ........... 16 pusillum

f. subsessile .......... 16

Codium

amplivesiculatum ......... 18

anastomosans .......... 18

conjunctum ............ 18

cuneatum ............. 18

decorticatum ........... 18

fernandezianum .......... 19

fragile ............... 19

isabelae ................ 19 
Codium

longiramosum .......... 19

Macdougalii ............. 19

Palmeri ................ 19

Setchellii .............. 19

simulans ............... 19

Ritteri ............... 19

Coeloseira

compressa ............. 93

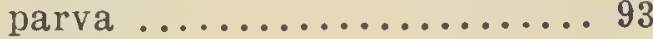

Coilodesme

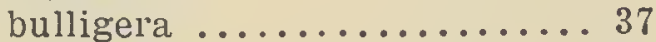

californica ............. 37

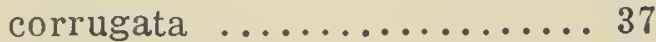

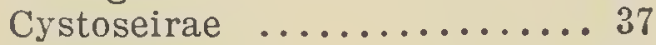

polygnampta ............ 38

rigida $\ldots \ldots \ldots \ldots \ldots \ldots \ldots . \ldots 38$

sitchensis $\ldots \ldots \ldots \ldots \ldots \ldots . \ldots 38$

Collinsiella

tuberculata ............ 3

Colpomenia

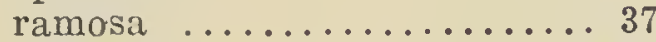

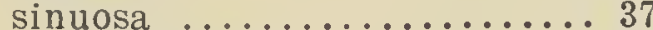

f. deformans ........... 37

f. expansa ............. 37

f. tuberculata........... 37

Compsonema

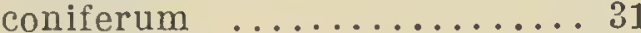

dubium ................ 31

fasciculatum ............ 31

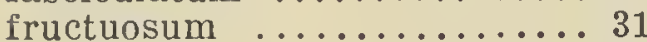

immixtum $\ldots \ldots \ldots \ldots \ldots \ldots . \ldots 31$

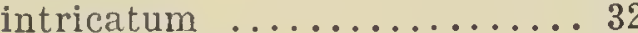

myrionematoides ......... 32

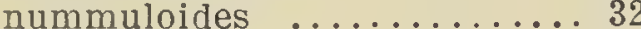

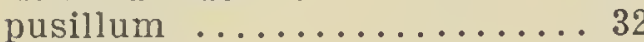

ramulosum ............. 32

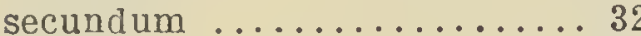

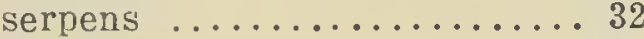

sessile ............... 32

speciosum

f. piliferum ........... 32

sporangiiferum ........... 32

streblonematoides ........ 32

tenue ................. 32

Conchocelis

rosea ............... 55

Constantinea

rosa marina ............6 62

simplex ..............6 62

subulifera ............6 62

Corallina

chilensis .............668 68

cubensis ..............6 68

gracilis ............... 68

v. densa ............ 68

v. lycopodioides .........69 officinalis

f. nilulifera ........... 69

pilulifera .............. 69

subulata ............. 69

vancouverielisis ......... 69

Corallopsis

salicornia ............ 81

Costaria

costata

Crouania

attenuata
Cruoriella

Dubyi ................63

Cryptonemia

borealis ................ 73

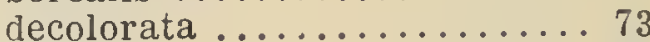

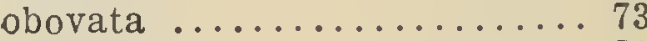

ovalifolia ............. 73

Cryptopleura

brevis ....................105

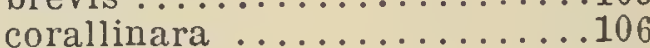

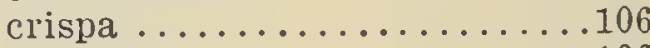

dichotoma ..............106

lobulifera ................106

Ruprechtiana ..........106

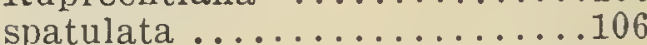

violacea ................106

Cryptosiphonia

Woodii .............. 60

Cumagloia

Andersonii ............ 56

Cutleria

Hancockii ............. 27

Cyamathere

triplicata ............ 40

Cystophyllum

geminatum ........... 47

Cystoseira

neglecta ............44 47

osmúndacea ............ 47

Setchellii ............. 47

Dasya

californica .............106

Eastwoodae ..............106

pedicellata ..............106

Stanfordiana ..............107

Dasyopsis

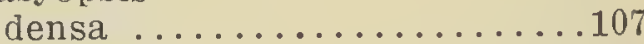

plumosa ................107

Delesseria

decipiens ...............103

Derbesia

Lamourouxii ............ 17

marina ................ 17

pacifica .............................. 17

vaucheriaeformis ........ 17

Dermatolithon

saxicolum ..............66 66

veleroae ............... 66

Dermocorynus

occidentalis $\ldots \ldots \ldots \ldots \ldots 72$

Desmarestia

farcta ............... 33

filamentosa ............. 34

foliacea ............... 34

herbacea ................ 34

intermedia ............ 34

Jordanii ............. 34

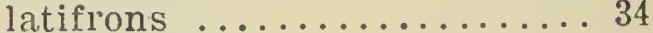

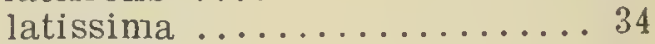

ligulata .............. 34

lillearis ................. 34

media ............... 34

v. tenuis .............. 34

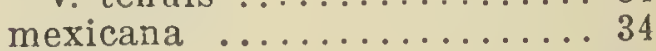

munda ............... 34

pacifica ................ 35

viridis $\ldots \ldots \ldots \ldots \ldots \ldots \ldots \ldots . . . . . .35$ 
Dicranema

rosaliae .............. 83

Dictyoneuropsis

reticulata.

Dictyoneurum californicum ...........4 41

Dictyopteris

delicatula ..............2 28

Johnstonei ............. 29

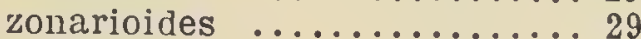

Dictyosiphon

foeniculaceus .......... 38

hippuroides ............. 38

hispidus .............. 39

sinicola ................ 39

tenuis ................ 39

Dictyosphaeria

australis ............... 14

Versluysi ............. 15

Dictyota

Binghamiae ...........2 28

concrescens ............. 28

crenulata .............. 28

cribrosa ............... 28

divaricata ............. 28

flabellata .............. 28

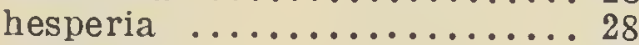

Johnstonii ............. 28

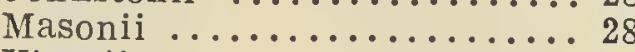

Vivesii ...............28

Digenia

simplex ...............116

Dilsea

californica

Dumontia

filiformis

Dunaliella

salina

Ectocarpus

acuminatus ............ 20

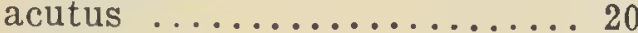

affinis ..................... 20

breviarticulatus ......... 20

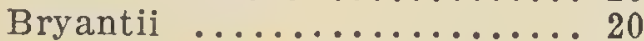

chantransioides ......... 20

chitonicola .............. 21

commensalis ............21

confervoides ............ 21

f. parvus .............. 21

f. pygmaeus ........... 21

f. typicus ............ 21

f. variabilis............24

corticulatus .............21

cylindricus ............. 21

f. codiophilus ........... 21

Duchassaingianus ......... 21

ellipticus ............... 21

ensenadanus ............. 21

eramosus .............. 21

flagelliferus ............ 22

flocculiformis ........... 22

fructuosus .............. 22

globifer ............... 22

gonodioides ............ 22

granulosoides ............ 22

จ. pygmaeus............ 22

granulosus ............. 22
Hancockii ............ 22

hemisphericus ............ 22

f. minor ............. 22

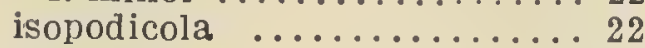

luteolus ................ 22

Mesogloiae .............. 23

Mitchellae ................. 23

mucronatus ............. 23

oviger .................... 23

Parksii ............... 23

Saundersii $\ldots \ldots \ldots \ldots \ldots \ldots \ldots 23$

siliculosus ............. 23

f. subulatus ........... 23

simulans $\ldots \ldots \ldots \ldots \ldots \ldots \ldots 23$

socialis .............. 23

sonorensis ............. 23

Taoniae ............. 23

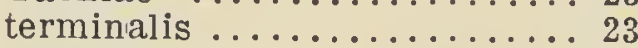

tomentosus ............. 24

variabilis ............... 24

Egregia

laevigata .............44 43

Menziesii ............. 43

Eisenia

arborea ............... 42

desmalestioides .......... 43

Masonii ............... 43

Elachistea

fucicola ............. 26

lubrica $\ldots \ldots \ldots \ldots \ldots \ldots \ldots \ldots 26$

Endarachne

Binghamiae ............ 36

Endocladia

muricata ............. 62

Endophyton

ramosum .................

Enteromorpha

acanthophora ........... 7

clathrata ................ 7

crinita ............... 7

compressa ........... 7

erecta............... 7

flexuosa .............. 7

groenlandica ........... 7

intestinalis .............. 7

f. clavata ............. 8

f. cylindracea .......... 7

f. $\operatorname{maxima} \ldots \ldots \ldots \ldots \ldots \ldots 7$

lingulata ............... s

marginata ............. s

micrococca ............ 8

f. subsalsa ........... 8

minima ............. 8

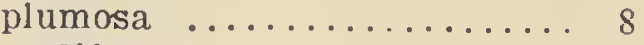

prolifera .............. 8

salina

v. polyclados .......... $s$

torta ............... 8

tubulosa .............. 8

Entocladia

cingens $\ldots \ldots \ldots \ldots \ldots \ldots \ldots \ldots$

codicola .............. 4

condensata ............. 4

mexicana ............. 5

Polysiphoniae .......... 5

viridis $\ldots \ldots \ldots \ldots \ldots \ldots \ldots \ldots$ 
Erythrocladia

irregularis ............. 50

subintegra ............ 50

Erythroglossum

californicum .............103

divaricata ...............103

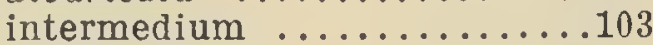

Erythropeltis

discigera ..............449

Eryth rophyllum delesserioides ...........899

Erythrotrichia ..............

californica ............ 49

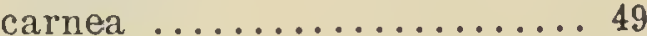

ceramicola ............. 49

Kylinii ............... 49

Parksii ............... 49

v. minor ........... 49

polymorpha ........... 50

porphyroides ........... 50

pulvinata ............... 50

tetraseriata ........... 50

Welwitschii ........... 50

Estebania

conjuncta ............ 73

Eucheuma

uncinatum ............ 79

Euthora

cristata .............. 81

fruticulosa ........... 81

Falkenbergia

Hillebrandtii ...........111

Farlowia

compressa ............6 61

crassa ................6 61

mollis ................61

Fauchea

crispa ............... 89

Fryeana .............. 89

laciniata ............. 89

media ............... 90

mollis ............... 90

pygmaea .............. 90

Sefferi ............... 90

Faucheocolax

attenuata .............990

Fosliella

ascripticia $\ldots \ldots \ldots \ldots \ldots 66$

dispar ..............66 66

intermedia ............666

minuta $\ldots \ldots \ldots \ldots \ldots \ldots \ldots 66$

Nicholsii ............. 66

paschalis $\ldots \ldots \ldots \ldots \ldots \ldots 66$

Fryella

Gardneri ..............990

Fucus

edentatus .............443

f. acutus ............... 43

f. costatus ............ 43

f. divaricatus ...........43

f. divergens ............4 43

f. hesperius ............44 43

evanescens ............. 43

f. cornutus ............4 43

f. cuneatus ............ 44

f. dendroides ............ 44

f. ecostatus ........... 44 f. flabellatus ............ 44

f. longifructus .......... 44

f. macrocephalus ......... 44

f. magnificus ........... 44

f. marginatus $\ldots \ldots \ldots \ldots .44$

f. nanus .............. 44

f. oregonensis .......... 44

f. pergrandis ..........444

f. robustus ........... 44

f. rudis ............. 44

f. stellatus $\ldots \ldots \ldots \ldots \ldots \ldots \ldots .44$

f. typicus $\ldots \ldots \ldots \ldots \ldots \ldots \ldots 45$

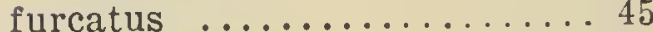

f. abbreviatus ......... 45

f. angustus ........... 45

f. contortus ............ 45

f. cornutus ............ 45

f. elongatus ........... 45

f. latifrons $\ldots \ldots \ldots \ldots \ldots \ldots . . \ldots 45$

f. linearis ........... 45

f. luxurians ........... 45

f. nigricans ........... 45

f. reflexus ............ 45

f. rigidus ............ 45

f. typicus ............ 46

f. variabilis ...........44 membranaceus

f. abbreviatus .......... 46

f. acuminatus .......... 46

f. latissimus .......... 46

f. limitatus $\ldots \ldots \ldots \ldots \ldots \ldots .46$

f. obtusus ............. 46

f. typicus $\ldots \ldots \ldots \ldots \ldots \ldots .46$

nitens .............. 46

Parksii ............. 46

\section{Galaxaura}

fastigiata ............ 57

filamentosa ............. 57

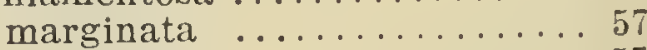

oblongata ............. 57

ramulosa ......................... 57

squalida .............. 57

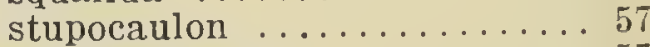

subfruticulosa ........... 57

ventricosa $\ldots \ldots \ldots \ldots \ldots \ldots \ldots . . \ldots 5$

veprecula ............. 57

Gardneriella

tubifera ................ 79

Gastroclonium

clavatum ............. 93

Coulteri .............. 93

Gayella

constricta ............. 10

polyrhiza ............. 10

Gelidiella

acerosa ..............6 60

Hancockii ............... 60

mexicana .............6 60

refugiensis ............6 60

Gelidiocolax

microsphaerica ......... 60

Gelidiopsis

tenuis ................6 60

variabilis $\ldots \ldots \ldots \ldots \ldots \ldots 60$

Gelidium

arborescens ............ 58

caloglossoides $\ldots \ldots \ldots \ldots \ldots \ldots$........ 58 
Gelidium

cartilagineum .......... 58

v. robustum .......... 58

Coulteri ............... 58

crinale ............... 58

v. luxurians ........... 58

decompositum ........... 58

densum ............... 59

Johnstonii ............. 59

microphysa ............ 59

nudifrons ............. 59

polystichum ............. 59

pulchrum ............. 59

purpurascens ............ 59

pusillum ............. 59

ramuliferum ........... 59

sclerophyllum .......... 59

Setchellii ............. 59

sinicola ............... 59

Gigartina

Agardhii .............. 85

armata .............. 85

asperifolia ............. 85

Binghamiae ............ 85

Boryi ................ 85

californica ............. 85

canaliculata ........... 85

corymbifera ............ 85

cristata ............. 85

dichotoma ............. 86

Eatoniana ............ 86

echinata .............. 86

exasperata ........... 86

Harveyana ............ 86

Jardinii .............. 86

Johnstonii ........... 86

latissima ................ 86

leptorhynchos .........886

Macdougalii ............. 86

mamillosa ............. 86

multidichotoma ........ 86

obovata ............... 86

papillata ............. 87

pectinata ............. 87

serrata ............. 87

sitchensis ............. 87

spinosa .............. 87

stellata .............. 87

tepida ................. 87

Turneri .............. 87

unalaschensis $\ldots \ldots \ldots \ldots \ldots . . . . .87$

Gloiopeltis

furcata .............. 62

miniata .............. 62

Gloiophloea

confusa .............. 56

Gloiosiphonia

californica ............ 62

capillaris ............. 62

verticillaris ............ 62

Gomontia

polyrhiza

Gonimophyllum

Skottsbergii

Goniotrichopsis

sublittoralis

Goniotrichum

A7sidii cornu-cervi .............449

elegans ................ 49

Gonodia

Johnstonii ............ 26

Marchantae ............. 26

Gracilaria

Andersonii ............. 81

cerlosiana .............. 81

compressa ............. 81

confervoides ............. 82

crispata ............. 82

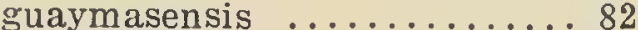

Hancockii ............. 82

Johnstonii .............. 82

lacerata ............... 82

lichenoides ............ 82

linearis ................ 82

pachydermatica ......... 82

panamensis ............ 82

pinnata ............. 82

robusta .............. 82

Sjoestedtii ............ 83

subsecundata .......... 83

tenuifolia .............. 83

veleroae .............. 83

Vivesii .............. 83

Gracilariophila

Gardneri ............. 83

oryzoides $\ldots \ldots \ldots \ldots \ldots \ldots \ldots . . . . .63$

Grateloupia

abreviata ............. 72

acroidalea .............. 72

californica ............. 72

cerrosiana ............... 72

filicina $\ldots \ldots \ldots \ldots \ldots \ldots . \ldots 72$

Hancockii ............. 72

Howeii .............. 72

Johnstonii .............. 72

$\operatorname{maxima} \ldots \ldots \ldots \ldots \ldots \ldots . \ldots 73$

pinnata ............... 73

prolongata ............ 73

Setchellii ............ 73

squarrulosa ............. 73

Griffithsia

multiramosa ............998

v. balboensis ................ 98

v. minor ............. 98

pacifica ................. 98

Schoesboei ............ 98

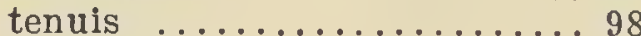

Grinnellia

lanceolata ...............104

Gymnogongrus

carnosus .............. 84

divaricatus ............. 84

Han cockii ................. 84

leptophyllus ............ 84

linearis .................. 84

martinensis ........... 84

nolvegicus ............. 84

platyphyllus ............ 84

sinicola .............. 84

Gymnothamnion

elegans ............... 97

Halicystis

ovalis ............... 16 
Halidrys

dioica

Halimeda

discoidea ............... 19

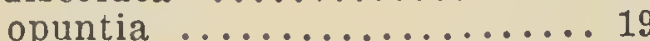

tuna .................. 19

Haloplegma mexicanum ............99 97

Halorhipis

Winstonii ................ 35

Halosaccion

glandiforme .............96

ramentaceum ............ 91

Tilesii .............. 91

Halothrix

lumbricaiis ........... 20

Ialymenia

abyssicola .............. 74

actinophysa ............ 74

Agardhii ............... 74

californica ............. 74

refugiensis $\ldots \ldots \ldots \ldots \ldots \ldots 74$

Hapalospongidion

gelatinosum ........... 26

Haplogloia

Andersonii ............. 33

Kuckuckii ............... 33

Hapterophycus

canaliculatus ...........26

Hedophyllum

sessile ...............4 41

subsessile ..............41

Helminthocladia

californica ............ 55

gracilis ............... 55

Helminthora

Saunaiersii ........... 55

stricta ............... 55

Herposiphonia

grandis ................112

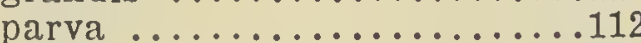

pygmaea .................112

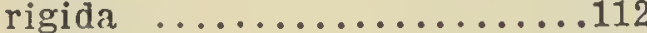

v. laxa .................112

secunda ..................112

subdisticha ................ 112

tenella ..................112

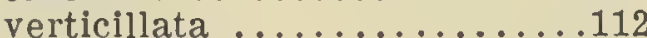

Hesperophycus

Harveyanus ............44 47

Heterochordaria

abietina ............... 33

Heteroderma

corallinicola ............ 66

Gibbsil ...............66 66

Heteronema

boreale ................104

Heterosiphonia

asymmetria ............107

densiuscula ................107

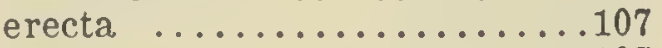

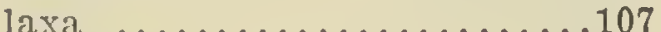

sinicola .................. 107

Hildenbrandia

occidentalis ............66 63

prototypus ....................6 63

rosea ...............6 63
PAGE

Holmesia

californica ................103

Hormiscia

doliifera ............... 11

grandis ............... 11

penicilliformis .......... 11

sphaerulifera ............ 11

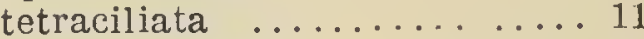

vancouveriana ............ 11

Wormskioldii ........... 11

Hydroclathrus

clathratus ............. 37

Hyärolithon

Setchellii ............66 65

Hymenena

flabelligera .............. 105

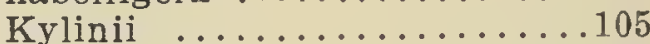

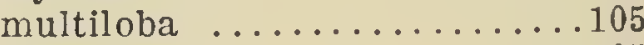

Setchellii ...............105

Smithii ................

Hypnea

adunca ................. 80

californica ............86

Esperi .............. 80

Evermanii ........... 80

Johnstonii ............ 80

nidifica .............. 80

nidulans ............ 80

pannosa ............... 80

spinella ............. 80

variabilis ............. 80

Hypoglossum

abyssicolum ............102

attenuatum $\ldots \ldots \ldots \ldots \ldots \ldots \ldots 102$

retusum ................ 02

Ilea

Fascia ................ 36

f. caespitosa $\ldots \ldots \ldots \ldots \ldots \ldots \ldots 36$

f. debilis ............ 36

f. typica ............. 36

f. zosterifolia ......... 36

Internoretia

Freyeana ............. 5

Iridea

ca7ifornica ............. 88

Iridophycus

californicum ........... 88

cordatum ............. 88

coriaceum ........... 88

flaccidum ............. 88

fulgens ............. 88

furcatum ............. 88

heterocarpum ........... 88

lineare ............... 88

Parksil ........................ 88

parvulum ............ 88

Reediae ................ 89

sanguineum ............. 89

sinicola .............. 89

splendens ............. 89

whidbeyanum ........... 89

Ishige

foliacea .............. 38

Janczewskia

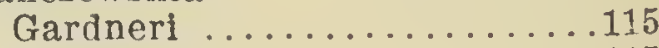

lappacea ...............115 
Janczewskia

moriformis .............115

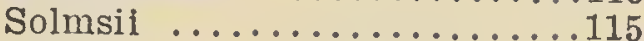

Jania

adhaerens ............ 70

capillacea ........................ 70

mexicana .............. 70

rubens ............... 70

Jantinella

sinicola ................112

verrucaeformis ...........112

Joculator

pinnatifolius

Kallymenia

angustata .............. 75

guaymasensis $\ldots \ldots \ldots \ldots \ldots .75$

oblongifructa ............ 75

ornata ............... 75

pertusa .............. 75

reniformis ............ 76

f. cuneata ............ 76

tenuifolia ............ 76

veleroae $\ldots \ldots \ldots \ldots \ldots \ldots \ldots 76$

\section{Laminaria}

Andersonii ............ 39

complanata ............. 39

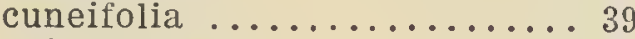

f. amplissima ........... 39

f. angusta .............. 39

f. subsimplex .......... 39

dentigera $\ldots \ldots \ldots \ldots \ldots \ldots \ldots . \ldots . \ldots . \ldots$

ephemera ..............440

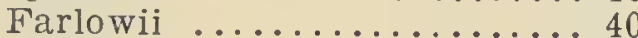

longipes ............. 40

personata .............. 40

platymeris ............. 40

saccharina ............ 40

f. linearis ........................ 40

f. membranacea .........4 40

Sinclairii ................ 40

Laurencia

clarionensis ..............113

crispa ......................

diegoensis ................114

estebaniana ............................

Gardneri ................114

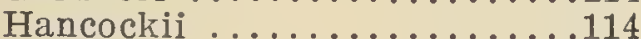

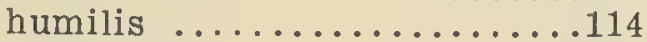

intricata ................114

Johnstonii ..........................

Masonii ..................114

obtusiuscula .............114

pacifica ................114

paniculata ...............114

papillosa

v. pacifica ..............114

peninsularis ........................

scrippsensis .............115

sinicola ..................115

Snyderae ................115

spectabilis ...........................

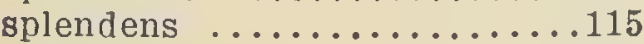

subopposita ...............115

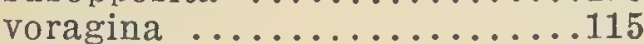

Leathesia

difformis .............. 30

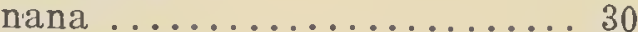

Leptocladia

Binghamiae ............6 61

conferta ...............6 61

laxa ................61

Leptofauchea pacifica ................990

Lessoniopsis

littoralis .............4 41

Liagora

californica ............ 56

ceranoides ............. 56

valida ............... 56

Lithoderma

fatiscens ............. 26

Litholepis

accola ................ 66

fertilis ............... 66

sonorensis $\ldots \ldots \ldots \ldots \ldots \ldots 66$

Lithophyllum

bracchiatum ............ 67

coibense .............66 67

decipiens ............667

Digueti .............667

divaricatum ............ 67

elegans .............66 68

fetum ..............667

grumosum $\ldots \ldots \ldots \ldots \ldots \ldots 67$

Hancockii .............. 67

imitans .............. 67

lithophylloides .........6 67

lividum ................. 68

Margaritae .............6 68

muricutum ...............6. 65

neofarlowii ...........6 68

pallescens ............. 68

proboscidum ...........6 68

propinquum

v. cocosica ........... 68

trichotomum ........... 68

veleroae ...............6.6. 68

whidbeyense $\ldots \ldots \ldots \ldots \ldots 68$

Lithoporella

pacifica ...............66 66

Lithothamnium

aculeiferum ............64

australe

f. americana ........... 64

f. minutula .......... 64

f. tualensis ..........6 64

californicum ............ 64

conchatum ...............6. 64

crassiusculum ........... 65

giganteum ...........665

indicum ..............6 65

lamellatum ............6 65

montereyicum .......... 65

muricatum .............6. 65

pacificum .............6 65

parcum ...............6. 65

phymatodeum ...........665

reclinatum ............. 65

validum ..............6 65

Lithothrix

aspergillum ...........6 69 
Lobocolax

deformans ............. 75

Lola

lubrica ................ 10

Lomentaria

Baileyana .............. 92

Caseae .................. 92

catenata ............... 93

Drouetii ...................... 93

hakodatensis $\ldots \ldots \ldots \ldots .93$

Lophosiphonia

mexicana ................110

obscura ..................110

villum $\ldots \ldots \ldots \ldots \ldots \ldots . .110$

Macl'ocystis

integrifolia .............41

pyrifera .............. 41

Masonophycus

paradoxa

Melobesia

marginata ..............6 64

mediocris .............. 64

Membranoptera

denticulata ...............102

dimorpha ...............102

multiramosa .............102

platyphylla ...............103

Setchellii ...............103

tenuis ..................103

Weeksiae ...............103

Meredithia

californica ............. 76

Mesophyllum

australe

v. menutula ...........6 64

v. tualensis ..........6 64

Microcladia

borealis ................101

californica ...............101

Coulteri ..................101

Microdictyon

Palmeri ................ 14

Monostroma

areolatum .............. 6

fractum ................ 6

fuscum $\ldots \ldots \ldots \ldots \ldots \ldots 6$

v. splendens $\ldots \ldots \ldots \ldots \ldots$. 6

v. Blyttii ............. 6

Grevillei .............. 6

v. Iubricum ........... 6

v. Vahlii ............ 6

latissimum .............. 6

orbiculatum ............ 7

quaternarium $\ldots \ldots \ldots \ldots \ldots .7$

zostericola ............. 7

Myelophycus

intestinale $\ldots \ldots \ldots \ldots \ldots \ldots . \ldots 36$

f. tenue $\ldots \ldots \ldots \ldots \ldots \ldots \ldots 36$

Myriogramme

divaricata ...............104

Hollenbergii ...............105

pulchra ..................105

repens ...................105

spectabilis ..............105

Myrionema

attenuatum

30 balticum

f. californicum .......... 30

f. pedicellatum ......... 30

compsonematoides ......... 30 corunnae

f. angulatum .......... 30

f. sterile ................. 30

f. uniforme ............ 30 foecundum

t. ramulosum ......

f. simplicissimum ....... 31

f. subulatum............ 31 globosum

f affine ................... 31

minutissimum ............ 31

obscurum ................. 31

phyllophyllum ........... 31

primarium $\ldots \ldots \ldots \ldots \ldots \ldots . . . .31$

setiferum ............... 31

strangulans .............. 31

Nemacystus

Brandegeei .............. 33

Nemalion

elminthojdes ............. 55

lubricum .................... 55

virens $\ldots \ldots \ldots \ldots \ldots \ldots \ldots$ 5 5

Neogoniolithon

trichotomum ............ 68

Neomeris

Vanbosseae .............. 15

Nereocystis

Luetkeana ..............4 41

Neurocarpu.s

delicatula ...............2s

zonarioides .................... 29

Nienburgia

Andersoniana ...............104

borealis ..................104

Nitophyllum

mirabile

.105

Odonthalia

dentata ...............116

floccosa ..................116

hamtschatica ..............116

Lyallii ...................116

washingtoniensis .........116

Opuntiella

californica ............. 79

Orcasia

senticulosa ...............107

Ostreobium

Quekettii ................ 17

Reineckei .............. 17

Pachyarthron

cretaceum ..............69 69

Padina

Durvillaei $\ldots \ldots \ldots \ldots \ldots \ldots . \ldots 29$

caulescens ................ 29

crispata ............... 29

mexicana ................ 29

tetrastromatica ........... 29

Pantoneura

Baerif ..................... 105

Juergensii $\ldots \ldots \ldots \ldots \ldots \ldots$..... 
Pelagophycus

porra ................ 41

Pelvetia

fastigiata

gracilis . . . . . ........ 46

Pelvetiopsis

arborescens ............44

limitata ...................... 47

f. lata .............. 47

f. typica ............. 47

Percursaria

percursa ............... 9

Petrocelis

franciscana ..........663

haematis ............. 64

Middendorffii ........... 64

Petroglossum

pacificum .............. 84

parvum ............... 84

Petrospongium

rugosum .

Peyssonnelia

calcea ...............6 63

clarionensis ............6 63

pacifica ..............6 63

rubra ................6 63

Phaeophiìa

dendroides .............. 4

Engleri ................ 4

polymorpha ............ 4

Phaeostrophion

irregulare .............. 38

Phycodrys

ambigua ..................104

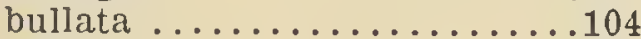

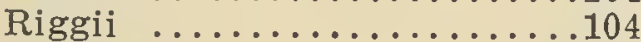

Setchellii ..............104

Phyllophora

californica ............ 83

Clevelandii ............. 83

Pikea

californica ............6 61

pinnata $\ldots \ldots \ldots \ldots \ldots \ldots \ldots \ldots 66 \ldots \ldots$

Pilinia

Lunatiae

f. $\operatorname{simplex} \ldots \ldots \ldots \ldots \ldots . \ldots 4$

maritima

f. pacifica ............ 4

Platymonas

subcordiformis ......... 3

Platysiphonia

Clevelandii .............103

Platythamnion

heteromorphum .......... 95

pectinatum .............. 95

v. laxum ............ 95

reversum ..................... 95

tepocensis ............. 95

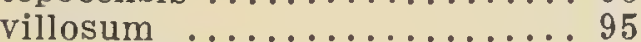

Pleonosporium

abysicola ............... 97

dasyoides ...................... 97

polycarpum ............ 97

pygmaeum ..............998

saccorhiza ............ 98

squarrosum ................ 98

v. obovatum ........... 98

vancouverianum ..........98
Pleurophycus

Gardneri ..............440

Plocamiocolax

pulvinata ............. 81

Plocamium

pacificum ............. 81

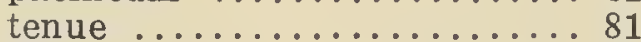

violaceum ............. 81

Pocockiella

variegata .............. 29

Pogonophora

californica ................107

Polycoryne

Gardneri .................104

phycodricola .............104

Polyneura

latissima ..................104

Polyneurella

Hancockii ...............104

Polyopes

Bushiae ............... 73

clarionensis ............ 73

sinicola ................ 74

Polysiphonia

acuminata ................107

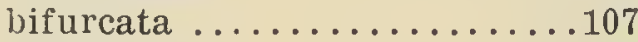

Brodiaei ..................108

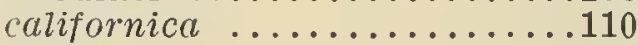

Collinsii ................108

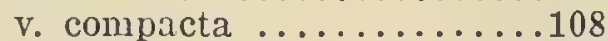

v. deliquescens .........108

v. luxurians ..............108

concinna ...............108

decussata .................108

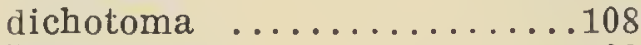

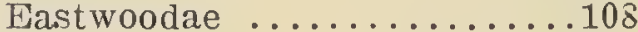

flaccidissima ............... 108

v. Smithii .....................

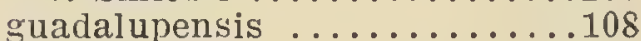

Hancockii ..............108

Hendryi ...............109

homoia .................109

Howei ..................109

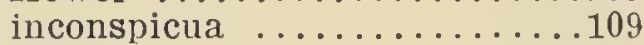

Tohnstonii ..............109

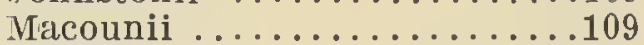

Marchantae ..............109

Masonii ..................109

minutissima ..............109

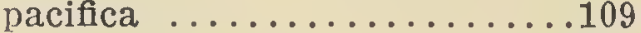

v. delicatula .............109

v. determinata ............109

v. disticha .............. 109

v. gracilis .............110

paniculata ..............110

pungens ................110

simplex .................110

Snyderae ................110

v. heteromorpha ........110

v:intricata ................ 110

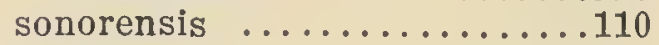

Porolithon

cocosicum ...........6 67

sonorensis $\ldots \ldots \ldots \ldots \ldots 67$

Porphyra

abyssicola ............. 50

amplissima ...........5 50 
laciniata ............ 51

f. umbilicalis .......... 51

lanceolate ............. 51 miniata

f. cuneiformis .......... 51

naiadum .............. 51

Nereocystis ............ 51

occidentalis ............. 51

perforata ............... 51

f. segregata ........... 51

pulchra ............... 51

schizophylla ............ 51

Thuretii ............. 51

tenuissima ............ 51

umbilicalis ............. 51

variegata ............. 52

Porphyrella

californica ............. 52

Gardneri ............. 52

Porphyropsis

coccinea ............. 52

Postelsia

palmaeformis ...........4 41

Prasinocladus

lubricus ................ 3

Prasiola

borealis ............... 10

calophylla ............. 10

Predaea

Masonil ................ 78

Pringsheimia

Marchantae ............ 5

Pringsheimiella

Marchantae ............ 5

Prionitis

abbreviata ............ 74

Andersoniana ............ 74

australis .............. 74

filiformis ............ 74

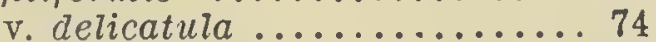

guaymasensis ........... 74

kinoensis ................. 75

lanceolata .............. 75

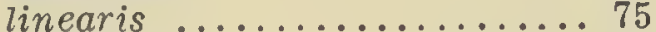

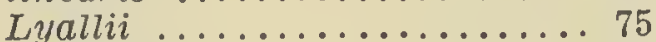

mexicana .............. 75

Sternbergii ............. 75

Pseudodictyon

geniculatum ............. 5

Pseudopringsheimia

apiculata ............. 5

Pseudoscinala Snyderae .............56

Pseudoulvella prostrata.............. 5

Pteridium spinulosum ..............102

Pterochondria

nygmaea ................112

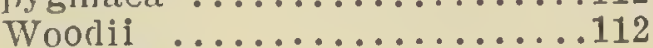

Pterocladia

mexicana .............. 59

Pterosiphonia

arctica ..................111

Balleyi $\ldots \ldots \ldots \ldots \ldots \ldots \ldots \ldots . \ldots \ldots$

bipinnata ................111

californica .............111

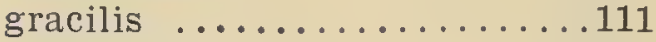

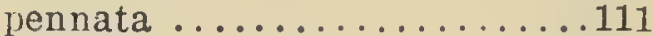

robusta .................111

v. divaricata ............111

v. inermis ..............111

Pterygophora

californica .............44 41

Ptilota

asplenioides ...............101

californica ................101

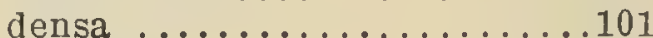

filicina .................102

hypnoides ................102

pectinata ................102

tenuis .................102

Pugetia

firma ............... 76

fragilissima .......... 76

Punctaria

chartacea .............. 35

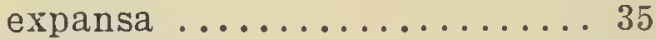

hesperia ............... 35

latifolia ............... 35

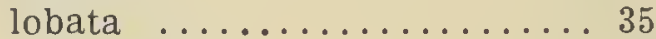

occidentalis ............ 35

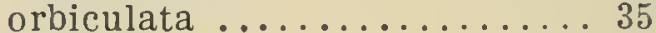

plantaginea ........... 35

Pylaiella

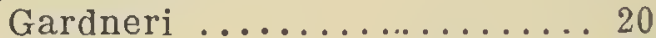

littoralis .............. 20

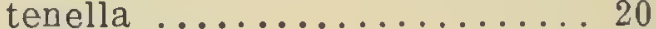

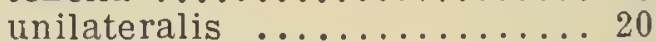

washingtonensis ......... 20

\section{Ralfsia}

californica ............ 25

clavata $\ldots . . . . . . . . . . . . .25$

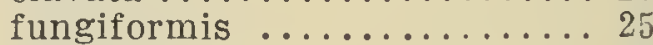

Hancockii ............. 25

hesperia .............. 25

occidentalis ............ 25

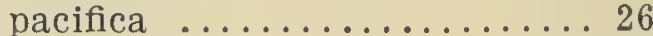

Rhizoclonium

implexum ............. 10

Kerneri .............. 10

lubricum ................ 10

riparium ............. 10

tortuosum $\ldots \ldots \ldots \ldots \ldots \ldots 10$

Rhodochorton

Amphiroae ............. 52

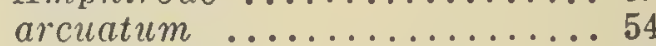

concrescens ........... 55

microscopicum ........... 54

penicilliforme ........... 55

purpureum ............ 55

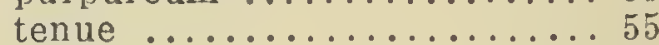

Rhodlodermis

elegans ............... 63

Rhodoglossum

affine ................ 87

americanum ............. 87

coriaceum ............. 87

Hancocki: ............ 87

latissimum $\ldots \ldots \ldots \ldots \ldots . \ldots . \ldots 88$

parvum ............... 88

roseum ............. 88 
Rhodomela

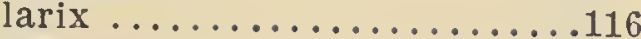

lycopodioides ...............116

Rhodophyllis

dichotoma

f. setacea

Rhodosiphonia

californica

Rhodymenia

arborescens ............. 91

attenuata $\ldots \ldots \ldots \ldots \ldots \ldots \ldots 91$

californica .............. 91

Dawsonii ...............91

divaricata $\ldots \ldots \ldots \ldots \ldots \ldots . . . . .99$

Hancockii ............... 91

lobata .................... 91

lobulifera ................ 91

pacifica .............. 91

palmata ...............99

f. mollis .............. 91

f. sarniensis ........... 92

palmettiformis .......... 92

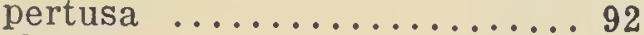

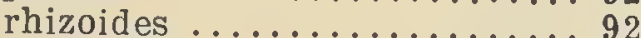

rosea ................ 92

stipitata ............... 92

tepocensis ............. 92

Rhodymeniocolax

botryoidea ............. 92

Ricardia

saccata

Rosenvingea

intricata

Sarcodiotheca

cuneata .............. 79

dichotoma .................. 79

ecuadoreana ............. 79

elongata .............. 79

furcata ................ 79

linearis .............. 80

meridionalis .............. 80

Sarcophyllis

arctica ...............61

Sargassum

acinacifolium $\ldots \ldots \ldots \ldots \ldots 47$

Agardhianum ............. 47

asymmetricum ..........4 48

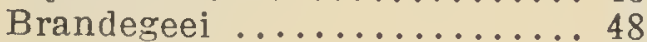

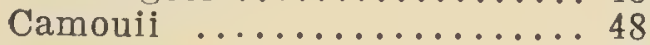

herporhizum ........... 48

horridum .............. 48

Howellii .............. 48

Johnstonii $\ldots \ldots \ldots \ldots \ldots \ldots \ldots \ldots 48$

f. gracile ............. 48

lapazeanum .............. 48

Liebmanni ............. 48

Macdougalil ............... 48

Palmeri ................ 48

sinicola ............... 48

Saundersella

simplex ............... 33

Schizymenia

epiphytica $\ldots \ldots \ldots \ldots \ldots \ldots . . .78$

Johnstonil ............. 78

pacifica ...................... 78

Sciadophycus

stellatus
Scinaia

articulata ............ 50

complanata ........... 56

Johnstoniae ........... 56

latifrons ................ 56

minima ................. 56

Scytosiphon

bullosus ......................... 37

lomentaria ............. 36

f. cylindricus .......... 36

f. typica $\ldots \ldots \ldots \ldots \ldots \ldots 36$

v. complanatus $\ldots \ldots \ldots \ldots 36$

Siphonocladus

pusilloides ............. 15

Soranthera

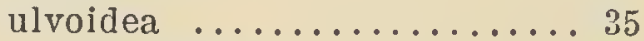

f. difformis ........... 36

Sorella

delicatula ................103

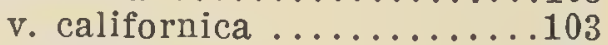

divaricata ...............103

pinnata ..................104

Spermothamnion

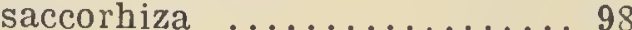

Snyderae ................. 98

Sphacelaria

brevicorne ............. 26

californica ............ 26

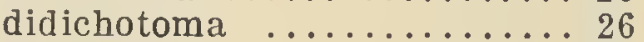

furcigera ............. 27

Hancockii ............. 27

Masonii ............... 27

mexicana ............. 27

novae-hollandiae ......... 27

racemosa .............. 27

subfusca ......................... 27

Spongomorpha

arcta ................ 14

coalita ................ 14

duriuscula .............. 14

hystrix ............... 14

Mertensii .............. 14

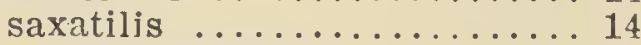

v. Chamissonis ........ 14

spinescens ................. 14

Sporochnus

pedunculatus ........... 33

Spyridia

filamentosa ...........997

Stenogramme

californica ............ 85

interrupta ............ 85

Stephanoptera

gracilis ................

Stictyosiphon

tortilis .............. 38

Streblonema

aecidioides

f. pacificum ........... 24

anomalum $\ldots \ldots \ldots \ldots \ldots . \ldots 24$

codicola ................. 24

corymbiferum .............. 24

Desmarestiae ............ 24

evagatum $\ldots \ldots \ldots \ldots \ldots \ldots . . \ldots 24$

investiens $\ldots \ldots \ldots \ldots \ldots \ldots 24$

irregulare ...................... 24

Johnstonae ............. 21

minutissium ............ 21 
Streblonema

myrionematoides ..........24

pacificum ..............25

penetrale $\ldots \ldots \ldots \ldots \ldots \ldots .25$

Porphyrae .............25

rugosum ...............25

scabiosum ...............25

transfixum ..............25

vorax .................25

Stromatocarpus

Gardneri ................111

Syringoderma abyssicola

\section{Taonia}

Lennebackerae .......... 29

Taenioma perpusillum .............103

Thalassiophyllum

clathrus

Thuretellopsis

Peggiana.................61 61

Trailliella

intricata ............... 93

Trentepohlia

odorata ............... 6

v. umbrina ........... 6

Turnerella

Mertensiana .............. 79

Tylotus

Cunninghamii ........... 83

Ulothrix

flacca ................. 3

implexa................. 3

laetevirens ............. 4

pseudoflacca

f. minor ............. 4

f. $\operatorname{maxima} \ldots \ldots \ldots \ldots \ldots, 4$

Ulva

angusta .............. 8

californica ................ 8

dactylifera..$\ldots \ldots \ldots \ldots \ldots .9$

expansa ................. 9

fenestrata ............. 9

Lactuca ................ 9

latissima ................. 9
Linza .................. 9

lobata ................ 9

rigida ................... 9

stenophylla .............. 9

taeniata ................ 9

vexata...$\ldots \ldots \ldots \ldots \ldots .9$

Ulvella

Lens .................. 5

Setchellii .............. 5

Urospora

peniciliformis ........... 11

Valoniopsis

Hancockii .............. 15

pachynema .............. 15

vaucheria

litoria $\ldots \ldots \ldots \ldots \ldots \ldots . \ldots 17$

Veleroa

subulata ...............111

Weeksia

Fryeana ...............61 61

Howellii ..............6 62

reticulata ..............66 62

Templetonii .............6 62

Whidbeyella

cartilaginea ............ 56

Wurdemannia

miniata ............... 80

Zanardinula

abbreviata ............... 74

Andersoniana ............. 74

australis ............... 74

filiformis ................ 74

v. delicatula .......... 74

guaymasensis ........... 74

kinoensis ............. 75

lanceolata ............... 75

linearis ................ 75

Lyallii ................. 75

mexicana ................. 75

Sternbergii ............ 75

Zonaria

Farlowii ...............29

variegata ................ 29 





